\title{
PATHS TO THE MARKET: DISTRIBUTION CHANNELS FOR COMMUNITY-BASED TOURISM \\ A CASE STUDY OF BANTEAY CHHMAR CBT, CAMBODIA
}

by

\section{Sochea NHEM}

\section{A thesis submitted to Victoria University of Wellington in partial fulfilment of the requirements for the degree of \\ Master of Tourism Management}

Victoria University of Wellington

2016 


\title{
DEDICATION
}

To my beloved family, most importantly for my mother (Chum Sothet) and my wife (By Molyvann)

\begin{abstract}
Also
To my late great Auntie, Ton Thav

[Your tremendous support is living with me forever. Losing you is so painful, especially when I cannot do anything from this far]
\end{abstract}

Professor Douglas G. Pearce

[You have provided me with the opportunity to exercise academic freedom during this challenging adventure called academia. I have found this journey extremely rewarding.] 


\section{ACKNOWLEDGEMENTS}

A number of notable people have provided invaluable support throughout my long academic journey at Victoria University of Wellington (VUW). Not only have they provided technical and professional support but also moral encouragement, especially during the critical process of writing my thesis. Without such support, I may have been unable to attain this level of educational achievement.

First and foremost, I would like to express my heartfelt thanks to my supervisor, Dr. Christian Schott, for his invaluable input and support. His knowledge, experience and wisdom have been greatly appreciated. His professional attitude influenced me strongly. It is my belief that the way in which he questioned and commented on my work was not only insightful but played a significant role in pushing me to achieve higher than I thought possible. In addition, I wish to express my thanks and appreciation to Professor Karen Smith who also provided exceptional support through her critical comments to help improve my work. I wish to take this opportunity to also express my sincere thanks to other members of the Tourism Management Group, in particular Professor Ian Yeoman, and the administrative team for their contribution to my academic journey.

Special thanks must go to NZAID for awarding me a ASEAN scholarship, allowing me the opportunity to pursue my academic passion. I would also like to express my appreciation to the charismatic ISO Dr. Helena Cook and her team for their exceptional support. My earnest gratitude also goes to Professor Roberto Rabel who contributed significantly to make my journey to the land of the long-white-cloud possible.

In addition, I would like to thank all of my Kiwi and Maori friends, the Cambodian community and my Cambodian friends (especially 3Aers) who have made my overall experience in Aotearoa enjoyable and meaningful.

Finally, but importantly, I would like to express my special thanks to each of my respondents, especially the gatekeeper who sacrificed invaluable time participating in my research. Without them, there is no way that I could have accomplished this research. Their support and assistance are greatly acknowledged and appreciated. 


\begin{abstract}
This study is to investigate the structure of distribution channels for community-based tourism (CBT) in Banteay Chhmar commune. It explores the factors influencing the distribution channel structure and then examines and discusses the implications of these factors as a means to help improve CBT sales. This study takes both the demand and supply side perspectives into account in order to understand the issues being investigated more comprehensively. Taking a case study approach, this study is based on in-depth interviews with the community and other relevant key channel members, and a survey is employed to collect information from visitors to the community.
\end{abstract}

The examination of the distribution channel structure for CBT reveals considerable channel diversity. The Banteay Chhmar community is found to utilize a distribution mix which includes a wide range of both direct and indirect channels to enable them to reach broader markets. The findings suggest that the CBT direct distribution channel is relatively short and straightforward while the indirect distribution channels are rather diverse and lengthy. Given the diversity of intermediaries involved, indirect distribution channels for the CBT are complex and often multi-levelled. The majority of visitors who travel to the community purchase their packages through ground travel operators making indirect distribution more prevalent in the CBT distribution structure.

The study also reveals that there is very limited connection among local channel members, such as, accommodation providers, transportation service providers and souvenir shops. This limitation inhibits CBT product sales. Regarding the domestic market, (mainly school groups), the findings show that the direct channel is more prevalent.

There are a number of factors that influence the structure of the distribution channels for CBT. These include commissionable products, product characteristics and market access, information communication and technology, partnership issues and the nature of the operators, capacity issues, and lastly, but most importantly market trends. 
This study identifies several implications for the Banteay Chhmar community. However, growth (increased sales volume), looks promising if the community develop sound distribution strategies and implement them accordingly; essentially bringing the community and the market together. In addition, the strategies could also help the community to have more control over the development process and opportunity to minimize adverse impacts.

Key words: Community-based tourism, Distribution channels, Banteay Chhmar community 


\section{ABBREVIATION}

\begin{tabular}{|c|c|}
\hline APLC & : Agir Pour le Cambodge \\
\hline $\mathrm{B} 2 \mathrm{~B}$ & : Business-to-Business \\
\hline $\mathrm{B} 2 \mathrm{C}$ & : Business-to-Community \\
\hline CBT & : Community-Based Tourism \\
\hline CCBEN & : Cambodia Community-Based Ecotourism Network \\
\hline $\mathrm{CCs}$ & : Community Committee \\
\hline CPI & : Centre for the Promotion of Imports \\
\hline DCCBT & : Distribution Channels Community-Based Tourism \\
\hline eWoM & : electronic Word-of-Mouth \\
\hline FITs & : Free Independent Travellers \\
\hline GHF & : Global Heritage Fund \\
\hline GITs & : Group Independent Travellers \\
\hline GTOs & : Ground Travel Operators \\
\hline ICT & : Information Community and Technology \\
\hline MICE & : Meetings, Incentives, Conferences and Events or Exhibitions \\
\hline MoU & : Memorandum of Understanding \\
\hline MSME & : Micro, Small and Medium Enterprises \\
\hline NGOs & : Non-Governmental Organizations \\
\hline OTAs & : Online Travel Agencies \\
\hline SNV & : Netherland Development Organization \\
\hline UNWTO & : World Tourism Organization \\
\hline WoM & : Word-of-Mouth \\
\hline
\end{tabular}


Table of Contents

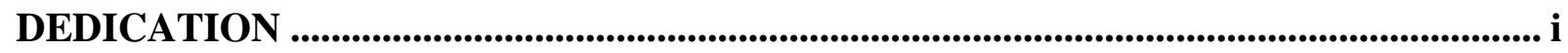

ACKNOWLEDGEMENTS ............................................................................................... ii

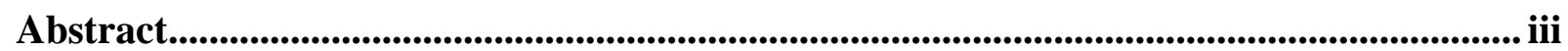

Abbreviation ............................................................................................................................. v

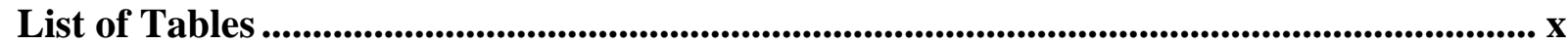

List of Figures...................................................................................................................................... $\times 1$

Chapter 1: Introduction .................................................................................................................................. 1

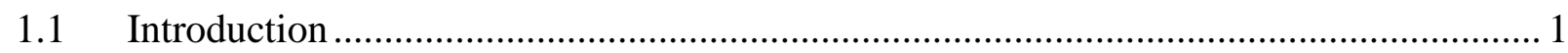

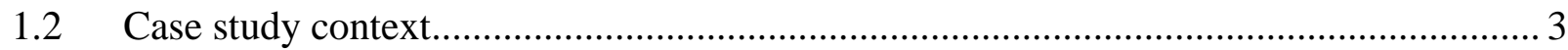

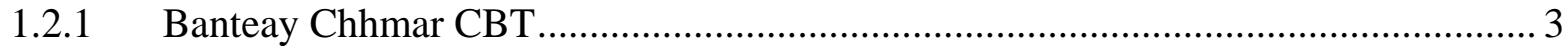

1.2.2 Brief overview of history and economy of Banteay Chhmar ……............................5

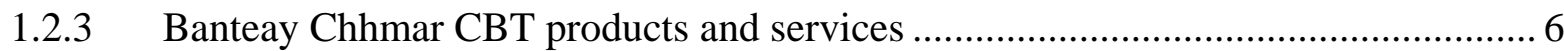

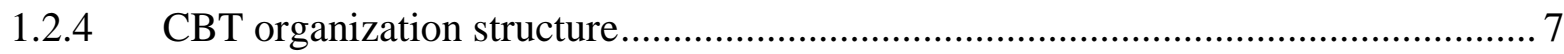

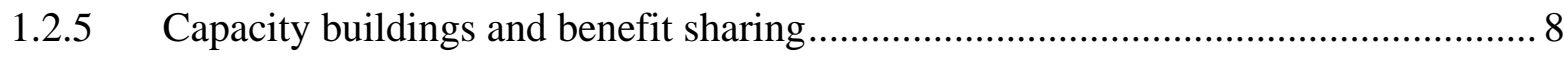

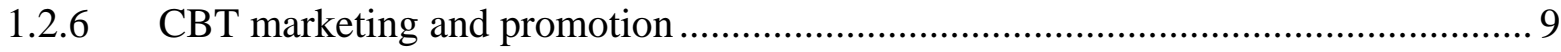

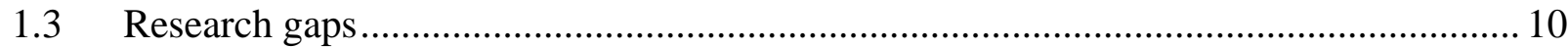

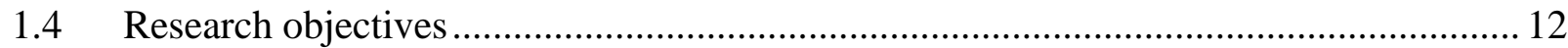

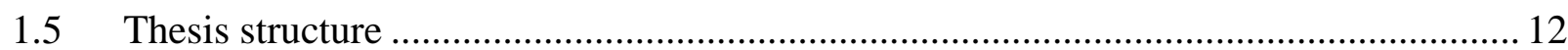

Chapter 2: Literature Review......................................................................................................... 13

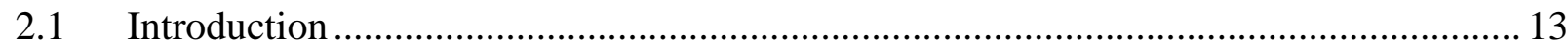

2.2 Defining Community-Based Tourism, its principles and characteristics......................... 13

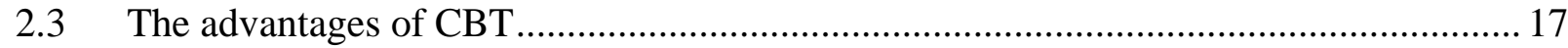

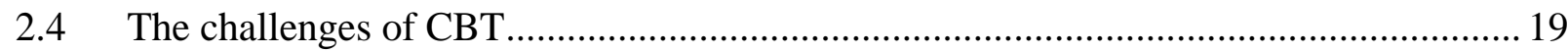

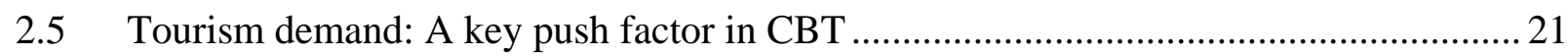

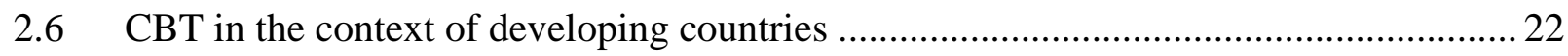

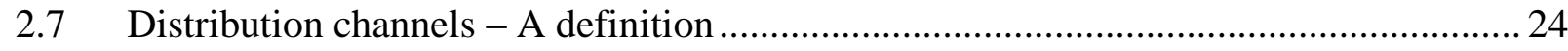

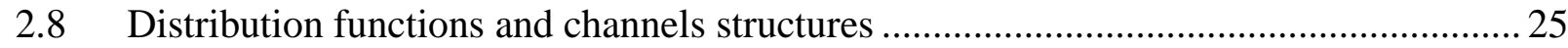

$2.9 \quad$ Factors influencing the structure of distribution channels ................................................ 27

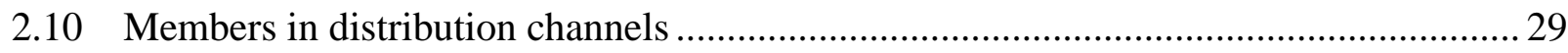

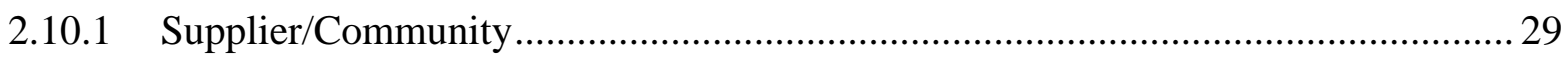

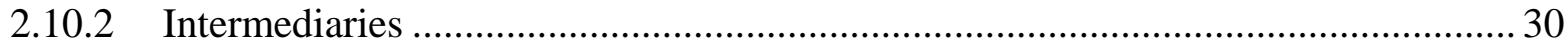




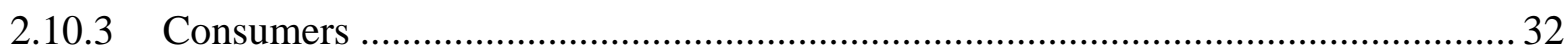

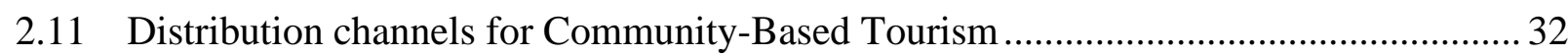

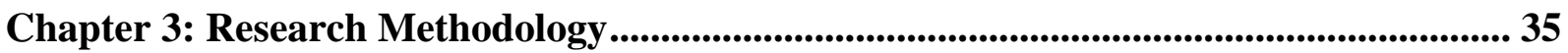

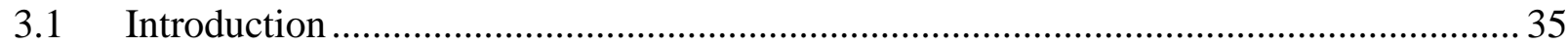

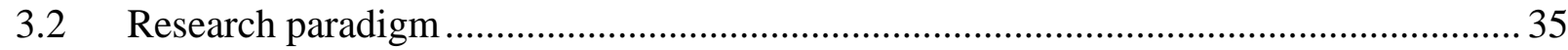

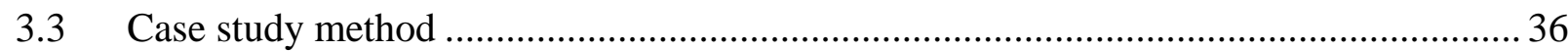

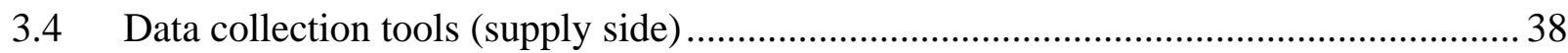

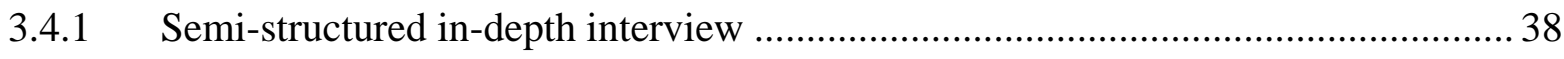

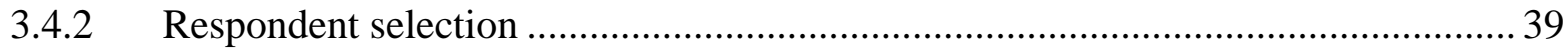

3.5 Data collection tools (demand Side) ………….......................................................... 43

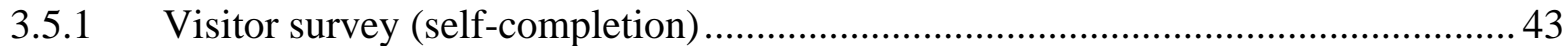

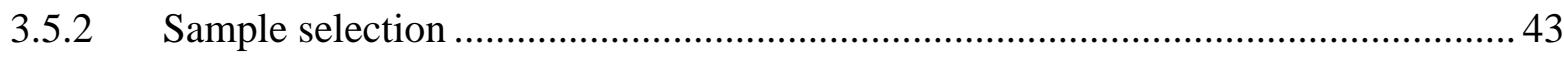

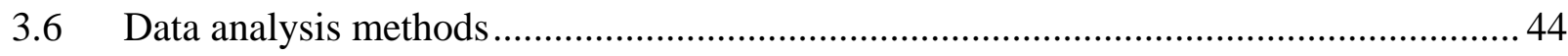

3.6.1 Qualitative data analysis ................................................................................... 44

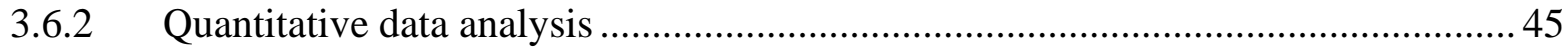

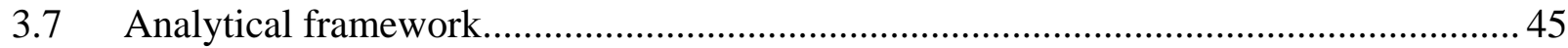

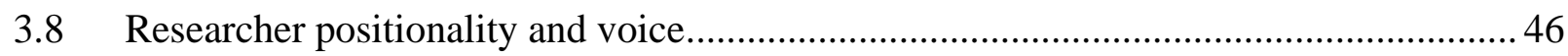

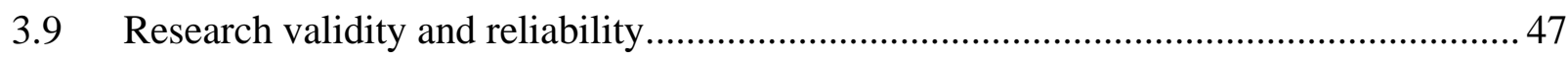

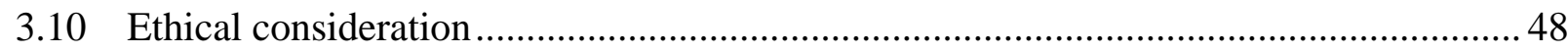

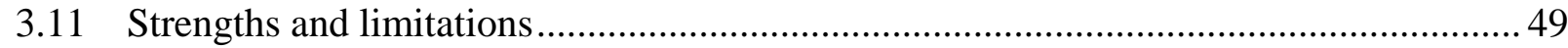

Chapter 4: Distribution channel structures for Community-Based Tourism..................... 51

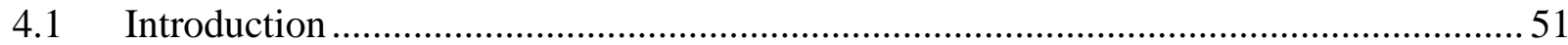

4.2 Marketing channels from a community and intermediaries' perspectives....................... 51

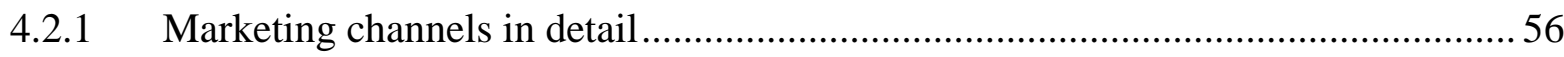

4.3 Booking and payment from community and intermediaries' perspectives .......................6 60

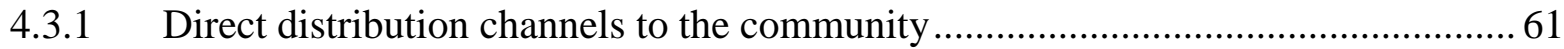

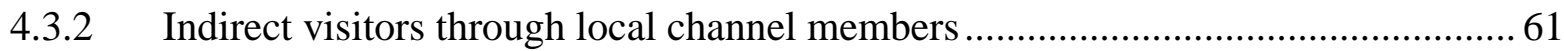

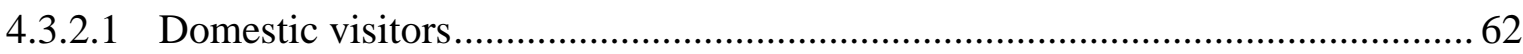

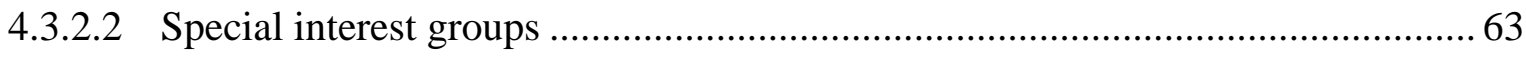

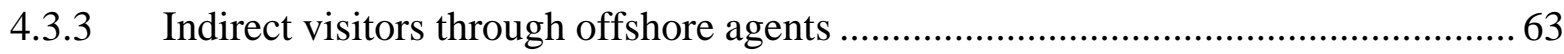

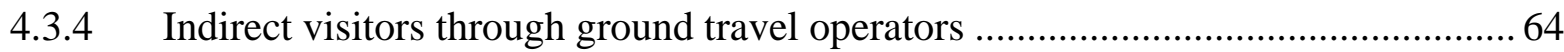

4.3.4.1 Indirect visitors to the community through GTOs direct channels ........................65

4.3.4.2 Indirect visitors to the community through local channel members and GTOs .. 66

4.3.4.3 Indirect visitors to the community through GTOs head or regional offices ......... 66 
4.3.4.4 Indirect visitors to the community through GTOs and offshore channel partners (multiple stages).

4.4 CBT distribution channels from the visitors' perspective ........................................69

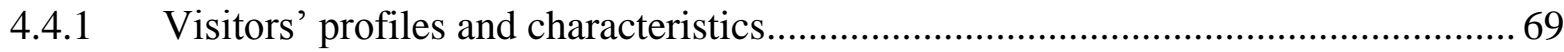

4.4.2 CBT information search and its influencing factors ....................................... 71

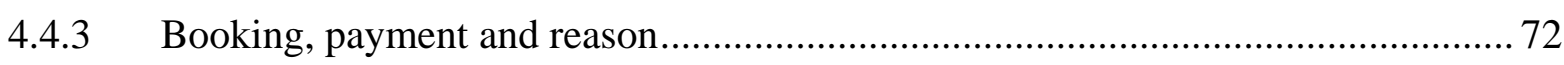

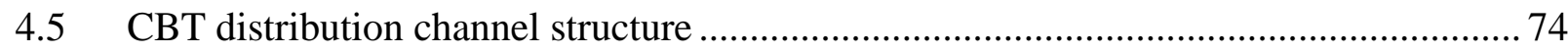

Chapter 5: Factors influencing CBT Distribution Channels................................................... 78

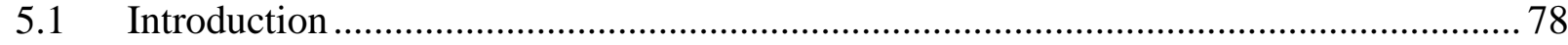

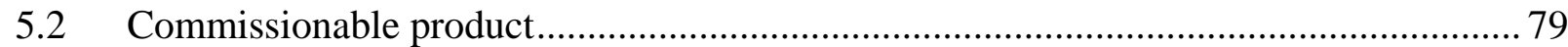

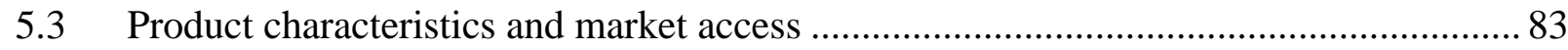

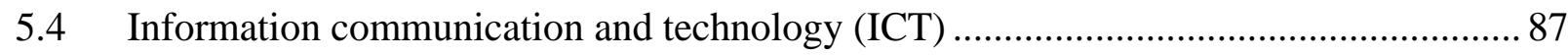

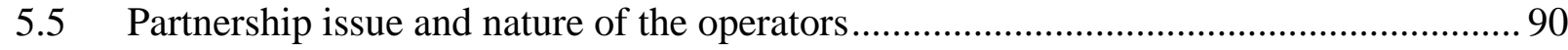

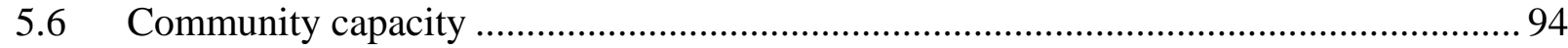

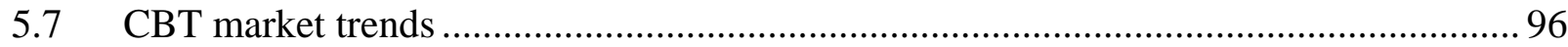

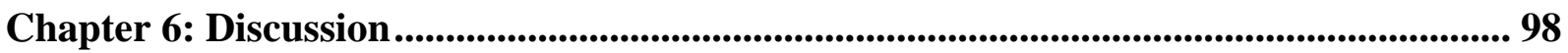

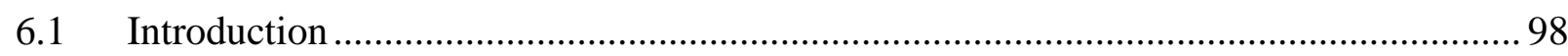

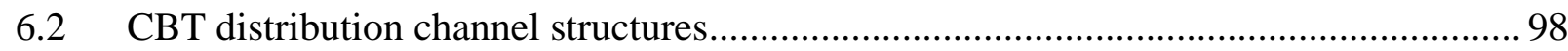

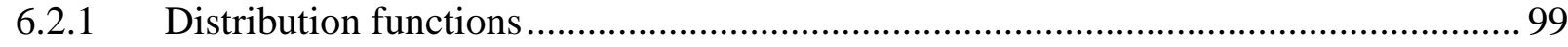

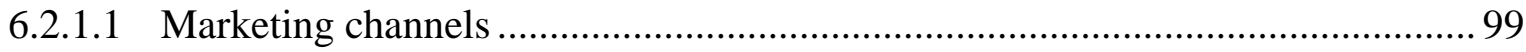

6.2.1.2 Bundling and packaging .................................................................. 101

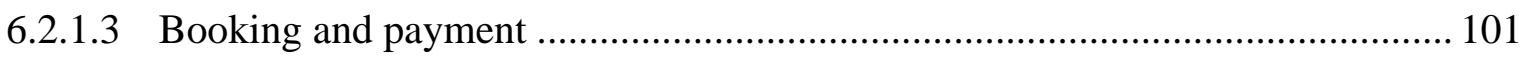

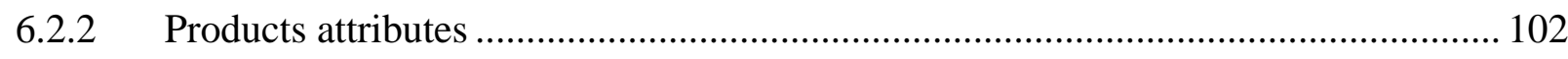

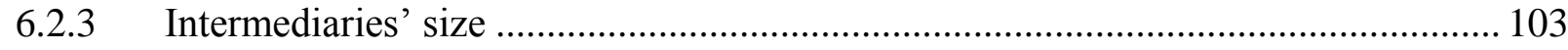

6.3 Factors influencing CBT distribution channel structures....................................... 103

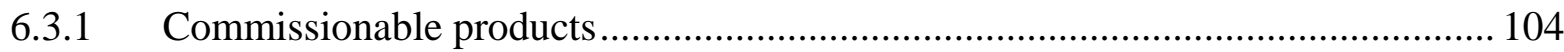

6.3.2 Information Communication and Technology (ICT) ..................................... 105

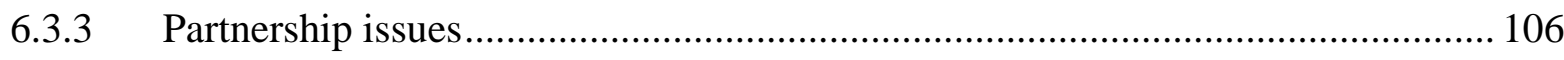

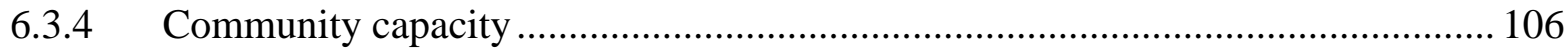

Chapter 7: Conclusion, implications and recommendations ................................................ 108

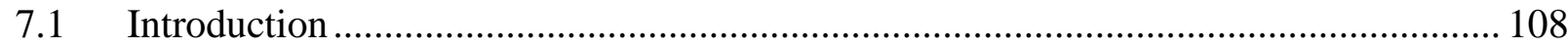

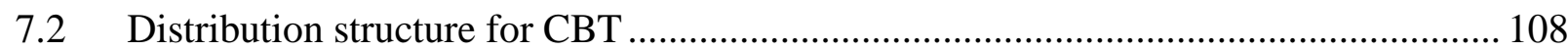

7.3 Factors influencing CBT distribution structure ................................................. 109

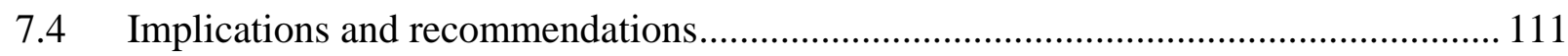


7.4.1 Implications and recommendations for the community .................................. 111

7.4.2 Implications and recommendations for other key channel members .................. 115

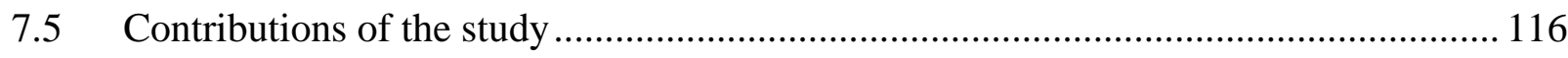

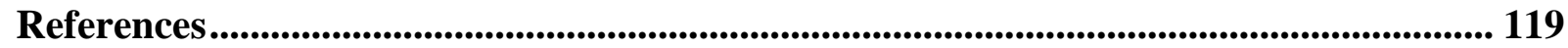

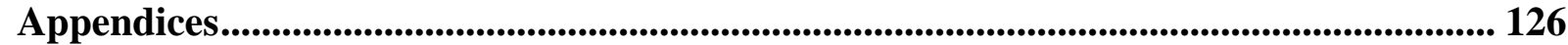




\section{List of Tables}

Table 1: Income distribution for Banteay Chhmar CBT ………........................................ 8

Table 2: Tourism arrival and receipt................................................................................ 10

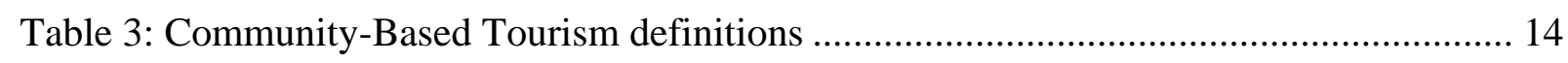

Table 4: Conventional approaches to tourism in the developing world ................................. 15

Table 5: Characteristics of the interview participants .............................................................. 42

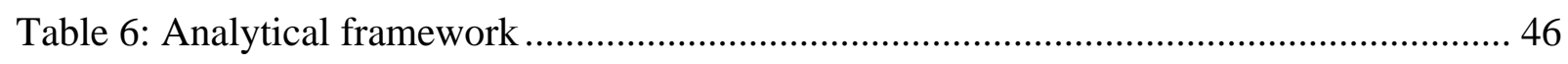

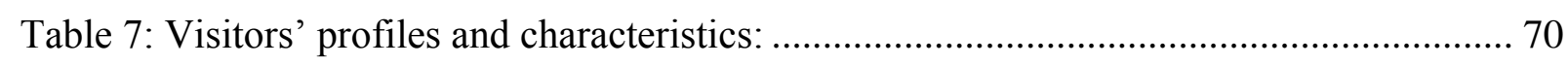

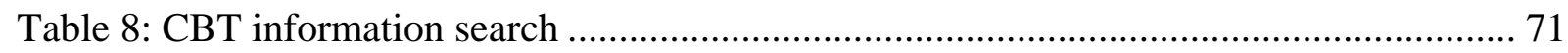

Table 9: Booking and payment and reasons for doing so................................................... 73

Table 10: Factors influencing CBT distribution channels .................................................... 78

Table 11: Price of products and service of Banteay Chhmar CBT .......................................... 80

Table 12: Elements determining CBT distribution channel structures..................................... 99 


\section{List of Figures}

Figure 1: Map of Cambodia indicating location of Banteay Chhmar CBT .............................. 3

Figure 2: Map of Banteay Chhmar CBT …...................................................................... 4

Figure 3: Some tourism activities in Banteay Chhmar CBT ................................................ 6

Figure 4: Figure 4: Banteay Chhmar CBT organization structure........................................ 7

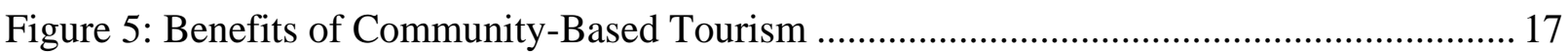

Figure 6: Distribution channels for cultural and heritage attractions in New Zealand.............. 26

Figure 7: Trade structure of Community-Based Tourism ................................................ 33

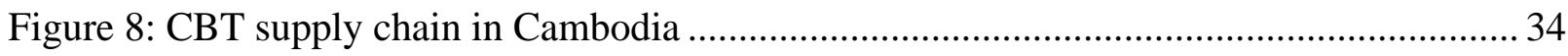

Figure 9: Marketing channels from a community and intermediaries' perspectives:................52

Figure 10: Marketing channels in details (community and intermediaries' perspectives) .........56

Figure 11: Visitors' booking and payment from community and intermediaries' perspectives 60

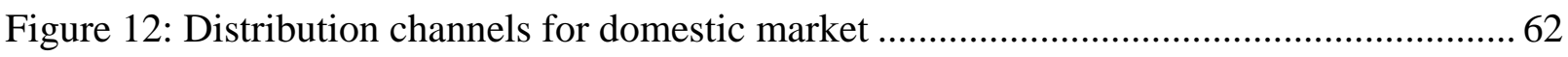

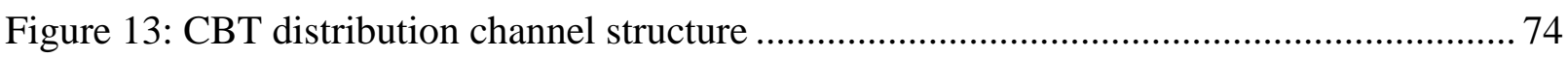

Figure 14: Commissionable and/or mark-up areas of the CBT distribution channels: ............. 81

Figure 15: CBT distribution channel structure and factors that influence it ......................... 104 


\section{Chapter 1: Introduction}

\subsection{Introduction}

This study aims at exploring the distribution channels for community-based tourism (CBT) by examining the distribution structure for CBT, the factors that influence the structure, and its implications for CBT development. This chapter introduces a broad overview of the study in the context of Banteay Chhmar CBT. Pearce and Schott (2005) argue that distribution channels did not receive serious academic attention until the 1990s. This may be because the topic has largely been thought to belong to marketing. However, this subject has emerged as an area of considerably interest in tourism literature during the last decade (Pearce, 2010). This increased attention may be due to the intense competition within the tourism industry where many companies struggle for survival, especially micro and small businesses.

Due to these pressing challenges, distribution channels are now believed to hold tremendous advantages. According to Pearce (2010), distribution channels are important as they help businesses to gain competitive advantage, bring demand and supply (products and visitors) together, while facilitating the marketing channels, packaging and bundling and booking and payment. In addition, Alcazar Martinez (2002, p. 17, as cited in Stuart, Pearce and Weaver, 2005), suggest that the main objectives of the distribution channel is “... to make the product available to the consumer in the quantity needed at the right time, place, state and possession utility to the consumer, thereby facilitating sales". According to perceived benefits of having sound distribution strategies, businesses are still likely to thrive even though they are in a highly competitive environment, because the distribution channels they choose can be an effective tool in determining success or failure of the company.

Distribution channels can also be an effective tool for a number of other reasons: (1) CBT focuses more on the supply side leaving the demand side largely unattended, and therefore, demand volume is very limited. In this case, distribution channels can come into play to raise awareness for concerned stakeholders, especially the community members and the development partners for whom both a supply and a demand focus is critical for economic sustainability. Therefore, CBT should develop appropriate distribution strategies for the business. (2) In most cases, CBT initiatives are located in remote destinations. This suggests 
that the distance between the community and the market is very large. In this case, the distribution channels are very important due to the fact that the information provision function helps to bring information about the community to the market through diverse marketing channels. Moreover, the bundling and packaging, and booking and payment functions are helpful for the community in the way that some or most parts of these functions can be performed by intermediaries in the distribution system, and therefore facilitating sales.

In the highly competitive tourism environment, business ventures find it is increasingly challenging to rely on traditional business practices. It is commonly understood that the key role of distribution channels is to bring suppliers and consumers together and sound distribution strategies enable suppliers to thrive even within a tight competitive business environment.

It is also accepted that distribution strategies not only help to increase sale volume but are also a mechanism which enable suppliers to have greater control of the whole process. This is valuable for environmentally and culturally sensitive destinations where adverse impacts need to be managed appropriately. Given these facts, distribution channels are undeniably important for CBT because they have the potential to further stimulate CBT development through facilitating demand and supply, by offering increased opportunity to the community to have more control on its business processes and to minimize possible undesirable impacts. Given that Banteay Chhmar CBT is located in a remote area, it is even more important for the community to introduce sound and robust distribution strategies into their business practices.

These arguments are deemed appropriate in the context of developing countries such as Cambodia where distribution channels should play more of an active role in connecting demand and supply. Similarly, it can be also argued that the notion of distribution channels is important for particular tourism products or services which are less known, such as, CBT. Freeman (2000) argues that in order to attain cultural goals and community outcomes, business practices are to be prioritized. Since distribution channels are an important element in business operation, then according to this argument, they are critical for CBT success. 


\subsection{Case study context}

\subsubsection{Banteay Chhmar CBT}

Banteay Chhmar CBT is situated in Banteay Chhmar commune, located in the north eastern province of Cambodia. It is in a remote area approximately $60 \mathrm{~km}$ from the Banteay Meanchey provincial town and approximately $105 \mathrm{~km}$ from Poi Pet, an important check point for crossing the border between Cambodia and Thailand (see map in figure 1). A newly constructed road now enables easier access to the community.

\section{Figure 1: Map of Cambodia indicating location of Banteay Chhmar CBT}

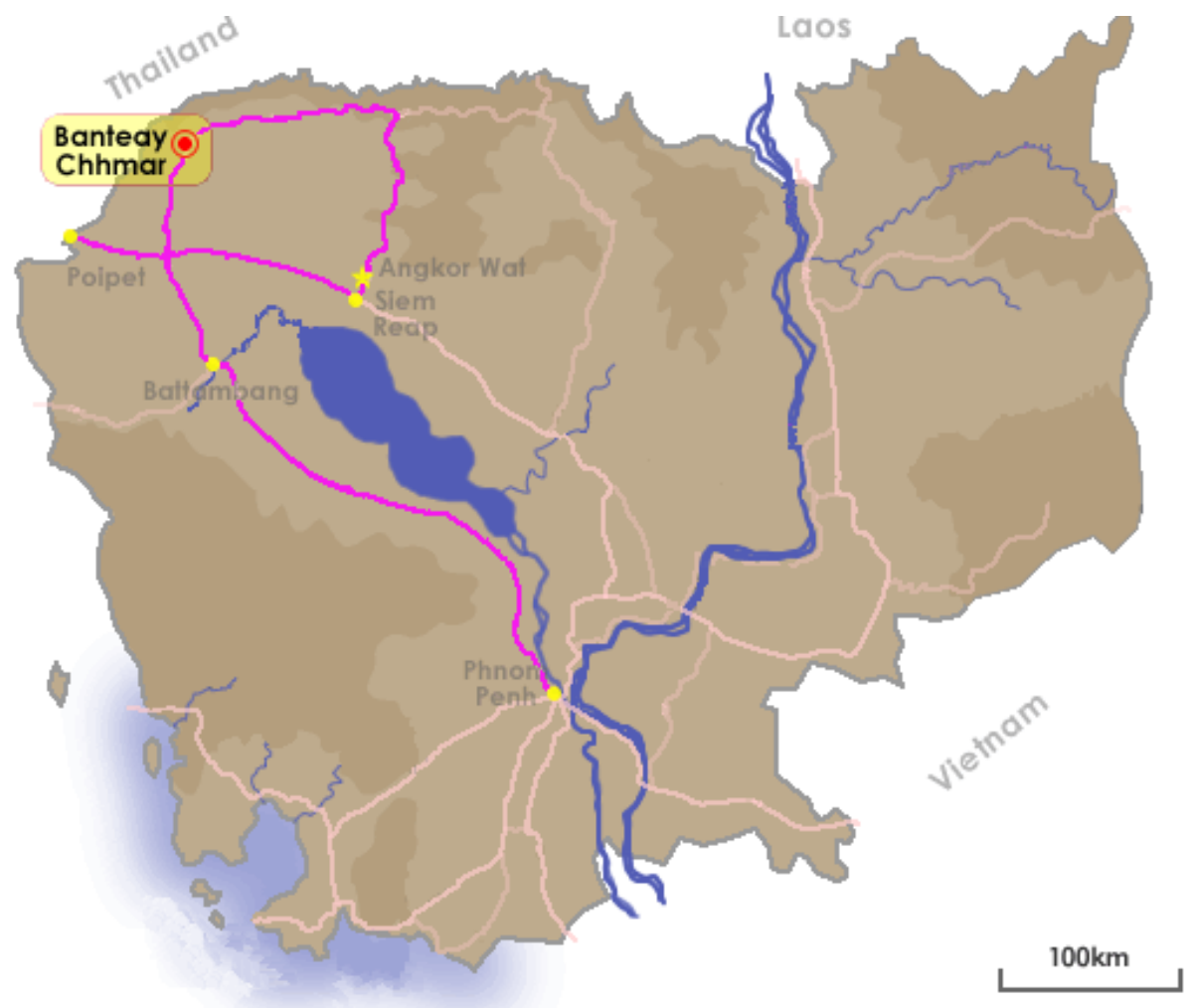

Source: Adapted from http://trekkingyaventura.blogspot.co.nz/2010/03/los-templosde-banteay-chhmar-eco.html, retrieved 02 February 2016

The Banteay Chhmar commune consists of 14 small villages. Five of them are located around Banteay Chhmar temple complex and they participate directly in the CBT development project. These five villages are called Eastern, Western, Southern, Northern and Sras Chrey. Figure 2 illustrates the layout of Banteay Chhmar temple complex and the main surrounding 
villages, the location of home-stays and other main tourism sites within the community. The figure also shows some satellite temples in the near vicinity.

\section{Figure 2: Map of Banteay Chhmar CBT}

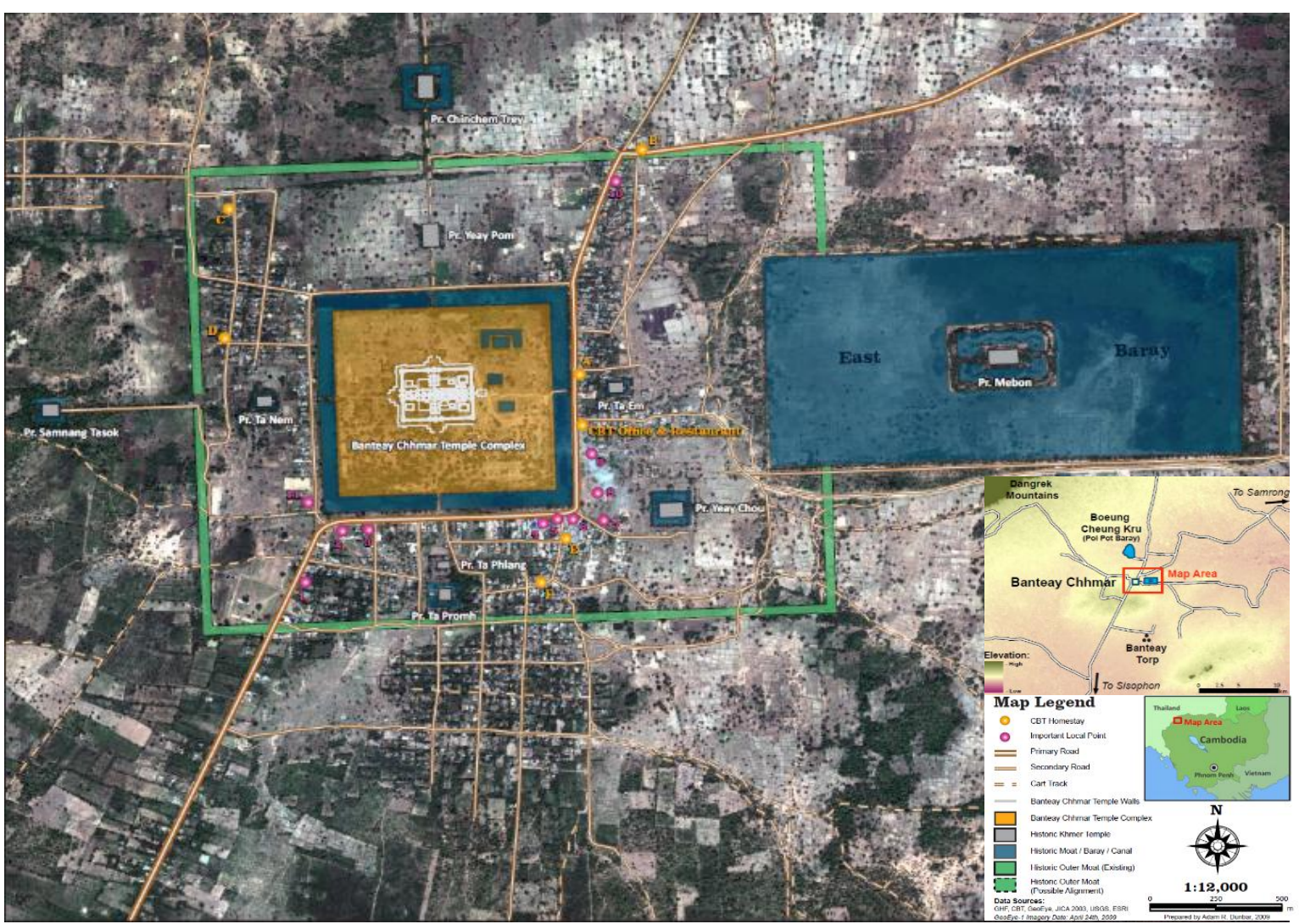

Source: Adapted from Banteay Chhmar's brochure

The size of the main temple complex is approximately one square kilometre and is surrounded by the temple's moats. Most parts of the main temple are in ruins. Very little of the large structure remains standing, but many parts of the walls and galleries, which hold the rarest legacies of the complex, including the beautiful carvings from the Angkorian period, are still in a good state. These are the main tourism attraction of the temple compound. A number of short treks around and within the temple connect it to other surrounding satellite temples located either in the villages or in the fields. These treks enable visitors to explore most parts of the community. 
The tourism infrastructure in the community is rather limited. There is no piped water in the area and only one small enterprise provides a purified spring water service to the whole commune at an affordable price. Electricity has only very recently become widely available in the area; however, some households still use batteries as their source of power.

Like everywhere else in the country, the local people in Banteay Chhmar are Buddhist. Due to its remoteness, many traditional practices and beliefs, such as, superstition and belief in ghosts and spirits are still influential to the local people. The local people are very conservative and their lifestyles are typical and highly representative of the unique Cambodian culture.

\subsubsection{Brief overview of the history and economy of Banteay Chhmar}

Banteay Chhmar and the other satellite temples were constructed under Jayavaraman VII at the end of the 12th century and are similar in construction and design to the iconic Bayon temple in the Angkor Archaeological Park, which was constructed on an older 9th century site.

The modern history of Banteay Chhmar is mainly associated with the Khmer Rouge regime. The effect of civil war on Banteay Chhmar and the surrounding area is still prevalent today. Much of the historical meaning of Banteay Chhmar temple has been lost over the years. During turbulent times and the civil war in the mid to late 1970s, many parts of the invaluable sculptures were looted and many others parts were later smuggled. Due to the long-standing civil war Banteay Chhmar became even more isolated. Post war redevelopment has been slow to progress because the government has paid limited attention to the area and as a result of this the local people have very limited access to education and health care.

Banteay Chhmar is primarily an agricultural community. Therefore, most people are farmers. People grow their own fruit and vegetables and raise livestock, all of which is traded within the community. The main crops are rice and cassava. The majority of the rice is traded within the community, whereas all the cassava is exported to neighboring countries. Most families participate in other work alongside farming. This includes, roadside stalls selling food or goods and providing goods and services to the visitors through the CBT project. 


\subsubsection{Banteay Chhmar CBT products and services}

The notion of CBT in Banteay Chhmar was originally proposed by a French organization called Agir Pour Le Cambodge (APLC) in 2006 with an expectation that local people would have opportunity to benefit from CBT through providing tourism-related services and products. There was also the expectation that CBT would help to stimulate community empowerment and ensure that they have capacity to manage and control their resources appropriately. The community would have to be actively involved in the development process, and be required to participate in a range of learning activities and fully engage in tourism. The benefits would be the long term sustainable development of an economic activity which would have direct and indirect benefits for the whole community.

There are a number of assets that could be transformed into tourism attractions and products. The presence of the main temple site and the surrounding satellite temples provided the strength for Banteay Chhmar to have potential in successfully establishing a CBT project. Located in a protected landscape, Banteay Chhmar community has a lot to offer. In addition to the temple building, there are number of other subordinate products, such as, Cherng Krus Lake which has great historical value, a lovely village and views of the fields.

\section{Figure 3: Some tourism activities in Banteay Chhmar CBT}
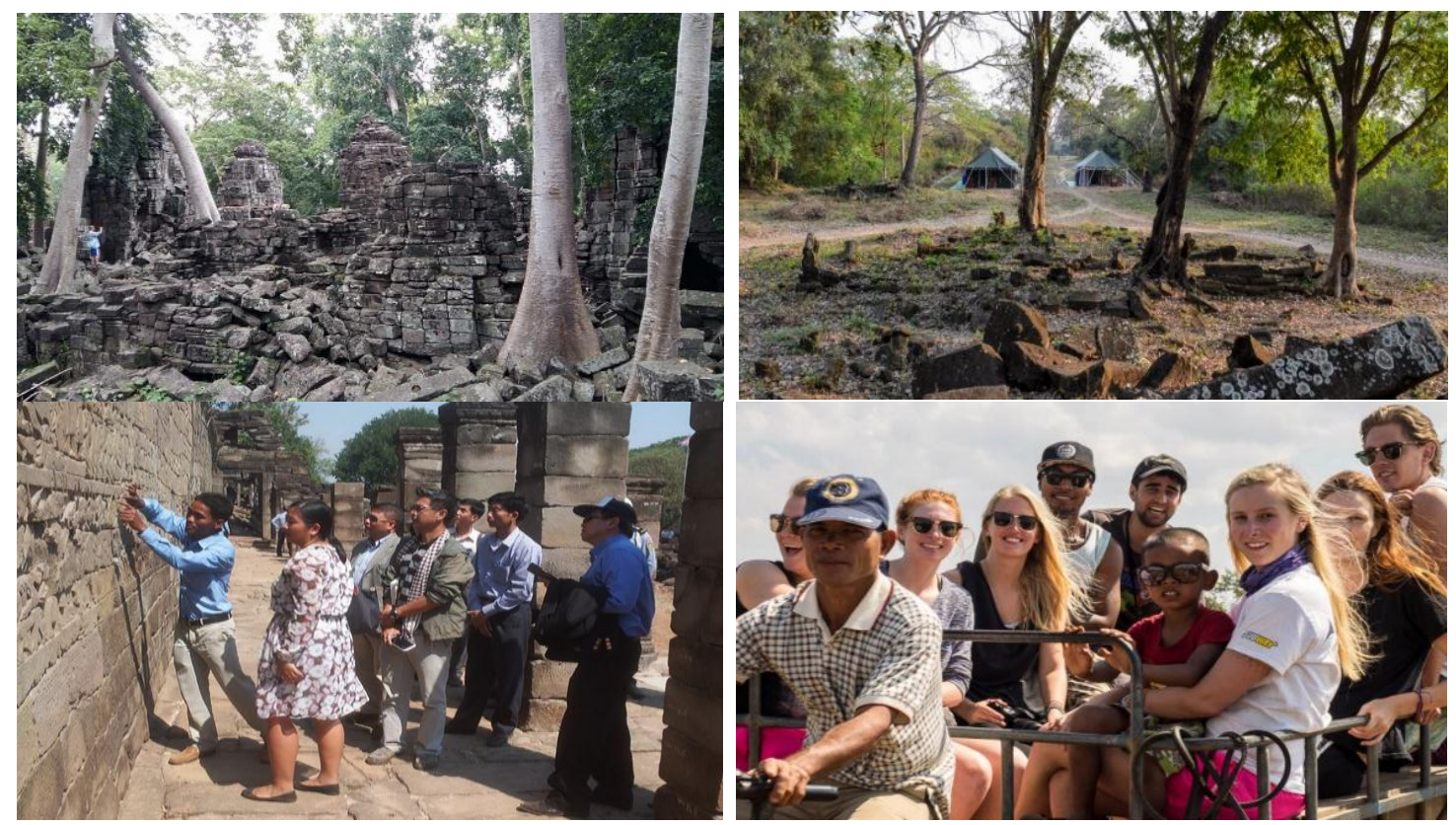

Source: Banteay Chhmar CC members 
Now the community also provides a wide range of activities which include; home-stay experiences, temple and village tours, dinning and local food experiences, rice flattening and other activities related to village life. The community also offers tourist activities which showcase local traditions and practices, such as, silk weaving, dal ombok, ox cart and kuyon rides, traditional music and dancing, boat trips and volunteer activities. In addition, the community offers camping services and additional visits to off the beaten track satellite temples.

\subsubsection{CBT organization structure}

The structure of Banteay Chhmar CBT centers on the tourism committee, consisting of - the president, vice president, assistant, accountant, the GHF liaison, local authority, and a head of each of the activities. There are 77 other people in the community who work directly with the committee and regularly participate in providing services and facilitating activities in the community. Each activity operates as part of the CBT and has a subcommittee with its own head. These subcommittees include cooks (11 members), home-stays (9 members), Dal ombok, oxcart rides, kuyon rides, and cultural activities (including silk weaving and traditional music).

\section{Figure 4: Banteay Chhmar CBT organization structure}

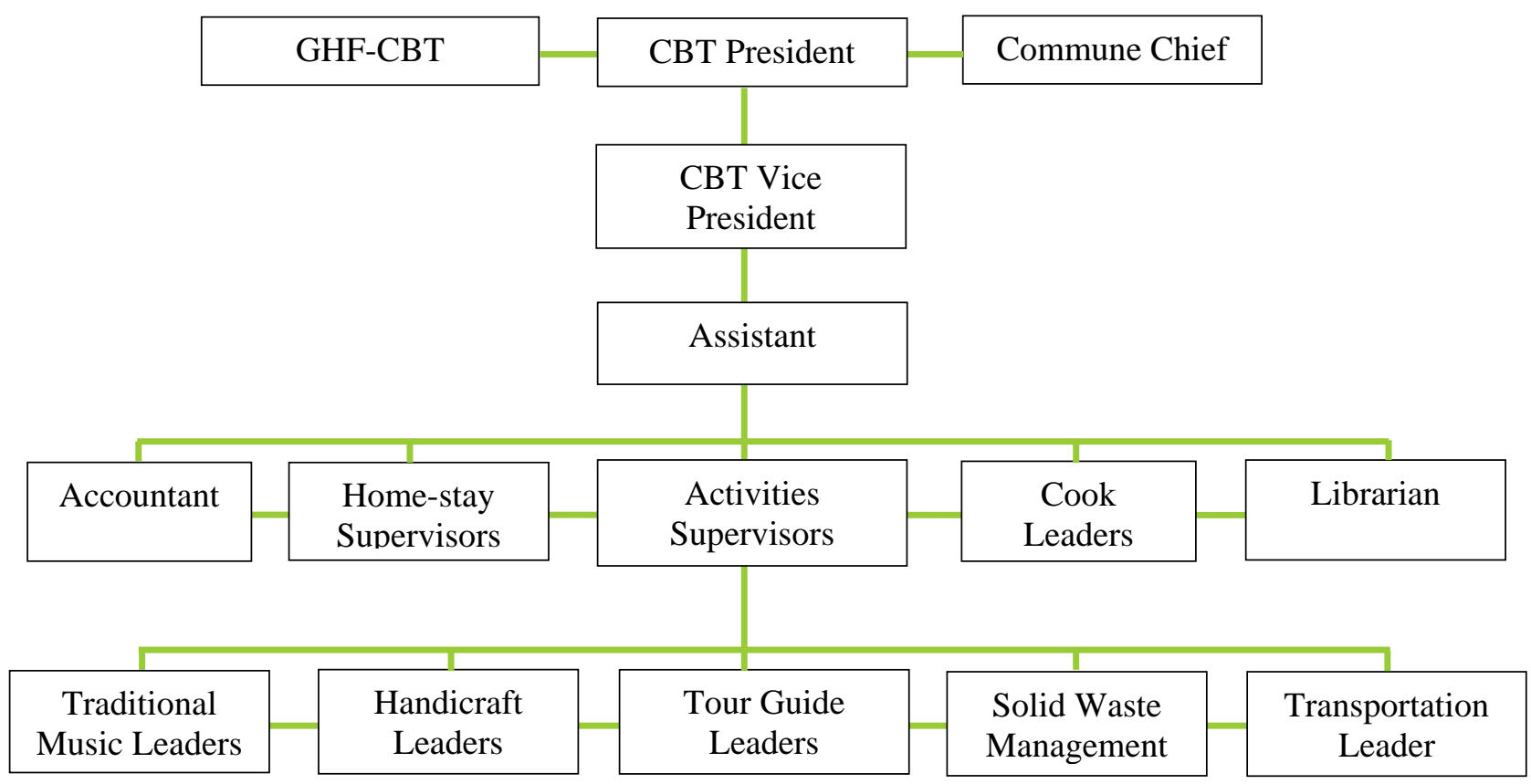

Source: Redraw from annual community report 2014 


\subsubsection{Capacity buildings and benefit sharing}

Due to the fact that most community members do not have sufficient knowledge and knowhow necessary for implementing CBT, a number of NGOs and government agencies have supported and facilitated a wide range of capacity building activities for them. These include hospitality training, the establishment of accommodation (home-stay), food and beverage services and local guide training. Furthermore, some private sector partners also help to provide practical experience to the community through regular meetings and feedback. Capacity issue is important for Banteay Chhmar CBT because it helps to ensure that the community can run their business by themselves.

The services and activities provided by the local people are based on a rotation system. This is to ensure that all participants have equal opportunity to reap the benefits from the initiative. The service providers in the community receive a direct income, with the remaining portion being used to fund operational costs, and to contribute to a collective fund for other community development projects. Table 1 shows the way in which income from tourism is divided among the community.

Table 1: Income distribution for Banteay Chhmar CBT

\begin{tabular}{|c|c|c|c|c|c|}
\hline $\begin{array}{l}\text { Service/ } \\
\text { Product }\end{array}$ & $\begin{array}{l}\text { Cost of } \\
\text { product/ } \\
\text { service } \\
\text { (USD) }\end{array}$ & $\begin{array}{l}\text { Amount } \\
\text { retained by } \\
\text { service } \\
\text { provider }\end{array}$ & $\begin{array}{l}\text { \% retained } \\
\text { by service } \\
\text { provider } \\
\text { (USD) }\end{array}$ & $\begin{array}{l}\text { Amount } \\
\text { retained by } \\
\text { tourism } \\
\text { committee }\end{array}$ & $\begin{array}{l}\text { \% retained } \\
\text { by tourism } \\
\text { committee }\end{array}$ \\
\hline $\begin{array}{l}\text { Home-stay } \\
\text { (per night) }\end{array}$ & 7 & 4 & $57 \%$ & 3 & $42 \%$ \\
\hline Food & $\begin{array}{l}3 \\
4\end{array}$ & 1 & $25-33 \%$ & $\begin{array}{l}2 \\
3\end{array}$ & $66-75 \%$ \\
\hline $\begin{array}{l}\text { Tour guide } \\
\text { (per group) }\end{array}$ & 5 & 2 & $40 \%$ & 3 & $60 \%$ \\
\hline
\end{tabular}

Source: Compiled by author 


\subsubsection{CBT marketing and promotion}

The promotion of Banteay Chhmar was formerly done through the Cambodia community based ecotourism network website. During the inception stage, APLC helped to promote Banteay Chhmar in Europe through printed brochures both in English and French. Other promotional efforts have led to the inclusion of Banteay Chhmar in many guide books, such as, Lonely Planet and Rough Guide for Cambodia. In addition, the community has also implemented business-to-business promotion by meeting with a number of potential tour operators in Cambodia.

Due to the unavailability of further funding, APLC phased out from the development projects in Cambodia in 2008. At that time, a second NGO, Global Heritage Fund (GHF), which is running a conservation and part restoration project of the main temple complex, took over the role in supporting Banteay Chhmar. This organization does not involve itself directly in tourism within the community, but the conservation program has had positive implications for tourism by restoring the main tourism asset, despite short term negative impacts as works restricted access to the site. Due to the shrinking financial support, the community does not have sufficient budget to pursue marketing activities. However, the recent launch of a website has come into play for direct marketing strategy opportunities.

In 2011, Banteay Chhmar won a hidden treasure contest award run by the USAID Cambodia MSME project. This offered more opportunities to the community in terms of technical support and business linkages, as well as promotion and marketing networks. Concerted efforts have been made in product and service development and linkages with private tour operators and travel agencies. 
Following the efforts of the community, the tourism arrivals and tourism receipts have increase noticeably. Table 2 below marks a steady annual increase.

Table 2: Tourism arrival and receipt

\begin{tabular}{lll}
\hline Year & Tourism Arrival & Tourism Receipt (USD) \\
\hline $2015^{*}$ & 470 & 18433 \\
2014 & 1288 & 36013 \\
2013 & 882 & 23970 \\
2012 & 671 & 13976 \\
\hline
\end{tabular}

Source: Compiled by author (Noted: * Data for the first four months of 2015 (Jan-Apr)

\subsection{Research gaps}

Ryan and Page (2000), suggest that it has taken until the last decade for the concept of sustainability to enter into the tourism debate. During this time, the link between marketing for tourism and sustainability has become one of the primary focuses in tourism literature. As part of this emerging phenomenon, the attention on marketing for CBT has also been developed. A study on marketing of host communities conducted by Moscardo and Pearce (2003), revealed that not only was there a lack of understanding of how host communities are marketed but also the distribution system for CBT in general have received very limited attention among tourism scholars. This may be due to the fact that most of the authors primarily consider that a direct channel simply links suppliers (destinations) directly to the market (tourists) and vice versa. This assumption underestimates the effect of distribution channels with wider information systems designed for a number of channel members, such as, affiliations, consortia, reservations companies, incentive houses, representation companies, travel agents, tour operators and wholesalers, discount brokers and international distribution systems (Lewis and Chambers, 2000).

Tourism marketing is extensively developed in tourism scholarship, yet relatively few scholars pay serious attention at the community level (Beeton, 2005). Meanwhile, the commercial aspect of CBT seems to be overlooked even though it is a critical element for sustainable tourism development. Middleton (1997) suggests that many small cultural and heritage sites do not have sufficient capacity to deal effectively with the function of marketing. Responsible 
staff are only knowledgeable on areas such as conservation rather than tourism management. This is especially true in the case of Banteay Chhmar CBT where a principle donor mainly invests in restoration of the temple ruins while limited attention has been paid on how to develop a sound commercial CBT project. Indeed Pearce and Tan (2004) also point out that marketing issues are largely overlooked in the heritage and cultural tourism literature.

In addition, one of the noticeable challenges of CBT products is the limited connection with the private sector and other mass tourism products. Mitchell and Ashley (2009) suggest that the issues of CBT development in developing countries are associated with the isolation from commercial distribution channels and hence, there is little focus on demand volume and commercial sustainability. Considering this, the distribution channels for CBT are an essential means to connect CBT products to their potential markets.

Considerable scope exists for examining distribution channels for CBT. While a growing body of literature has emerged in recent years dealing with tourism distribution channels (Buhalis \& Laws, 2001; Schott, 2007; Smith, 2007; Liu, 2012; Andrade, 2013; Mkumbo, 2010; Pearce \& Tan, 2004; and Peace, 2005), this has essentially focused on different aspects of tourism rather than on CBT. Conversely, most CBT studies have taken a social science perspective with little attention being given to the more commercial and operational aspects of this sector. As a consequence, there is very little work that examines the way in which those who are responsible for CBT seek to distribute their products to visitors and the structure of their distribution systems.

Therefore, it is important to investigate further this identified research gap in order to; (1) build on the literature of tourism distribution channels, and (2) provide insight into how to develop CBT effectively by taking advantage of the various distribution channels. 


\subsection{Research objectives}

After consideration of the identified research gap, this study is to investigate the distribution channels for Banteay Chhmar CBT. The objectives of this research are:

- To investigate the structure of the distribution channels for Banteay Chhmar CBT from both the demand and supply side perspective

- To examine factors influencing the distribution structures for CBT

- To find the implications for CBT from both the demand and supply side perspective and how these implications can help improve CBT product sales

\subsection{Thesis structure}

Following this introductory chapter, which has provided a broad overview of the study and the case to be examined, including the research objectives, chapter 2 focuses on the literature review related to distribution channels and CBT, and indicates how this study will fill in the identified research gap as described above. In addition, chapter 2 attempts to bring these two divergent concepts - distribution channels and CBT- together. Chapter 3 introduces the research methodology and the way in which this research will be conducted; this includes the characteristics of respondents, data analysis techniques, validity and reliability and research strengths and the limitations.

Chapter 4 outlines the key findings of this research, breaking down those findings into various sections associated with marketing channels and the structure of CBT distribution channels. Chapter 5 provides the key findings associated with the factors that influence the CBT distribution structure. Chapter 6 then provides detailed discussion of the key findings from chapters 4 and 5 and interlinking these with the literature review in chapter 2 . The concluding chapter summarises the key research findings, draws out the implications and recommendations for concerned channels members, especially the community, and also makes suggestions for further research. 


\section{Chapter 2: Literature Review}

\subsection{Introduction}

This chapter is divided into two parts. The first part discusses a broad overview of the literature that relates to the concept of CBT, its definition, principles and characteristics. Next, the important issues of opportunities and challenges for CBT development are explored. This will be followed by discussions dealing with CBT demand and CBT in the context of developing countries. The second part of this chapter critically discusses the body of literature on distribution channels. This review of the literature particularly focuses on distribution channel structures, including both direct and indirect distribution channels, and also the pivotal functional aspects of the distribution channels. This part of the chapter concludes with a discussion on key channel groups, that is, suppliers, intermediaries and consumers.

Both parts of this chapter initially look at the broader aspects of the existing literature and research on the topics of CBT's and distribution channels before narrowing the scope and focus in relation to the current study. Therefore this literature review aims to communicate and inform readers about the previous studies and then to contextualize into the present investigation. Additionally, this chapter also infers the appropriate research methodologies for the chapter that follows (chapter 3 - Research methodology).

The final section of this chapter is to marry two divergent concepts, (CBT and distribution channels), and use this analysis to work out how paths to the market for CBT products and services can be better facilitated. By doing so, more specific issues related to the distribution channels for CBT are highlighted.

\subsection{Defining Community-Based Tourism, its principles and characteristics}

The term community itself can be defined in a number of ways because it not only refers to a place or neighbourhood, but also the interconnection among people who have similar interests and concerns. For whatever purpose in most cases, this definition embraces three key components namely - geographical location, people and the connection between themselves (Phillips \& Pittman, 2009). 
Fundamentally, CBT focuses on tourism development that is community-oriented. The community should have the power to control the development processes from the inception stage to the planning phases (Muhanna, 2007). In addition, benefit sharing mechanisms need to be designed that are transparent and accountable amongst all of the key stakeholders, especially among the community members themselves. Also, a meaningful host-guest interaction is a critical component in CBT, especially through home-stay promotion.

The CBT concept is a very elusive and vague term according to Salazar (2012). Thus, there is no single way to conceptualize CBT and it can be defined in many different ways. Yet, to some extent, its key characteristics and principles largely remain the same in order to ensure a systematic way of understanding. The CBT concept first emerged in Murphy's work in 1985 (as cited in López-Guzmán et al., 2011; López-Guzmán et al., 2013). Since then a number of prominent scholars have defined CBT in similar but slightly different ways, as shown in table 3 below.

\section{Table 3: Community-Based Tourism definitions}

Authors/sources CBT definitions

The Mountain CBT is a visitor-host interaction that has meaningful

Institute, 2000, p.1 participation by both, and generates economic and conservation benefits for local communities and environments.

Mowforth \& Munt, CBT seeks to increase people's involvement and ownership of 2009, p.99 tourism at the destination end. CBT should initiate from and control stay with the local community, but sometimes arising from operator initiative.

CCBEN \& SNV, $\quad$ CBT is a form of tourism that is managed and owned by 2009, p.3 community in collaboration with other stakeholders in order to enhance the local well-being; natural and cultural resource conservation; host and guest interaction and education. 
Salazar, 2012, p.14 CBT is a tourism initiative that are owned by one or more defined communities, or run as joint venture partnerships with the private sector and with equitable community participation, as a mean of using natural resources in a sustainable manner to improve their standard of living in an economically viable way.

Goodwin \& Santilli, CBT is a form of tourism that is owned and managed by 2009, p.4 communities and intended to deliver wider community benefit, benefiting a wider group rather than those employed in the initiative.

A CBT scheme involves multiple stakeholders; these include local dwellers, local and national governments, private sector and development partners. Due to the diversity of backgrounds, views and other contributing factors, these key stakeholder group members perceive tourism differently. For instance, private sector tend to believe that whatever form of tourism their business is it involves commercial activities, profit making and product development. Meanwhile, government, non-governmental organizations and local residents have the similar perception, where, they consider tourism as an alternative development option and conservation tool. Ashley (2000), points out that defining tourism in a developing context can be formulated based upon a wide range of perspectives (see table 4).

\section{Table 4: Conventional approaches to tourism in the developing world}

\begin{tabular}{|l|l|}
\hline $\begin{array}{l}\text { Economists generally see tourism as a } \\
\text { route to macro-economic growth and } \\
\text { particularly as a means of generating } \\
\text { foreign exchange. }\end{array}$ & $\begin{array}{l}\text { For the private sector, tourism is a } \\
\text { commercial activity, so the main concerns } \\
\text { are product development, competitiveness } \\
\text { and commercial returns. }\end{array}$ \\
\hline $\begin{array}{l}\text { Many conservationists now see tourism } \\
\text { as a way of using wild resources } \\
\text { sustainably, and hence as a way to } \\
\text { enhance incentives for conservation. }\end{array}$ & $\begin{array}{l}\text { For local people, and the development of } \\
\text { NGOs that support them, tourism is one } \\
\text { component of rural development. }\end{array}$ \\
\hline
\end{tabular}

Source: Ashley (2000:8) 
According to Blackstock (2005), conceptualizing CBT is rather naïve and unrealistic. Similarly, Ndlovu \& Nyakunu (2011), indicate that there is no universal agreement on a CBT definition. However, guided by its characteristics and principles, CBT should focus on a number of elements, such as, local ownership of development projects, strong and meaningful participation in all stages of decision-making, transparent and accountable benefit sharing mechanisms among community members and the meaningful host-guest interaction. Therefore, CBT is an alternative form of tourism development that concentrates on community participation in all processes starting from idea formulation, planning, implementation, management, monitoring and evaluation, and benefit sharing.

In a Cambodian context, Cambodia community based ecotourism network (CCBEN) and the Netherland development organization (SNV) (2009), define CBT as described above in table 3 , and in addition to this definition, they also suggest ten guiding principles for CBT as below:

1. Involve and empower community members to ensure ownership and transparent management

2. Establish partnerships with relevant stakeholders

3. Gain legal recognition from relevant authorities

4. Achieve social well-being and human dignity

5. Establish a fair and transparent benefit sharing mechanism

6. Enhance linkages to local and regional economy

7. Respect the local culture and tradition

8. Contribute to natural resource conservation

9. Improve quality of visitor experiences by strengthening meaningful host and guest interaction

10. Work towards financial self-sufficiency

(CCBEN \& SNV, 2009 p.3)

Stemming from the sustainable tourism concept, the CBT definition (and the ten guiding principles), encompass three bottom line approaches which include socio-cultural, environmental and economic dimensions. Although there is a strong claim on the significance of economic sustainability, more research tends to focus on the environmental component. This may be due to the fact that most CBT projects are located in environmental and culturally 
sensitive areas where commodification of such resources is not a priority of the initiative. In addition to this, large numbers of CBT schemes, especially in developing regions, are being supported financially and technically by donors, through local or international organizations, who put conservation goals at the forefront.

\subsection{The advantages of CBT}

CBT offers a number of advantages to the community. One of the fundamental benefits, according to (Boonratana, 2010), is that the community is highly encouraged to participate in planning, implementing and managing the CBT products and services. Hence, this promotes a sense of ownership over such a development project. Compared to other industries, investment in CBT is more economical and plausible because its selling points are facilitated and supported by available natural and cultural resources within the community, such as, local culture or waterfalls (Vajirakachorn \& Nepal, 2011). Therefore the focus of the CBT is not only on economic returns, but also on sustainability (Dolezal \& Burns, 2015)

\section{Figure 5: Benefits of Community-Based Tourism}

\section{Economic:}

- $\quad$ Direct and indirect employment opportunities

- $\quad$ Support the development of enterprise

- $\quad$ Provide invigoration and development to local economies

- Provide alternatives to changing or fading traditional industries

\section{Environment:}

- Improve environment - less degradation

- Encourage awareness and appreciation

- Enhances management and stewardship of natural resources

\section{Socio-cultural}

- Promote and stimulate infrastructure development

- Increase safety and security

- $\quad$ Facilitate workforce development

- Fosters civic pride

- Mutual benefits and create opportunities

- Promote cultural understanding

- Preserve cultural and social heritage

- Support and preserve local crafts and skills

- Create a sense of well-being

- Promote greater cross institutional understanding
Building of skills and influence

- Influencing and enforcing government policy

- Skill enhancement

- $\quad$ Building capacity collectively and individually

- Fosters empowerment

Source: Adapted from Simpson (2008) 
Figure 5 above shows an adaptation from Simpson's (2008) summary of the key benefits of CBT to the community. These key benefits cover four major dimensions; socio-cultural, economic, environment, and skill and influence building.

CBT development goals tend to be rather ambitious because they embrace broad issues associated with political, socio-cultural, environmental and economic dimensions (Kogtogeorgopoulos, 2005). Given the fact that CBT is an alternative form to mass tourism and it centres on sustainability, it tries to balance all aspects of these dimensions. From an economic lens, CBT is believed to have direct economic impact at the grass root level because it helps to improve local living standards through local job creation (Manyara \& Jones, 2007; López-Guzmán et al., 2011). Similarly, Lapeyre (2010), also states that CBT helps to enhance rural local livelihood and offers better local economic connections while minimizing economic leakages. While Zapata et al., (2011), suggest that CBT can diversify rural economic choices. Though it is not a lucrative venture, it offers long-standing economic solutions most appropriate at the community level. In addition, through indirect and inducement impacts, in most cases, where there is a sound benefit sharing mechanism, it can ensure economic benefits are delivered among members appropriately.

From a political stand point, CBT is an approach that encourages local participation, empowerment and decision-making concerning a community's future direction (Duffy, 2002; Suansri, 2003). It helps to promote democratic processes through consensus agreement. From a socio-cultural view point, CBT can be an important catalyst to revitalize local tradition, helping to promote local pride and self-esteem. Additionally, it encourages culture and knowledge exchange between host and guests (Duffy, 2002; Suansri, 2003; Kibicho, 2008), and improves local infrastructures, such as, health care, transportation and communication which can serve non-tourism purposes as well (Manyara \& Jones, 2007). According to Al-Oun and Al-Hamoud (2008), CBT has the potential to conserve the local culture and heritage that are both tangible and intangible. Furthermore, local people have more opportunity to increase awareness and capacity necessary for the CBT operation through involvement in local culture and heritage conservation (Lapeyre, 2010). From an environmental perspective, CBT can be an effective tool to generate environmental and cultural awareness and conservation (Duffy, 2002; Suansri, 2003; Hall, 2010a). 


\subsection{The challenges of CBT}

Even though there are number of benefits associated with CBT initiatives, it also faces some severe criticism. Matarrita-Cascante (2010), argues that such initiatives present utopian ideals, where it is almost impossible for the CBT project to achieve the goals and reap the benefits as originally stated. The discourse of CBT lies in the fact that its overarching goals are too ambitious and very often the processes are mainly beyond community control, therefore, as a consequence those goals cannot be sufficiently accomplished. Another noticeable challenge is that CBT products show either none or very limited connection to the private sector or other mass tourism products. Thus, CBT is not in the position to relieve local poverty (Mitchell \& Muckosy, 2008; Mitchell \& Ashley 2009). Mitchell \& Ashley (2009), go further to suggest that:

“...developing countries are littered with well-intentioned community-based tourism projects, delivering small benefits to few people. Developed in isolation from commercial distribution channels, they lack the client volumes needed for commercial sustainability. "

Other issues include conflict and jealousy (Simpson, 2008), inadequate skills and knowledge necessary for running CBT enterprises (Manyara \& Jones, 2007), power imbalance and the project being influenced by a small number of local elites (Manyara \& Jones, 2007; Kibicho, 2008; Pongponrat \& Pongquan, 2007; Mowforth \& Munt, 2003; Feng, 2008; Rogerson, 2007), and ownership of tourism resources (Manyara \& Jones, 2007) which can hamper CBT from healthy growth. These challenges prevent the community from a meaningful participation in the development project. Furthermore, Butcher (2007) and Mitchell \& Muckosy (2008) similarly argue that the so-called participation plans have already (mostly) been designed by outsiders and then brought into the community for consensus. In this regard, direction has already been set out as most of the critical decision-making has been made by outsiders therefore leaving little room for the community's voice.

In most developing country contexts, according to Ellis (2011), CBT is led and implemented by external parties, (usually a NGO or in some cases government), and the community are not fully included in some of the critical decision-making and planning stages. Therefore, the community does not fully participate and have control of their project and subsequently relies 
on the external parties; which potentially impacts on the effectiveness of one of the key factors to CBT success in the long run (Ellis, 2011; Ellis \& Sheridan, 2014; Buccus et al., 2008; Manyara \& Jones, 2007). This inhibits the community from sustainable growth and condenses its capacity to reap the benefits effectively. Without proper community control the projects are likely to fail once such supports are phased out or no longer available (Manyara \& Jones, 2007; Shunnaq, et al., 2008; Ellis, 2011).

CBT is certainly associated with number of management and implementation challenges which can be somewhat limiting on its development and sustainable growth. Heated debates about such issues have been found comprehensively in the body of CBT literature (Vignati \& Laumans, 2010; Scheyvens, 2007; Mitchell \& Hall, 2005). Mohamad \& Hamzah (2013) suggest that many of these challenges are originated from the limited community capacity in dealing with sound commercial development approaches which is very critical for economic sustainability. Furthermore, Nyaupane et al., (2006), indicate that financial constraint is another critical challenge that most rural communities encounter. Thus, they do not have sufficient budget to invest in costly infrastructure, capacity building, marketing and product development necessary for CBT. The commercial aspect of CBT seems to be overlooked even though it is a critical element for sustainable tourism development. As a consequence, in the context of cultural and heritage based tourism, research on CBT receives minor attention among scholars. Middleton (1994) confirms that many of these sites are challenged by a lack of capacity to manage them effectively, especially in terms of marketing management. While the people responsible may be trained and knowledgeable about their particular resource, they typically lack expertise in the management skills required to deal with modern international tourism. Indeed, marketing issues are largely overlooked in the heritage and cultural tourism literature (Pearce \& Tan, 2004). Freeman (2000) argues that in order to attain cultural goals and community outcomes, business practices should be prioritized. Since distribution channels are an important element in business operation, according to this argument, it is critical for CBT success. 


\subsection{Tourism demand: A key push factor in CBT}

An extensive literature review suggests that demand related studies in specific context of CBT are largely overlooked. This is probably due to the fact that the origin of such a concept is superficially associated with the commercial aspect, and although the demand side is regarded as important for CBT success in the latter stages, it is not put at the forefront of the projects. However, there are some studies investigating demand characteristics in the context of sustainable tourism and ecotourism and these certainly have implications for CBT.

A successful tourism community can also be determined by the volume of consumption Rocharungsat (2008). Therefore, according to Ellis (2011), tourism satisfaction is an integral part of tourism planning. In order to ensure long lasting tourism development, Fyall et al., (2003) and Gilmore \& Simmons (2007) suggest that there should be a concerted effort to invest in maintaining tourism satisfaction and tourism demand. Yet, in the form of responsible tourism such as CBT, tourist satisfaction alone is not sufficient to address this issue. Hence, there should be broader concentration on other components namely socio-cultural, environmental, political and economic. The symbiotic relationship among these dimensions brings daunting challenges to the vulnerable community.

Tourists can bring considerable adverse impact to the host community in the form of cultural and social acculturation which ultimately diminishes their well-being. However, they also bring more positive impacts and contribute significantly to the sustainable goals of the community through enhancing environment, social and cultural knowledge. CBT can be an effective tool to promote appropriate travel behaviour, for example, a well-designed CBT initiative can take on an important educational role, that is to educate tourists to ensure they are well-behaved and susceptible to pro-conservation (Fyall, et al., 2003; Scheyvens \& Momsen, 2008).

Ethical tourism consumption behaviour is on the rise and, optimistically, this suggests that the responsible tourism market is also more appealing. Yet, according to Tepelus (2008), there is no systematic and inclusive understanding on what being responsible means to tourists, hence

some private sectors take advantages from being so-call responsible operators. Therefore, there is much concern on how tourist satisfaction and subsequently tourist demand to visit the 
host community can be maintained in the long run, which ultimately will have implications for the CBT sustainability.

According to Goodwin and Santilli (2009), in order to ensure that CBT can accomplish its overarching goals, concerted efforts should be invested in its business sustainability. However, there is common criticism that a CBT venture is associated with the issue of supply-led and this then ignores the demand side considerably. Although the business dimension seems critical for the communities, operationally, their product design is not innovative and there is no or very limited input from private sectors. Therefore, in many cases, there is limited or no consistency between the demand and supply sides. Goodwin and Santilli (2009) argue that CBT largely overlook the fact that its business success is primarily based on the ability to meet the needs of tourist demands, on a competitive and on-going basis. As a consequence, there is a high tendency for a CBT venture to fail if they do not have capacity to generate sufficient financial return. A survey conducted with 200 CBT initiatives across the Americas by Rainforest Alliance / Conservational International suggested that the occupancy rate of accommodation was as low as 5\% (Mitchell \& Muckosy, 2008). Such a low demand volume suggests that communities are not able to generate sufficient financial return and consequently the likelihood to fail is more prevalent.

\subsection{CBT in the context of developing countries}

The concept and practice of CBT was originally implemented in developed countries. However, this concept has become more popular in developing countries, from where the majority of the literature has emerged in recent times (Vajirakachorn \& Nepal, 2011). Developing CBT is to create tourism services and products based upon the resources available in the community for the visitors. The community should have full control at all stages of the CBT development and also the decisions which may affect them, therefore, they should have the opportunity to take full advantage from the development, while maintaining the drawbacks at the lowest possible level (Ellis, 2011).

As mentioned earlier, the notion of CBT was first identified by Murphy in 1985; however the topic received very little attention until the extensive debates on sustainable tourism in the 1990s. Since the drawbacks of mass tourism and also poorly-planned tourism projects have 
become more prevalent, engaging local stakeholders from the grass root level is becoming a norm in most regions. This is happening especially in developing countries because such a strategic solution is key in keeping pace with an emerging development trend, while alleviating negative impacts on socio-cultural, environmental and economic spheres (Murphy, 1985; Richards \& Hall, 2000).

In developing countries, CBT is regarded as an alternative form of tourism that helps to minimize the negative impacts from mass tourism (López-Guzmán et al., 2011). Such initiatives offer opportunities for alternative development solutions. According to Goodwin (2008), CBT helps to combat poverty, especially in rural communities. The challenges of sustainable CBT development for developing countries lies in the fact that the benefits gained from the initiative need to be shared widely amongst its members while ensuring business sustainability (Ellis, 2011). In order to combat these challenges, Gossling (2003) and Rogerson (2007), recommend that community capacity building should be prioritized while maintaining a transparent and accountable benefit sharing mechanism.

Traditionally, tourism was developed through a top-down approach (Timothy, 1999). This suggests that only the government is responsible for the overall development project. Nevertheless, an emerging trend shows this to be the other way around. A focus on a bottomup approach is becoming more prevalent in tourism development planning. Local people, especially those who are affected by the tourism projects, play an important part in the planning and decision- making processes. Murphy indicates that "tourism development is a local issue because that is the level where the action takes place” (1985, p. 172).

Comparing this to other industries, Vajirakachorn (2011) indicates that investing in CBT is very economical and more plausible because selling points are readily available resources that belong to the whole community, such as, local culture and heritage, beautiful beaches and the wilderness, and local people as service providers. A number of CBT initiatives have been largely focused on other dimensions, such as, environment, conservation, culture and social, while significantly overlooking the importance of economic return. Therefore, according to recent studies, numerous researchers call for more systematic and applicable business strategies which are appropriate for the community to safeguard long-term financial return 
(Mitchell and Hall, 2005; Hamzah and Khalifah, 2009; Baromey et al., 2011). It is suggested that the community should be more proactive in terms of profit-making and embrace whatever appropriate strategies there are available, such as, distribution channels.

\subsection{Distribution channels - A definition}

Conceptualizing a term distribution channel is important as it provides clear and consistent understanding for readers and the author throughout the research process. According to Pearce and Schott (2005), distribution channels did not receive any serious research attention until the 1990s. Since then, a number of researchers have defined this term in either similar or relatively dissimilar ways. This is primarily due to the fact that the authors view it from different angles (supply-side versus demand-side). The other contributing factors could be technological changes (ICT) and time period (evolution of the concept itself).

According to Middleton (1994), a distribution channel is any organised and serviced system paid for out of marketing budgets and created or utilized to provide convenient points of sale and/or access to consumers, away from the location of production and consumption. This definition does not encompass every aspect of the distribution channel. It does not say anything about the channel members involved in the distribution channel, and it focuses mainly on the traditional distribution system from the supply side (Buhalis, 2001). It largely overlooks the role of the intermediaries, which is very important to bridge the gap between producers and end-customer users. More importantly, promotional and marketing research functions are ignored and it underestimates information provision functions, and local distribution channels, such as, destination-based inbound travel agents (Buhalis, 2001). Furthermore, the definition does not consider the emerging role of ICT, especially for micro, small and medium enterprises in distributing their products and services. Additionally, this definition suggests that production and consumption are in different locations, but this is not always necessarily true.

McIntosh (1985) defines distribution channels as operating structures, systems or linkages of various combinations of travel organizations, through which a producer of travel products describes and confirms travel arrangement to the buyers. Although, in this case the 
information provision function is emphasised, Stuart et al. (2005) criticises this definition in that it trivializes the promotional function of distribution systems.

A broader definition was coined by UNWTO (1975), "A distribution channel can be described as a given combination of intermediaries who cooperate in the sale of a product. A distribution system can be and in most instances is composed of more than one distribution channel, each of which operates parallel to and in competition with other channels". This definition embraces the complexity and depth of the distribution system and also recognises the importance of intermediaries, and the main purpose of the channel which is to sell the product. Although this definition has made a significant contribution in recent advances in distribution channel literature, it does not take into account the technological evolution, especially ICT that has had a major impact on current distribution structures. Despite its few critics, this study uses the UNWTO's definition as its basis, as well as acknowledging and including the role played by ICT.

\subsection{Distribution functions and channels structures}

Alcazar Martinez (2002:17) as quoted in Stuart et al. (2005), suggests that the main objectives of a distribution channel is "... to make the product available to the consumer in the quantity needed at the right time, place, state and possession utility to the consumer, thereby facilitating sales”. Similarly, Pearce (2010) indicates that the distribution channel is important as it helps to gain competitive advantage, especially in a very competitive business environment; it acknowledges the emergence markets and how to tap into them, and the effects of technology in the overall distribution system. In addition, he suggests the major function of the distribution channel is to marry demand and supply, to bring together markets and destinations, and to build strong linkages between suppliers, consumers and intermediaries. In a study on distribution channels for cultural tourism, Pearce (2005) highlights the importance of distribution channels which can help to facilitate; information from the demand to the supply sides and via versa, bundling and packing that can reduce unnecessary and costly transactions, and bring time, place and state of possession utility to the tourists. 
Figure 6 below depicts common characteristics of cultural and heritage based tourism distribution channels. Adapted from a New Zealand case by Pearce and Tan (2004), the current study makes use of this structure as a guiding framework. They suggest that this structure shows how suppliers reach different markets simultaneously. These markets include local, international, group and interdependent. In addition, this distribution mix also shows two-way relationships among suppliers, intermediaries and the consumers in terms of information provision, bundling and packaging, and booking and purchasing.

\section{Figure 6: Distribution channels for cultural and heritage attractions in New Zealand}

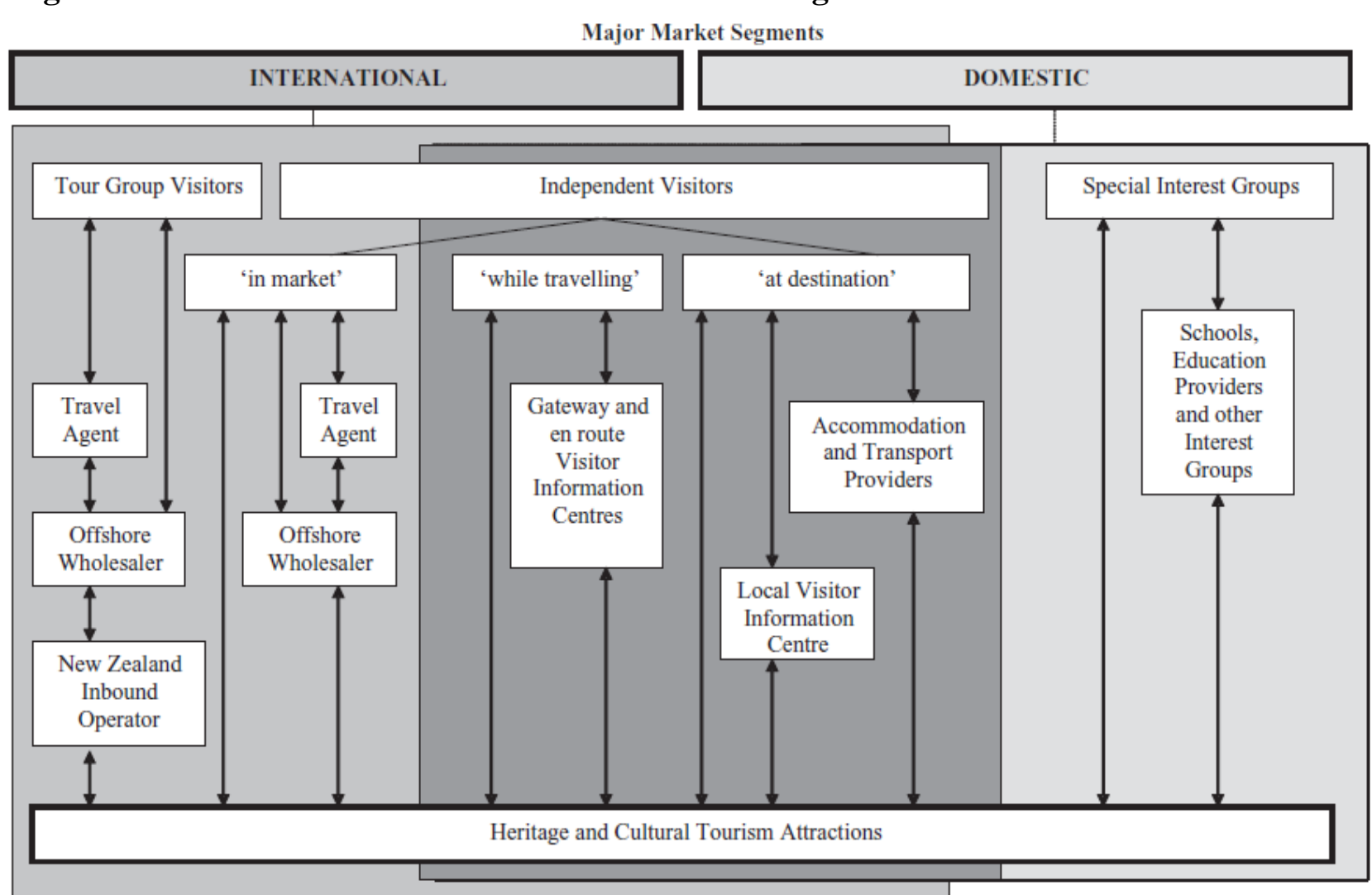

Source: Pearce and Tan (2004)

Song (2012) explains that the distribution channel structure shows how products or services are organized and delivered to the market through various distribution functions. It connects demand and supply - that is tourists and products. As shown in the figure 6 above, Peace and Tan (2004) indicate that distribution channel structures are divided into two categories - direct (zero-level) and indirect (one or more intermediaries such as retailers, wholesalers, inbound 
and outbound operators). A direct distribution channel, as its name infers, is a point of sale where the suppliers deal directly with the consumers or travellers without intervention or facilitation from any intermediary. The proliferation of information communication and technology (ICT) has accelerated the growth of direct channels (Song, 2012). Some suppliers tend to focus more on direct channels because they believe that they can perform better by their own, in terms of cost saving, prompt responses and greater consumer satisfaction. Yet, according to Mkumbo (2010), it is not always the most cost effective for suppliers.

Indirect distribution channels refer to a point of sale where one or more intermediaries are involved in facilitating the sale process. The intermediaries' involvement is critical in market access, information provision, bundling and packaging, and finally booking and payment. Yet, in many cases, introducing intermediaries into the distribution systems can be an issue as the price of the same products or services ultimately goes up, especially when a commission and/or mark-up is applied, and this then decreases the suppliers' profit margin (Song, 2012). Therefore, it is largely dependent on the suppliers' attitude towards different channels, the incurred costs, and the needs of the target markets when deciding whether to choose direct or indirect distribution channels (Stuart et al., 2005; Pearce \& Tan, 2004). Volume versus yield is another critical determinant factor in distribution channels choices (Mkumbo, 2010).

Because both direct and indirect distribution channels have their own advantages and disadvantages, there is no recommended ideal choice. It is dependent on many contributing factors as well as product types and contexts. For example, certain channels may be effective for CBT or adventure markets and ineffective for the luxury market. Operationally, in most cases, tourism businesses use all available channels in the hope of increasing their sales. Likewise, Song (2012) concluded that tourism suppliers tend to use a distribution mix too which included both direct and indirect distribution channels.

\subsection{Factors influencing the structure of distribution channels}

Cooper and Lewis (2001) note that the patterns of consumer behaviour are changing over time and consequently this affects the way in which they consume products. Following this, Stuart (2004), suggests that the greater awareness in environmental issues and enthusiastic attitudes toward cultural diversity have encouraged more visitors to explore off the beaten track 
destinations. In order to take best advantage from these inexorable trends while remaining competitive, tourism suppliers need to be adept and act quickly to find the best possible ways to bring the products to the market, whether directly or indirectly. This suggests that these continuous changes impact on the way in which consumers react to the market and simultaneously how suppliers respond to the demands. This two-way-relationship has critical implications for distribution channels, especially in a niche market such as CBT.

A study on distribution channels for cultural and heritage tourism by Pearce and Tan (2004) indicates that there are three major factors determining suppliers' distribution channel choices. They are - breath of product appeal, capacity issues and commission related issues. The first refers to the appeal of the products to the channel members and the consumers; that is product popularity determines whether it is widely included in the itineraries or tour packages. The second refers to the capacity of the suppliers in dealing with the market. The last factor is associated with indirect distribution channels where financial interests come into play within the systems. Commission and/or mark-up are relatively common in indirect distribution channels and it plays a critical role in determining the preference of channel usage.

To some extent, Smith (2007) suggests similar factors. These factors are target market, capacity and partnership relationships. The characteristics of the target market can influence distribution channel preference, for example, domestic and international visitors are likely to use different channels. Similarly, certain channels tend to be popular for backpackers while the same channel would receive little interest from luxury consumers.

In a study on adventure tourism from a distribution channel perspective, Scott (2007) indicated a number of factors influencing travel choices. These factors are impulse products, flexibility (the reluctance of adventure tourists to have a fixed travel schedule), and the expense that personalize the nature of some of high-end adventure products.

The proliferation of ICT has influenced tourism distribution channels in many ways. Tourism suppliers can reach customers globally through certain market channels, such as, the website and other forms of social media. Yin (2012) indicates that technology can play role as intermediaries and, therefore, it affects the way in which consumers and suppliers work. The 
on-going increase in technology has greatly influenced the way in which consumers receive and find the information from a destination and this subsequently influences their travel choices. Murphy and Tan (2003) point out that the internet offers consumers more information access, increased expectations for specialized trips and competition. Following these trends, ICT transforms traditional distribution strategies to digital distribution strategies making the whole process easier for both suppliers and consumers. In addition, young dynamic visitors who are well-educated tend to buy their holiday packages online (Song, 2012).

Stuart (2004) also suggests that there is a tendency towards visiting off the beaten track destinations. This is mainly due to a continual surge in awareness of environmental issues and the recognition of cultural diversity (Cooper \& Lewis, 2001). Another important point noted by Stuart (2004) is a shift in population movement. People tend to move to warmer climates, from rural to urban, and from city to suburb and via versa. These on-going changes have implications for points of sale and subsequently affect tourism distribution channels. In addition to this, Buhalis (2001) explains another influencing factor which determines whether a consumer chooses a particular destination; the existing distribution systems that influence various stages in holiday planning - while in tourism generating regions, en route or at the destination.

\subsection{Members in distribution channels}

As stated earlier, the use of the term distribution in the tourism industry means the organizations and the arrangements which together help the visitor access and consume the products. It includes all channel members involved in the process and how the members relate to each other. Channel members in tourism are grouped mainly into three types - suppliers, intermediaries and consumers. There are also sub classifications within the groups, based mainly on their different functions and geographical locations. The three groups - suppliers, intermediaries and consumers are discussed in turn.

\subsubsection{Supplier/Community}

Of the whole tourism distribution system, suppliers are one of the most important channel members because the point of sale initially starts from them. They basically develop the products and packages and then sell either directly to consumers or indirectly through one or 
more intermediaries. In some cases they bundle individual components such as transportation, accommodation, and food and beverage into a package ready for consumers. In the context of developing countries, micro, small and medium enterprises (MSME) dominate other large corporations in the tourism industry.

In the context of this study, supplier refers to rural CBT's which offer tourism products and services based primarily on the available cultural and heritage resources. As already mentioned in the previous chapter, the community offers a number of products and services which include home-stay, temple and village tours, local transportation, food and beverage, and many other tourism related activities. The community offers inclusive packages which include most elements necessary for the visit and, in many cases; it provides tailor-made packages based on consumers' needs and wants. In addition to this, the community also works with ground travel operators (GTOs) in designing packages for group visitors.

\subsubsection{Intermediaries}

Intermediaries play a very important role in bringing and/or bundling products for the consumers, intermediaries only exist in indirect distribution channels. They are the bridge linking consumers and suppliers and in some cases they connect with one or more other intermediaries, especially in multi-level distribution channels. They are mainly involved in facilitating the sale. In addition to their main business, some intermediaries sell products on behalf of suppliers for financial incentives in the forms of price mark-up or commission.

From a suppliers' perspective, Middleton et al. (2009), contend that selecting the right intermediaries is critical for marketing channels for a number of reasons. Firstly, intermediaries, on behalf of suppliers, are able to make effective communication with end-user clients and therefore increasing the access of products or services and sale volume, especially for the products that are off the beaten track. Secondly, intermediaries have an important function in facilitating the purchase of products in advance of their production. This is vital for tourism businesses and destinations in order to have a concrete marketing plan. Thirdly, by having connection to a great deal of customers, intermediaries have capacity to sell left-over

products on a last-minute basis by offering special deals or discount. Fourthly, the right intermediaries provide a range of marketing and customer services for the suppliers, such as, 
advertising, sales promotion and marketing research. Similarly, Pearce (2007) points out that intermediaries are essential in that they (1) provide information necessary for decision-making and establishing sales, (2) sort the suppliers' products and services for customers, (3) bundle and package the products and services by gathering all facilities necessary into packages and arrange the travel, and finally (4) book and purchase the tourism products and services.

From a customers' point of view, intermediaries make it easier for consumers by bundling products available in the form and at the time and place they require. In addition to this, they offer reassurance to far-in-advance-booking clients (Middleton et al., 2009). In a similar vein, Christopher (1992) explains that intermediaries bridge five gaps; time, space, quantity, variety, and communication of information all together. Therefore, intermediaries are very helpful for customers, especially those who buy package holidays indirectly.

However, the flip side of having intermediaries is that the suppliers need to tailor their own needs to the customer's demands (Coughlan et al., 2008). In doing so, they have to discount for volume business or pay commission which will ultimately affect their total revenue. Another common challenge lies in the choice as to whether a business wants to have a regular flow of supply with minimal benefits or have a more intermittent lucrative business deal based upon its own direct channels.

Multi-levels in a distribution channel, means two or more intermediaries are needed, therefore the cost of products are higher, made worse if there is an insufficiency of management capacity within the distribution system. As a result, the complexity issues in intermediaries, to some extent, may dwarf the competitiveness of the products or services themselves. In some circumstances, intermediaries do not provide added value to the overall tourism distribution systems. For example, in a study on tourism distribution in peripheral areas in New Zealand, Stuart (2004) suggests that destination-based intermediaries have limited significance in the overall context of tourism distribution systems. However, in the case of adventure tourism in Queenstown, Schott (2007) indicates that local agents play a very important role in facilitating sales.

By underlining the importance of intermediaries in the distribution system, Wanhill (1993) coins that the principal role of intermediaries is to bring buyers and sellers together, either to 
create markets where they previously did not exist or to make existing markets work more efficiently and thereby to expand market size. In this regard, the intermediaries connect the suppliers and customers together and therefore facilitate business.

\subsubsection{Consumers}

Song (2012) advises that in order to develop tourism distribution channels effectively, it is necessary to understand consumers clearly. The consumer characteristics basically include purchasing behaviour and power and demand volume. In general, they are very diverse in terms of their place of origin, tastes, interests and purposes, cultural, social, and economic backgrounds. These distinctive characteristics influence the way in which they purchase products. For example, Song (2012) suggests that young and dynamic visitors who are welleducated tend to buy their holiday packages directly through high-tech applications whereas older counterparts are likely to buy their holiday package through traditional intermediaries, such as, tour operators or travel agencies. Because consumers are the ultimate goal for the

suppliers and most intermediaries, they try to offer services and products that fit to the consumers' needs and wants by providing all means of access and trip arrangements.

\subsection{Distribution channels for Community-Based Tourism}

Mitchell and Ashley (2009) argue that commercial distribution channels are critical for CBT in developing countries. Yet, as pointed out in the introduction chapter, Moscardo and Pearce (2003) indicate that study in this area has received minimal attention so far, and a review of the literature confirms this is still relevant.

Although there are limited studies on this topic, a few of related pieces has been found in nonacademic settings. These articles suggest that key CBT stakeholders find distribution channels, (though termed differently), for CBT crucial at the implementation level. In a non-academic CBT market information sheet, Centre for the Promotion of Imports from developing countries (CBI, 2007) CBT trade channels are shown, (see figure 7 of page 33), in order to explain the connections among CBT suppliers, intermediaries and travellers. This figure illustrates visitor flow, the relationships in the channels, and also the roles of information provision, such as, travel guide books and internet or website in facilitating the travel process. CBI underscores the significance of the internet or the website in linking demand and supply. 
However, it also notes that the internet or the website is not the only means for information provision or booking because tour operators can also come into play.

Similar to the distribution structure developed by Pearce and Tan (2004), figure 7 shows both direct and indirect channels. However, there are number of differences between these two structures. Firstly, the indirect channels of the CBI structure appear to be lengthy, especially for group tour visitors. Next, in comparison to the CBI's structure, Peace and Tan's structure has more detailed information regarding the intermediaries and the connections between them and additionally, there are also clear bi-directional relationships among each channel member. Finally, in most cases, CBI seems to assume that the flow is only from the suppliers to the intermediaries and subsequently to the consumers.

Figure 7: Trade structure of Community-Based Tourism

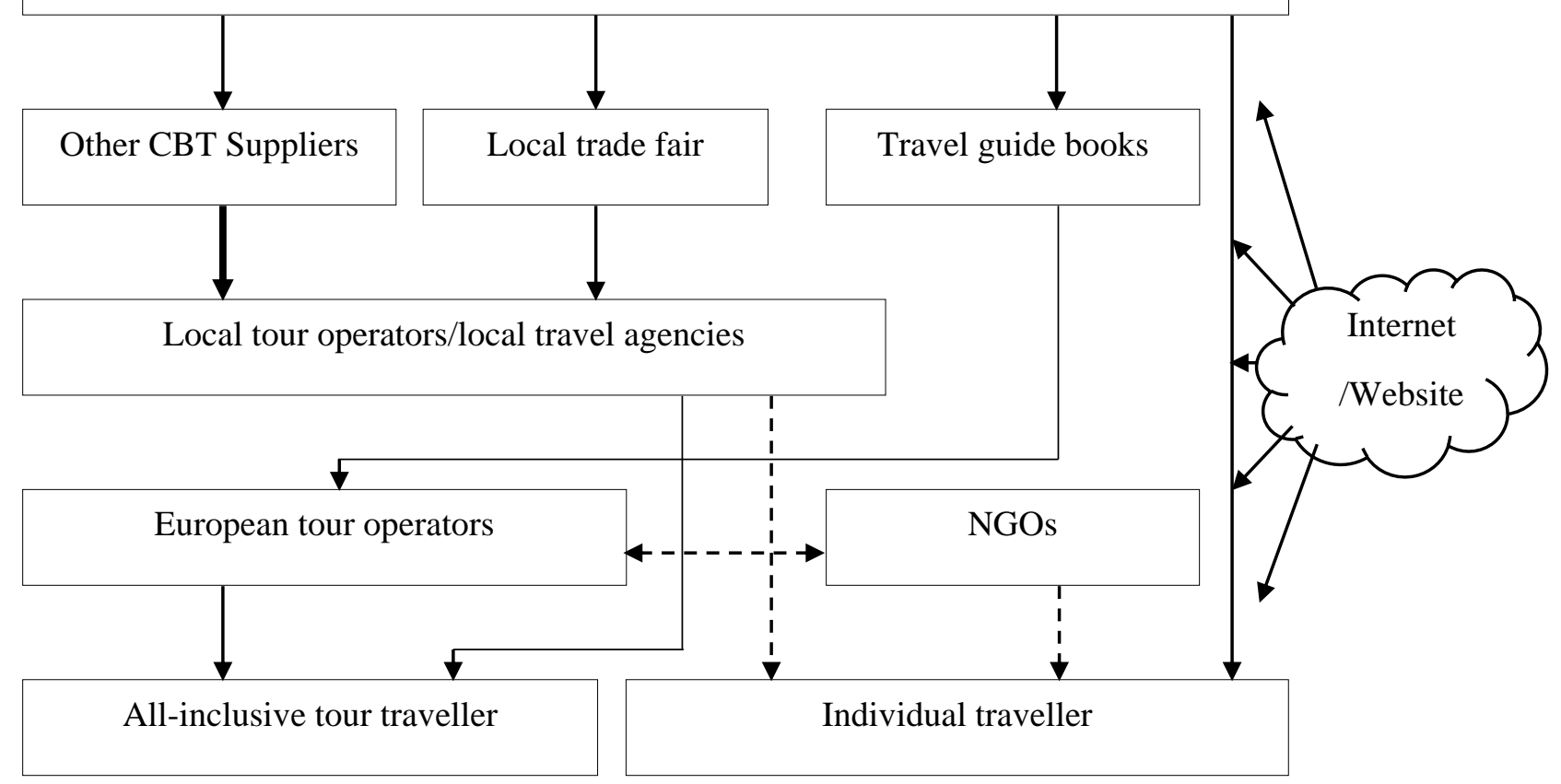

Source: CBI (2007)

Another related piece of work has been developed in a Cambodian context by CCBEN and SNV (2009). The CBT supply chain, as shown in Figure 8 (page 34), depicts common visitor flow from the markets to the destination community. The market is separated into two groups - independent travellers (FITs) and group packages (GITs). 
It is indicated that transportation plays a consistently important role in connecting the international market to the local market and subsequently to the community. FITs tend to follow a more straightforward channel, while GITs tend to follow lengthier processes through inbound tour operators, accommodation providers, and subsequently through surface transportation before reaching the community. It is important to note that, CBT network, internet and guidebooks play important roles in facilitation of the distribution processes, especially in international and national markets.

Overall, because it is a supply chain, it does not show the complexity issues associated with the whole distribution system. It does not show detailed information about the direct and indirect channels, two-way relationship among channels members and some other key aspects of distribution channels, such as, the role of other intermediaries, packaging and bundling, and finally booking and payment.

\section{Figure 8: CBT supply chain in Cambodia}

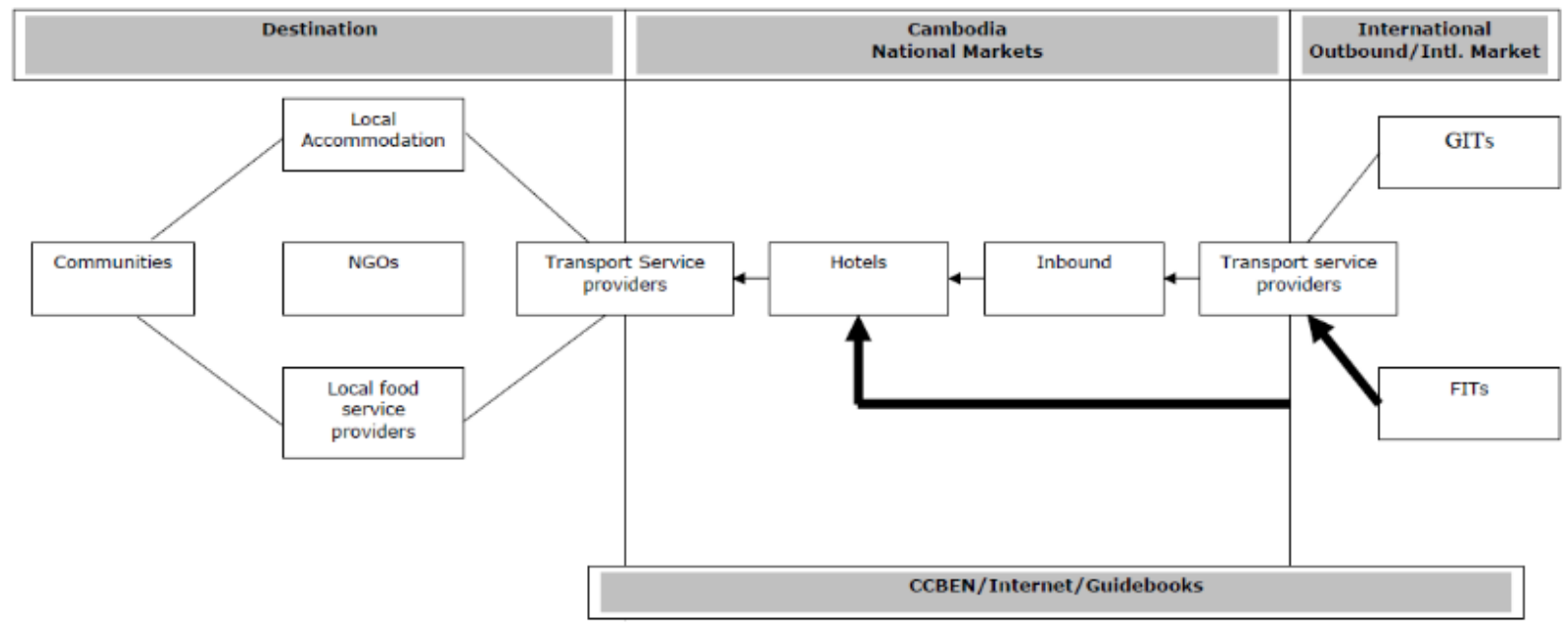

Source: CCBEN \& SNV (2009)

This chapter deals with two divergent literature reviews, CBT and distribution channels. The former provides key concepts and a guide through critical issues, including advantages and disadvantages of CBT, tourism demand, and the issues associated with CBT in the context of developing countries. The latter discusses in detail about the important aspects of distribution channels, such as, the key concepts, functions and structures, factors influencing distribution channels, channel members, and finally distribution channels for CBT. 


\section{Chapter 3: Research Methodology}

\subsection{Introduction}

The current study focuses on exploring the structure of distribution channels for Banteay Chhmar CBT from both the demand and supply side perspectives, identifying the factors that affect the distributional structure, and then bringing to light the implications that can be derived from the above two research objectives. The case study method is deemed appropriate for the study according to Yin (2014) as the method allows the researcher to examine the complexity of the issue in the current context. Case study method involves both quantitative and qualitative investigations. For this study, qualitative investigation is employed to gather information from the community and the intermediaries by using semi-structured interviews and quantitative investigation is used to collect information from the demand side by using a self-completion visitor surveys.

This chapter begins with a discussion on the methodology appropriate for the current study. This is followed by two sections explaining the data collection tools and the data analysis techniques for both qualitative and quantitative methods. Next is a discussion on the analytical framework to help structure the analysis of the data and to communicate the findings clearly. The last four sections of the chapter focus on research positionality and voice, validity and reliability, ethical consideration, and strengths and limitations.

\subsection{Research paradigm}

This study takes a pragmatic worldview from a researchers' position. According to Creswell (2014), such a worldview focuses greatly on research problem(s) being examined rather than the methodology (ies) being employed. Pragmatism as a worldview arises out of actions, situations and consequences (Creswell, 2014). This suggests that a focus on a particular case is deemed appropriate. Due to the fact that the paradigm does not hold to a single system of philosophy or reality, mixed method can be an ideal choice for collecting and analysing data for the pre-determined research problem(s) (Creswell, 2014; Tashakkori \& Teddie, 2010).

Patton (2002) also suggests that the pragmatism approach helps researchers to understand the respondents' worldview. Based on the above, the complexity of this study's research problem 
can be addressed through; (1) interviewing key channels members which include suppliers (CC members), intermediaries (travel agencies and tour operators) and other key developmental partners (government agencies, non-governmental organization, and experts in CBT) and (2) conducting an on-site visitor survey.

\subsection{Case study method}

A case study method is employed to empirically examine the research question. According to Neuman (2014);

"It is defined as intensive investigations on one or small set of cases, focusing on many details within each case and the context. In short, it examines both details of each case's internal features as well as the surrounding situation”.

According to Yin (2014), such a method is considered appropriate because it addresses either the contextual conditions or the phenomenon of the study being examined. Case studies have been used to tackle research problems in many different ways (Stake, 2005). Multiple data collection tools are typical (Jennings, 2010; Stake, 2005; Yin, 2014; and Neuman, 2014). Thus, this allows the author to adapt multiple data collection procedures according to the availability of different types of evidence, either quantitatively or qualitatively. Similarly, Yin (2014) suggests that this kind of method can be supported by many investigation techniques to ensure sound data collection and improve the researcher's understanding on the particular issues.

Though there are some drawbacks, such as, demand of resources and the lack of in-depth or thick descriptions, there are number of advantages associated with the case study method. According to Jennings (2010), these conclude - collection of in-depth empirical materials, evidence is grounded in a social setting, and triangulation of data being collected and methods being employed. Additionally, Neuman (2014) also notes that case study can elaborate on an entire situation or process holistically and permit the incorporation of multiple perspectives or viewpoints. Case study gives researchers and readers an insightful perspective through which to form appropriate research methods and how to apply it in empirical study (Creswell, 2007). 
Case study also helps researchers to earn a lot of experiences through the process from data collection to data interpretation (Stake, 2005).

Stake (2005) categorized case study into three major types; intrinsic case study, instrumental case study, and collective case study. The first type involves that the researcher has a strong personal interest in the particular case. The researcher is passionate to discover the issue and intends to have an in-depth understanding of it. The second type of case study refers to the study of a particular case in-depth in order to give insight into a particular issue or to refine a theory (Stake, 2005). The last, a collective case study, is an extended instrumental case study where multiple cases are examined in order to learn more about the phenomenon, population or general condition.

Creswell (2007) advises that the researcher should select an appropriate type of case study which provides useful information for the research. The type of case study selected will illustrate the appropriate form of information needed to address the research questions or issues being examined. Based on its characteristics, instrumental case study is used in this current research because it allows the researcher to insightfully investigate the particular phenomenon or issue in-depth. The researcher focuses on distribution channels for a particular CBT site, Banteay Chhmar. This investigation involves both the demand and supply sides, and is more intensified given that the topic of distribution channels of rural heritage and cultural based CBT is under researched; case study is a good method to use to gain a richer and deeper understanding of the research problem.

Incorporating both qualitative and quantitative methods to explore distribution channels for CBT is critical for understanding the holistic distributional channel issues. From the qualitative side, the literature suggests that a semi-structured interview is commonly appropriate to gather information from supply and intermediary sides (Buhalis, 2000; Schott, 2007; Pearce, 2008; Pearce \& Tan, 2004; and Yamamoto \& Gill, 2002). In this case, the interview was employed to gather information from the community (as the supplier). The contents of the interview mainly focused on general information about the community operation, background information, products and services and marketing activities. Direct and indirect distribution of their products, partnership issues with intermediaries and other key 
channels members, as well as factors that may influence their sales were also examined in detail.

In addition to the community, intermediaries, and other key stakeholders, such as, travel agencies and tour operators, the NGO, relevant government authorities and key experts were also approached to interview about similar issues. Inclusion of the NGO, relevant government authorities, and key experts could not be ignored as it allowed for a richer and greater depth of information gathering, relevant in the context of CBT. Involvement of all the above mentioned key participants meant that the complexity issues of distribution practices for CBT could be constructed and developed.

Few studies have investigated distribution channels from the demand side (Pearce \& Schott 2005; Smith 2007; Pearce, Reid and Schott, 2009; Pearce and Schott, 2011). Therefore, this study has been extended to cover the demand side in order to build a comprehensive structure of distribution channels. To enable collection of information from the demand side, a quantitative technique is deemed appropriate.

\subsection{Data collection tools (supply side)}

\subsubsection{Semi-structured in-depth interview}

The qualitative side of this study is employed to understand the views from the key channel members, especially suppliers and intermediaries. Regarding tourism distribution channel studies, many prominent authors suggested that semi-structured in-depth interviews are appropriate to collect the information from the supply side (Bhhalis, 2000; Schott, 2007; Pearce \& Tan, 2004; Pearce, 2005; and Yamamoto \& Gill, 2002).

In his study on the relationship between hotels and tour operators, Buhalis (2000, p.119), noted that;

"Semi-structured in-depth personal interviews were used in order to collect sufficient data. Personal interviews were regarded as the only data collection method which could provide the response rate and the wealth of information required in order to support qualitative analysis, the approach also established an 
element of trust between interviewees and the researcher and enabled them to offer truthful and accurate answers."

Furthermore, Finn, et al. (2000) indicated that a semi-structured in-depth interview is critical in the way that it enables the researcher to make comparisons among key questions and provides the opportunity to seek clarification and elaboration on the responses obtained from research participants. In addition to the interviews, the author also used observation techniques and research field notes.

The interviews were structured around a list of developed questions which focused on the nature of their operation, target markets, marketing strategies and marketing plan, the distribution channels being used, factors influencing these, relationships and partnerships among channels members, and the overall market trend.

\subsubsection{Respondent selection}

Miles and Huberman (1994) (as cited in Punch, 2014) suggests that "you cannot study everyone everywhere doing everything. " It is true of course that for a qualitative study a whole population cannot all be interviewed. Qualitative research would rarely use probability sampling. In contrast, purposive sampling is more common (Punch, 2014). According to Patton (2002), there is no specific method to guide a rigorous sample selection process in qualitative research. He goes further to suggest that the sample size may vary according to the purpose of inquiry, what researchers want to explore, what can be done with the available time and resources, and the application of theory that could make sense of the data. In case study research, Punch (2014) suggests that sampling is required even within a case study because the researcher cannot study everything. Such sampling involves identifying the cases and setting the boundaries, which then indicate the aspects to be studied and construct a sampling frame.

The art of designing qualitative research lies in identifying a number of individuals, who are true representatives of the population being studied, and then contacting and interviewing them to reveal detailed insights. Based on the nature of the qualitative investigation, respondent selection is very critical for the current study. Only those who are fully capable and qualified about the issue being examined are invited to take part in the interviews and 
discussions, as they are able to provide the insightful information and relevant content useful for the analysis and interpretation. A number of authors argue that non-probability sampling techniques are useful to identify the relevant focus of the study rather than the representation of the population (Warren \& Karner, 2005; Newman, 2003).Therefore, both snowball and purposive sampling techniques are employed to define potential respondents for the study.

The participants for this study are selected and recruited based on their level of engagement in CBT operations. Their characteristics are described in more detail below:

- Supplier (community): Three out of thirteen CC members were invited to participate in the interviews. They are among the most active committee members. They know many of the finer details about the CBT contemporary issues. Thus, they are able to provide more useful background information about, marketing and promotion activities being implemented, partnership issues among key channel members, current CBT distribution channels, factors influencing CBT distribution channels, and some other issues associated with community capacity. The committee members selected are capable of providing this vital and insightful information for the study being undertaken.

- Intermediaries: For indirect distribution channels, intermediaries are necessary. For CBT, intermediaries such as travel agencies and tour operators, and in some cases a NGO, play important roles in the distribution channels because they are actively participating in the selling and distribution of products and services to the visitors. Their fundamental role can be seen as connecting suppliers to the market and via versa. As critical partners to CBT, intermediaries contribute to a greater sales volume through providing market support and other facilities to the CBT. They also help organize and bundle the packages based on visitors' needs and wants.

According to the 2014 Banteay Chhmar community annual report (CBT annual report, 2014), there are 37 private tour companies and non-governmental organizations working with the CBT and sending visitors to the community. Among these, only 15 companies were approached and invited for the interview. The recruitment procedure was predominantly established based on three selection criteria; (1) the consultation meeting with CC members and an NGO representative, (2) the level of community- 
company engagement through the feedback meetings and frequency of business communication, and (3) frequency of trips the intermediary makes and number of visitors they bring to the community. Eleven representatives from the companies agreed to participate in the interviews. Eight of these interviews were conducted in their office or in a café in Phnom Penh or Siem Reap. Three interviews were conducted via Skype because these companies are based overseas. The individual research participants from the selected companies were recruited based on their qualification and capacity to be capable of providing rich and insightful information for the study. Therefore, research participants are managers or owners of the selected companies.

- NGOs: In almost all cases, non-governmental organizations are strong supporters to CBT, especially in the context of developing countries. They are either partners or donors who constantly provide both technical and financial supports to the initiatives. In the case of the Banteay Chhmar CBT, Global Heritage Fund (GHF) is an important donor and developmental partner. Thus, a representative from GHF was included in this study. This was mainly due to the fact that this key person is a long-standing supporter and advisor to the community. He has been involved in advising, guiding and facilitating the community for years. Therefore, he is highly qualified and capable of providing more detailed and insightful information for the issues being examined.

- Tourism authorities: Government plays an important role in policy design and guidance for the tourism industry. This institution oversees the rules and regulations and ensures the industry is functioning well. In addition, the government allocates a reasonably sized budget for marketing and promotion nationwide. In principle, for CBT, tourism authorities provide a number of supports which include financial and technical assistance as well as other interventions for the initiatives. In developing countries such as Cambodia or elsewhere such support is still minimal. However, their opinion regarding distribution channels for CBT is still essential in order to develop a comprehensive structure of the distribution channels, to understand the effects of distribution and the key general trends in the CBT market. Subsequently, a representative from the provincial department of tourism and a representative from the Ministry of Tourism are included in the study. 
- Key informants: Experts in CBT are also included, as they can provide in-depth information about the issues being studied. This group is highly capable of providing resourceful data which is important to cross check with the data from the other research participants. As the author of this study was working for CBT projects over the past few years, the key respondents were already identified. Thus, they are recruited primarily based on purposive sampling technique.

Table 5: Characteristics of the interview participants

\begin{tabular}{llll}
\hline Respondents & $\begin{array}{l}\text { Number of } \\
\text { participants }\end{array}$ & $\begin{array}{l}\text { Location of the } \\
\text { interviews }\end{array}$ & $\begin{array}{l}\text { Duration of the } \\
\text { interview }\end{array}$ \\
\hline CC members & 3 & Community & Approx. 1 hour \\
NGO & 1 & Community & 1.20 hours \\
Key informants & 3 & PP & $1-1.5$ hours \\
Tourism Authorities & 3 & PP, BMC, SR & 45 minutes -1 hour \\
GTOs & 11 & SR, PP & Approx. 1 hour \\
\hline
\end{tabular}

Note: PP: Phnom Penh, BMC: Banteay Meanchey Province, SR: Siem Reap Province; Due to the characteristics of two of the GTOs (not for profit), they will be labelled as NGOs in the next chapters.

As indicated in the table 5 above, the interviews ranged from 45 minutes to one and a half hours. This depended on the complexity and variety of their business and the information they were prepared to offer.

The interviews were conducted in three locations - the community, Siem Reap province and Phnom Penh. Most of the respondents' offices are in Phnom Penh or in Siem Reap. In many cases, the interviews were conducted in a café or restaurant while others in the respondents' office. In order to accommodate the tight business schedule of a number of the respondents and their current locations (a few respondents are based overseas), these interviews were conducted through Skype. During the interviews notes were taken and also digitally recorded. The data was then transcribed in order to capture the full contents of the material and identify 
themes for the analysis. Most interviews were conducted in Khmer and in few cases as the respondents are expatriates these interviews were arranged in English.

\subsection{Data collection tools (demand Side)}

\subsubsection{Visitor survey (self-completion)}

Self-completion visitor surveys are deemed appropriate for the current study. Such a tool is not demanding in terms of administration, Jennings (2010) identified that self-completion visitor surveys were also good from the respondents perspective as they can complete the questionnaire at a convenient time and at their own pace. However, a number of issues should be taken into consideration. These include - a low response rate, inability to seek clarification, and partial completion resulting from the language used in the questionnaire (Jennings, 2010).

The questionnaire (see appendix 7) was developed around an introductory set of questions relating to the trip characteristics of the respondents, followed by the main body of questions relating to their choices, in terms of, transportation to the community, how they find out about the community, and booking and payment behavior. The next part of questionnaire constitutes a set of profile questions. The range of questions also seeks to understand factors that influence their choice, especially organization of the trip. The final section of the survey was a set of open-ended questions to explore further the reasons of their choices. The construction of the survey is primarily developed in order to draw the structure of distribution channels from the visitors' perspective.

The questionnaire was designed to be completed within ten minutes. The questions were a combination of both multiple choice and open-ended questions. With assistance from the CCs, a total of 64 questionnaires were collected during the study period and subsequently enter into SPSS for data analysis.

\subsubsection{Sample selection}

Consumers are a very important part of the distribution channel. Yet, studies with a particular focus on visitors' perceptions have received minimal attention among scholars (Pearce \& Schott, 2005; Smith \& Garnham, 2006). Thus, in order to understand the comprehensive 
distribution channels for CBT, this study also seeks to explore their perceptions by employing on-site visitor surveys.

Although sophisticated sampling techniques have been a critical issue when undertaking quantitative study, Punch (2014), points out that this is not the case in present times. He goes further to suggest that this changing trend can be influenced by number of factors which include proliferation of qualitative investigations, a growing focus on smaller sample size for quantitative study, and the increasing practical challenges in accessing larger and perfectly defined sample size as suggested by sophisticated sampling technique. Very often the researcher must take whatever sample is available and the incidence of convenience samples is increasing (Punch, 2014).

Based on the content of the investigation, only visitors taking a trip to the community are qualified and able to provide useful information for the research. Given the fact that the total annual visitors to the community is still marginal, [1,288 in 2014 with appropriately $20 \%$ annual increase expectation (community annual report (2014)], and the study period covered the off-peak season, there were potential practical challenges, therefore the risk of generating insufficient data to support the study.

\subsection{Data analysis methods}

\subsubsection{Qualitative data analysis}

The interview is the main data collection technique. Most interviews were conducted in Khmer. All digitally recorded interviews were transcribed and translated into English sentence by sentence in order to maintain the nuance of the interviews.

Taking a pragmatism approach, perspectives from channel members is explored. In the process of data analysis, the author used the thematic technique to group ideas and subsequently developed these ideas into common themes for thematic analysis. According to Matthews and Ross (2010), thematic analysis is a process of working with raw data to identify and interpret key ideas or themes. Codes were developed to represent the themes which are identified and applied to the raw data as a summary marker for later analysis (Guest et al., 2012). The information from the interviewees is clustered against the objectives - the structure 
of distribution channels, the factors affecting distribution channel, and consequently the implications for distribution channels for CBT.

The scripts were read numerous times, and by doing so, various responses to the same questions from the respondents could be compared and contrasted. The emerging themes were developed by the repetitive responses from various informants. The identified themes are helpful to provide structure for the analysis chapter that follows. Each theme is drawn out to support the explanations of the distribution systems. This is considered important as distribution channels are complicated, particularly in tourism.

\subsubsection{Quantitative data analysis}

As mentioned above, data from visitor surveys is important to provide a comprehensive understanding in a distribution channel study. In line with previous studies in the field, Statistical Package of Social Science (SPSS) is typically used for data analysis. The survey questionnaires were divided into two parts: open-ended and close-ended questions. SPSS is used to conduct a simple frequency analysis, while summation is employed to analyse the open-ended questions. The results of the analysis will be presented in the form of tables. These findings are useful to support the study and triangulation is necessary to cross check with the responses from the interviewees.

\subsection{Analytical framework}

Analytical frame is very useful for both the author and the reader. As suggested by Pearce (2012), analytical framework helps to structure the analysis of the data and to communicate the findings clearly. He also notes that without a clear analytical framework, the analysing tasks can be daunting and more complicated than it should be, and the communication of the findings becomes rather problematic and consequently discussions turn unnecessarily lengthy. It is even more beneficial when dealing with a larger and a sophisticated body of data because it can be utilized to organize the structure of the analysis, and guide the way in which the data can be analysed and presented (Pearce, 2012).

For the current study, table 6 serves as the analytical framework. This framework is beneficial in many aspects. Firstly, it guides the author through the process of the data analysis by clustering the various groups of information from both the demand and supply sides. 
Secondly, this framework indicates sequences of the data analysis and interpretation, and finally it helps to inform the overall structure of the study by working towards the predetermined research objectives.

Table 6: Analytical framework

\begin{tabular}{|l|l|l|}
\hline Research Objectives & $\begin{array}{l}\text { Supply side } \\
\text { (community, GTOs, } \\
\text { Government and experts) }\end{array}$ & $\begin{array}{l}\text { Demand side } \\
\text { (visitors) }\end{array}$ \\
\hline 1. Distribution channels structure & $-\ldots$ & $-\ldots$ \\
& $-\ldots$ & $\ldots$ \\
\hline 2. Factors influencing DCCBT* & $-\ldots$ & $\ldots$ \\
& $-\ldots$ & $\ldots$ \\
\hline 3. Implications & $-\ldots$ & \\
& $-\ldots$ & \\
\hline
\end{tabular}

In order to develop a comprehensive structure of distribution channels (objective 1), the first part of the framework shows that data from interviews and survey will be analysed together. In this case, the responses from both sides are used to develop and confirm the structure of the distribution channels. The second part of the framework shows the way in which multiple responses regarding the factors that influence the distribution channels for CBT can be developed (objective 2). The framework also shows that the last objective (objective 3) can be done through synthesizing the two earlier objectives.

\subsection{Researcher positionality and voice}

For qualitative inquiry, the researcher needs to be explicit about their stance and interest in doing the study as this is a very important because, to a certain level, interpretation of the study can be influenced by the researcher's gender, personal background, culture, experience, socio-economic status, and education (Creswell. 2014). The researcher's identity helps the audience to understand how and why such a study is designed and interpreted in a particular way. 
Since qualitative investigation constitutes an important part of this study, as mentioned above, it is vital to address the author's positionality and voice. The researcher grew up in the nearby town to where the study location is situated. After graduation with a tourism degree several years ago, the author worked for a USAID funded project. This project supported many CBT initiatives in terms of technical and business linkages and Banteay Chhmar was one of them. Based on this involvement, the author has a comprehensive understanding of the case being examined. During that time, personal and professional relationships were developed with key community stakeholders, especially the CCs and the NGOs. Therefore, trust has been developed, and subsequently the interviews were like a conversation with the respondents being more accepting to open and honest discussion. However, it should be emphasised that the author is no longer working with the community and there is no commercial interest involved in the study. Also, ethical guidelines were followed at all time during the whole research process.

\subsection{Research validity and reliability}

Validity is a contentious topic for qualitative investigation. The level of validity is based on the perceived accuracy of the research findings; that is from the author, the research participants, as well as the audiences (Creswell 2007). Triangulation is one of the most commonly used strategies for ensure validity (Creswell, 2014). When information is collected from multiple sources, the triangulation method is helpful for the author to make comparisons and confirm the result. This study uses existing data, interview, observation and survey. Thus, triangulation is necessary to ensure the quality of the research.

The consistency of qualitative data is also very important. This requires a thorough examination on the raw data collected before starting the analysis. In the current study, the author constantly checked the raw data, especially the interview scripts and the research notes from the fieldwork. Where requested through the consent form, a final transcription was sent to the respondent for review before verbatim quotes are used.

As highlighted in the interview section above, (3.6.1 Qualitative Data Analysis), most of the interviews were conducted in Khmer. Therefore, in order to ensure the accuracy of the raw data in the translation to English, assistance was sought from a tourism expert proficient in 
translating Khmer to English, to spot check and verify the data before processing the analysis. This is mainly done in order to ensure that verbatim quotes still retain the original thoughts as expressed by the interviewees. Furthermore, verbatim quotes were reworked and consulted with the interviewee before reaching the final version.

According to Patton (2002), credibility or internal validity can be viewed from the researcher's experiences and their beliefs. As previously mentioned in the positionality and voice section, the researcher is experienced in CBT and he was involved in a project working to support Banteay Chhmar. Therefore, the author is familiar with the selected site, the overall situation of the CBT, and the key stakeholders who work in the same field. This to some extent facilitated the data collection process (interviews) and may influence the way in which the data is interpreted.

\subsection{Ethical consideration}

Compliance with ethical requirements is a very important part of research. For this study, ethical approval was granted from the Human Ethic Committee of Victoria University of Wellington. To some extent, the nature of exploring distribution channels may involve certain degrees of commercially sensitive information or other associated risks for both research participants and their organizations. Therefore, following ethical requirements is necessary to protect research participants as well as the researcher.

Confidentiality is an important part of ethical consideration. According to Punch (2014), it refers to the researcher's assurance that the connection between the research participant and the given information is not revealed to a third party. For the qualitative side of the current study, the respondents are referred to by role or association with an organization rather than by name in the report, for example, a marketing manager of Company X. However, due to the fact that there are only a small number of people or companies engaged in CBT in Banteay Chhmar, there is the possibility of identification of a few of the respondents by the stakeholders themselves. Furthermore, in some cases, contextual clues may lead to identification of a respondent when a quote is used. 
For the current study, the participant consent form (appendix 3) and the information sheet (appendix 1 and 2) for both the interviews and the visitor surveys make it clear that confidentially is treated very highly. Personal information was not revealed to any other person, nor was it used in the interview transcriptions or written in the reports.

Each research participant received the information sheet and the consent form well in advance through email. Just prior to the interview each of them was given the documents again and the key message in the consent form was repeated verbally to make sure that they understand the ethical issues clearly. The author also asked for permission to record the interview and requested a signature of approval on the consent from. For the visitor surveys, the respondents offered their consent through voluntary participation in completing the questionnaire.

\subsection{Strengths and limitations}

The critical strength of this study lies in the mix methods used in order to investigate both the demand and supply sides to build a comprehensive structure of distribution channels for CBT. Rigorous literature review suggests that the current study is very much under-researched. Thus, it is hoped that this will contribute to the body of literature in CBT and distribution channel studies. The authors' experience shows that many CBT initiatives in Cambodia are highly dependent on external support, especially donors and NGOs. Furthermore, selling CBT products and services is hindered by many factors, such as, limited supporting infrastructures, community capacity, marketing and promotions, and limited community-private sector linkages. Given these issues, this study is expected to provide a strategic solution for CBT initiatives by improving the sales, resources usage and strategic partnerships with channel members.

This study employs semi-structured in-depth interviews for the supply investigation. This method is deemed appropriate and efficient to explore the issues being studied. In order to collect rich detailed information, key respondents mainly in management positions, from all relevant institutions are invited for the interviews. These include community members, NGO, government, private tour companies and experts in the field. Punch (2014) says that qualitative study is a complex, changing and contested field. Thus, the findings may be limited by the researcher's skill and experience. Yet, this is potentially outweighed by the fact that the author 
was born in a town near to the study site and he has served multiple years in CBT development projects. Therefore, he has a good understanding of the study area and the contemporary issues of CBT.

However, a number of limitations have to be acknowledged. One limitation is associated with the demand side of the investigation, that is, the small body of data from the visitor surveys, which may be a drawback. This is mainly due to the fact that the survey was conducted during low season and only visitors who were visiting the community during the study period were invited to complete the survey. Given the fact that the total visitor arrival to the community is limited (1,288 visitors in 2014), the number of visitors who were travelling to the community from August to early November was even more limited.

Some issues regarding the semi-structured in-depth interviews should also be noted. One is the turnover of the tourism business professionals. In a few cases, new managers were contacted and invited to take part in the interviews, therefore subsequently some parts of the information are not as rich as it should be. Similarly, although most of the research participants were very supportive and willing to help, a few of them had time constraints which resulted in the interviews being rushed and this may mean that some of the finer details are missing. Another noticeable limitation was the inability to adequately cover the overseas partners, a number of the private tour companies. Therefore, how they work together to channel information, conduct marketing and promotion, and reach the end-customer user (visitors) is largely overlooked. 


\section{Chapter 4: Distribution channel structures for Community-Based Tourism}

\subsection{Introduction}

Pearce (2012) advised that it is advantageous in analysis of data and research findings to use a well-developed analytical framework. This can help to break down daunting tasks into small manageable pieces making it less problematic and easier to follow. Further, it indicates the way in which findings are structured, its sequences and flow. This chapter is organized according to the analytical framework as shown in table 6 (page 46).

In order to explain the comprehensive distribution systems for CBT from both demand and supply sides, this chapter begins with a presentation on marketing channels for CBT from a community and intermediary perspective, followed by a more informative section dealing with each marketing technique in closer detail. The second section of this chapter covers CBT distribution channels from a visitor's perspective; information search, booking and payment and the reasons for doing what they do.

\subsection{Marketing channels from a community and intermediary perspective}

The fundamental functions of distribution channels are to provide information or to provide a marketing channel. This refers to the way in which suppliers, (in this case the community), and intermediaries create points of sale through communicating and providing information about their products and services to the market. In order to ensure that this information reaches their customers, the community tries to use all available marketing channels; both direct and indirect. The former refers to the direct contact between the community and the market. The basic processes are through information communication and technology (ICT), word of mouth (WOM), printed materials and meetings, incentives, conferences and events or exhibitions (MICE). The latter refers to the marketing channels that go through one or more of the intermediaries. The details of these marketing channels will be discussed in the sections that follow.

Figure 9 below depicts the structures of the marketing channels, which are guided by the conceptual framework (table 6 of page 46), where customers are located on the top of the figure and the community is located at the bottom of the figure. In the case of indirect 
marketing channels, where multiple intermediaries are involved, the layers are built up based on the responses given by the research participants, and located in between the customers and community. The figure is developed based on the level of complexity of the marketing channels ranging from the left to the right. The upward arrows indicate that the marketing channels are from the community to the market. The thickness of the arrows indicates the frequency of use of the channels - the thicker the arrows the more frequent the use.

Figure 9: Marketing channels from a community and intermediary perspective:

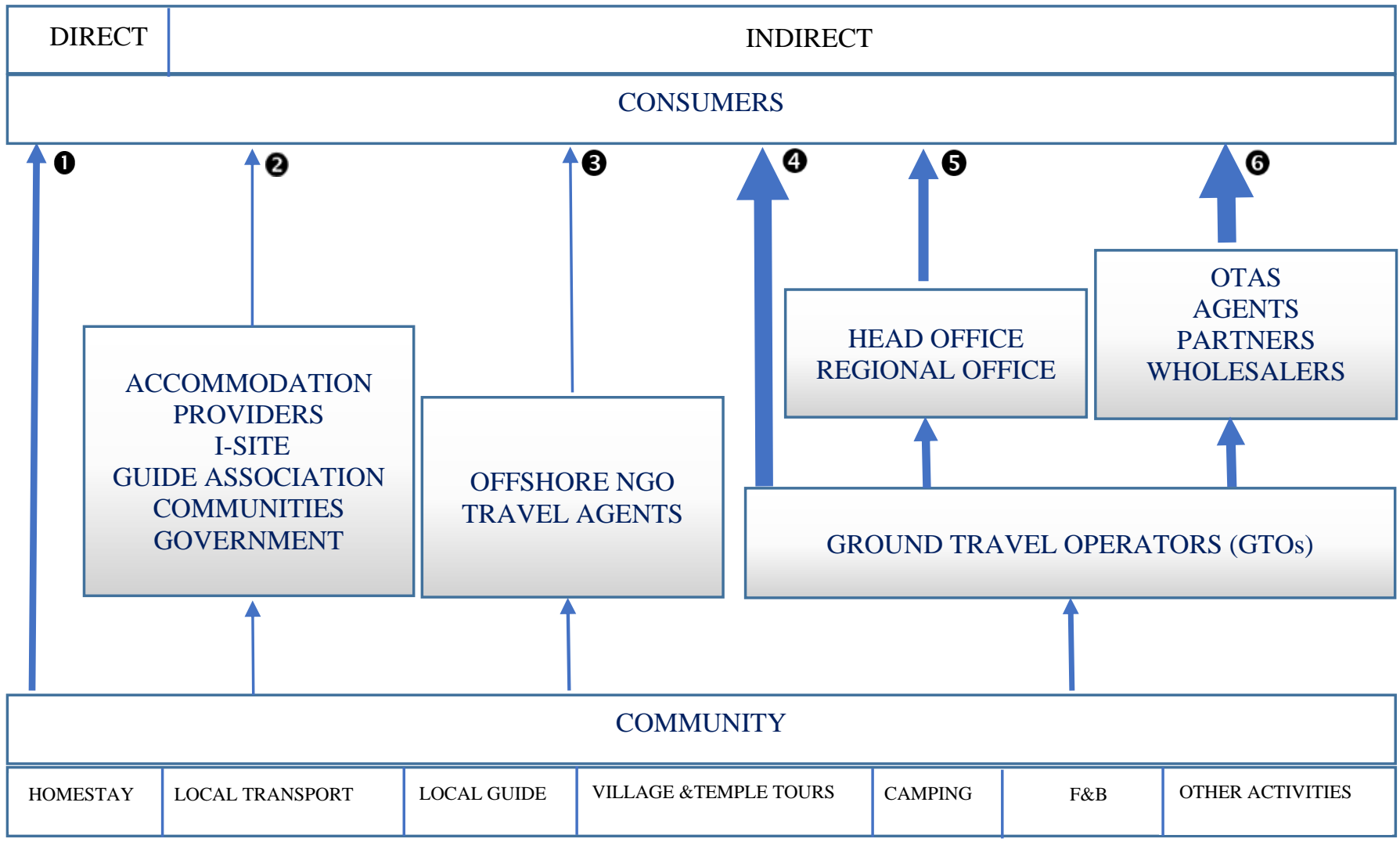

The marketing channels were developed based on the responses from suppliers and intermediaries. Fundamentally, the data accumulated from the questions "How do you reach your visitors?" and "What marketing activities are you implementing? In addition, in order to gather more in depth from the interviewees (and to capture the finer details), another question was asked "How do your customers hear about you? 
Marketing channel \#1, (indicated by the numbered arrows in the figure 9), represents the way in which the community reaches the market directly. Marketing channels \#2 to \#6 show the indirect marketing channels utilised by the community in order to reach a broader market through its business partners, both locally and offshore.

Marketing channel \#1 as described indicates that the community uses a direct marketing channel as a means to reach visitors. Typically, this is the most common information provision channel that a community or other business entities implement in order to attract and capture their clients. This direct marketing is crucial for a community as they, (the members), then have full participation in the process, which enables them to provide more detail about their products or services and allows them to respond to visitors' inquires effectively and in a timely manner. This is even more important for independent travellers who tend to be detailoriented and for travellers who arrange many aspects of their trip themselves. However, the extent to which a community invests in such activities is primarily based on available resources and their capacity. This is true more so for CBT initiatives where limited resources hinder their marketing activities. For the case of Banteay Chhmar, although respondents acknowledged the significance of direct marketing, they also raised a number of challenges which are mainly associated with capacity issues and available funding.

Marketing channels \#2 and \#3 constitute quite important parts of the indirect marketing channels being implemented by a community with key channel members both locally and offshore. Marketing channel \#2 indicates that local channel members such as accommodation providers, tourism information centres, guide association, other communities and government agencies also play a role in circulating information to the visitors. This is through word of mouth (WoM) and/or allocating a small space to display community brochures or other marketing materials. Yet, such a connection is largely based on informal relationships and a willingness to support the community. As explained by both community and NGO representatives:

“...we also advertise through local stakeholders such as ministry of tourism, provincial department of tourism that we asked to share our leaflets to visitor along the border and checkpoints, but we have not known yet how many visitors 
get our leaflets......word of mouth through visitors who used to visit Banteay Chhmar is also one of the effective marketing strategies. They are willing to share community information to their friends or relatives..." (CC. B)

"simply, we still have plan to print brochures and disseminate through nearby hotels and other tourism destinations...we will bring the materials to Phnom Penh and Siem Reap and deliver to hotels and information centres..." (Representative of $N G O A$ )

Tourist arrivals in 2014 suggested that $50 \%$ of total visitors came to the community through ground travel operators, (annual community report, 2014). This is consistent with the connected marketing channels with thicker arrows indicating that the GTOs have been active in promoting their CBT packages. In order to channel information to customers, the community has been working with the GTOs. However, due to the fact that community does not have sufficient budget, the marketing efforts are still limited.

As indicated in figure 9, the thickness of the arrows suggest that the community focuses more on direct marketing rather than indirect marketing through the GTOs. Interestingly, marketing channel \#4 (a far thicker arrow) shows that the GTOs are more active in marketing and promotion of their own packages which also include community products. This inconsistency explains the common practice in CBT, where the community does not recognize the significance of indirect marketing efforts through their business partners. In the case of Banteay Chhmar, although the community realizes that the GTOs are important marketing partners, it appears the community pays little attention on this marketing channel. A CC noted that:

"we had business meetings to present and update information about our products and services with 10 companies last year... and we have planned to meet with 20 new tour companies who are interested in working with us...we have planned to corporate with Tour Companies that provide tent services too. Now, we are working with company [I] ..." (CC B) 
In practice, the roles of the travel agency and the tour operator are somehow overlapping and it is quite challenging to depict the distinctive characteristics of these two, especially in an environment that is very competitive and struggling for survival. For this study, the terms tour operator and travel agency are used interchangeably and commonly referred to as ground travel operators (GTOs). However, it is important to note that while some of them are locally based and, in most cases, operate directly to the end-user customers, many others operate more sophisticatedly by channeling through head or regional offices or involve multiple partners or agents in wide geographical areas. Based on figure 9, marketing channel \#4 suggests that GTOs use direct marketing channels to reach their customers. In the case of marketing channel \#6, information is circulated through their offshore agents, partners, OTAs and/or other wholesalers. In some cases, (marketing channel \#5), where local GTOs are part of a global travel chain, marketing channels flow from them to their head or regional office, the main center for marketing and promotion. In this case, local GTOs are only responsible for collecting and updating information and the final marketing tasks are largely the responsibility of their head or regional office, offshore partners or agents. 


\subsubsection{Marketing channels in detail}

Figure 10: Marketing channels in details (community and intermediary perspective)

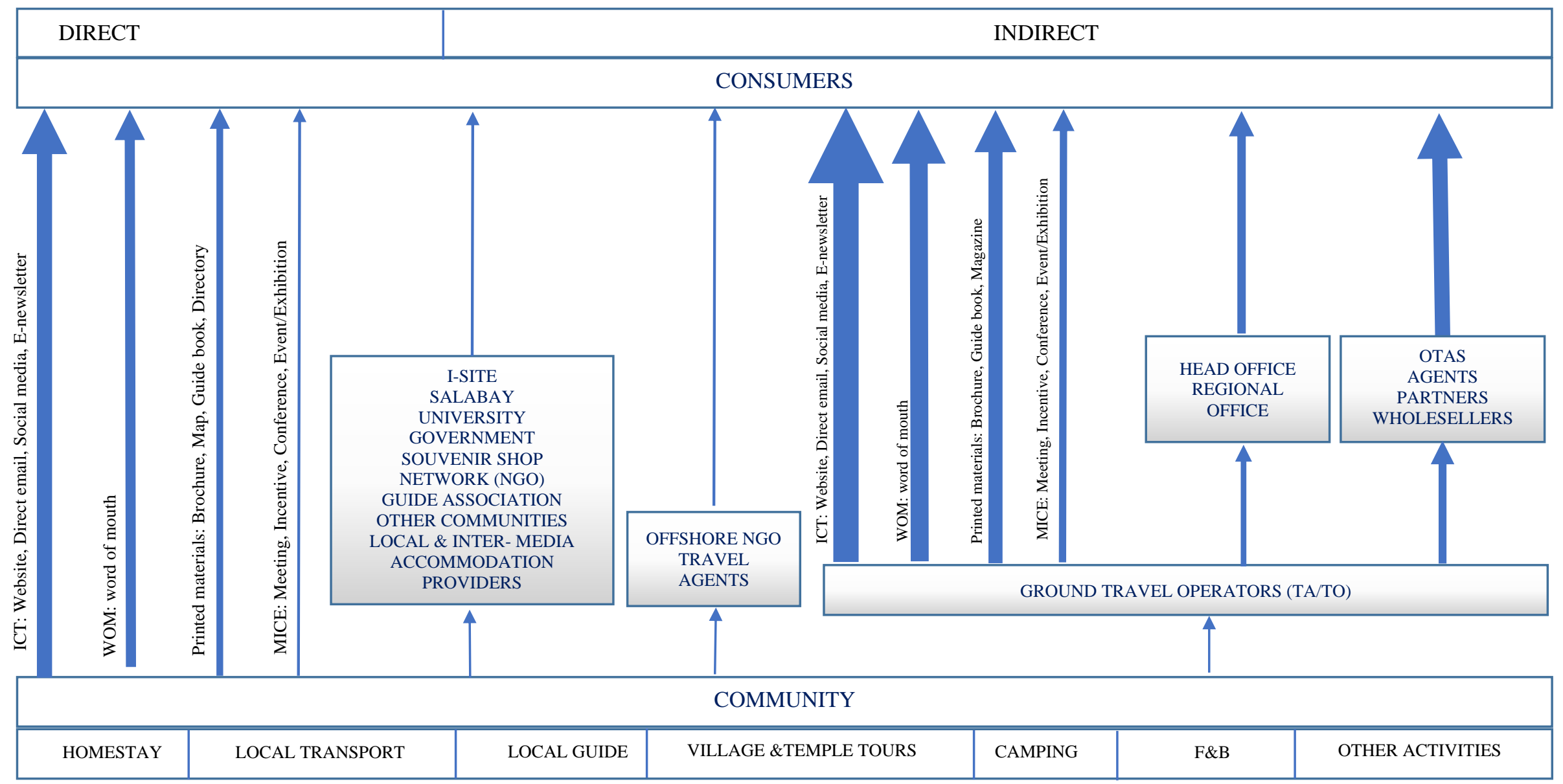


This section covers in closer detail the marketing activities being implemented by the community and the GTOs. Figure 10 shows, that both the community and the GTOs use similar marketing techniques to promote their CBT products and packages. They use many promotional techniques to reach their customers, some of which are very traditional. However, the noticeable difference lies in the fact that the community's marketing channels are far less aggressive than those implemented by GTOs. As mentioned earlier, this is mainly due to the fact that the community does not have the same level of resources the GTOs have access to, especially budget and knowledge necessary for marketing implementation.

Figure 10 (page 56) illustrates that information communication and technology (ICT), which includes website, direct email marketing, e-newsletter and social media, (such as Facebook and Blogger), is the most frequently used channel. Both the community and the GTOs reported that ICT plays a crucial role in facilitating detailed information about the products to the market. In addition, it is very cost-effective, less labour-intensive and can reach larger numbers of visitors in a timely manner. As one NGO representative mentioned:

“...Our main promotion is done through website and direct email...it is very important to share information to visitors. There are many people who check community website today...social media (Facebook) is also very popular....when we have something new or updated information, we need to send to our partners that we have in our email group..." (Representative of NGO A)

Word-of-mouth (WoM) or electronic word-of-mouth (eWoM) is also an important marketing technique which can bring many advantages for the community and the GTOs. This zero-cost tool is very effective in the way that information can be circulated among friends and relatives. The sources of information are considered very trustworthy and the messages are usually very convincing to potential visitors. However, it can be a possible drawback if the consumer is not satisfied with the services or products. Respondents noted that:

“...Word of mouth through visitors who used to visit Banteay Chhmar is also one of the effective marketing strategies... Visitors who used to visit us help to share information to their friends, relatives and other people...” (CC B) 
"...Some tourists are recommended by their friends about the good experience about community... Some of the groups know our office through their friends...” (Marketing manager of company $\mathrm{H}$ )

Printed materials which comprise of brochures, maps, guide books and magazines are the third most used direct marketing tool. Both the community and the GTOs commonly use these traditional marketing materials. However, due to issues of available resources, especially financial capital, marketing efforts become problematic for the community, with year-round marketing diminishing and "off and on" ad hoc marketing becoming more common. This makes it challenging to see how effective it is in terms of reaching potential visitors directly.

Although printed materials are a traditional means for many GTOs to reach their clients, a few suggested that it is a waste of time and money to print them; this is possibly because of the pre-developed channels they are practicing. In many respects, most of these operators rely on their overseas agents and partners in terms of marketing and promotion efforts.

"I think that they [printed materials] are as not important as website since technologies enable them [visitors] to reach information very fast. It is not important to print brochures or booklets as they [community] have to pay more money on it. It could waste a lot of money. For some customers, they just want to know about Banteay Chhmar on website. Some of them bring the brochure, do not read but throw it away..." (General Manager of company A)

The least used marketing channel is MICE (meeting, incentive, conference, event and exhibition). Occasionally the community attend or are invited to attend a workshop, conference or exhibition where they can display their information and advertise their products to the participants. They also attend network meetings with other communities, NGOs and local travel agents which are helpful for them to have the opportunity to promote the community and network; at times partnerships with GTOs are built during these meetings. As a representative of the government mentions:

“... We help potential CBTs to promote their products through attending events such as local and international conferences, workshop and exhibition..." (Government representative C) 
It is common for travel operators to practice a variety of marketing strategies to attract their overseas partners or visitors in order to sell their CBT packages. Among them, some are keen to invest in exhibitions and events. They believe that attending overseas tourism and travel exhibitions allows them to search for potential long-standing travel partners who can bring mutual benefit to their businesses. As sale manager of company B mentions:

“...We promote our services through exhibition.... when we first attended in exhibition, no one was interested in our services. But we never gave up. We have tried more than five times. Finally, we can attract some partners who are currently working with us... Every year, our owner join exhibition in order to promote our company. In addition, we also attend exhibitions in France, Thailand and other ASEAN countries. We get new market from exhibition... Exhibition is our main activity. We believe that it is good strategy..." (Sale manager of company B)

Figure 10 (page 56) also suggests consistency of indirect marketing channels being implemented by both the community and the GTOs. However, the GTOs have a far more complicated and well-designed structure. Very often, the community has informal relationships with a number of local channel members, such as, the tourism information center, the local universities, government agencies, non-governmental organizations, accommodation providers, media agencies, other communities and other associations that are involved in the tourism industry. In terms of information provision, these local channel members help to circulate information about the community products and services to the visitors, (in most cases to the end route visitors). Some of these local channel members are willing to help in other ways, such as, allocating a small space of their lobby to display printed materials from the community. However, the challenge is that most of these local channel members do not know the community in detail and many of them have never been to the community in person. Thus, although it may be important to have more people involved in such a channel, the effectiveness of the information being conveyed to the visitors is questionable. In most cases, they operate as non-profit organizations and are heavily involved in volunteer activities within the community, such as participating in farm activities, repairing the old school buildings or even teaching at the local school. For indirect marketing channels, the GTOs mostly work with their offshore agents, partners, wholesalers or other online travel agents, who constantly collaborate through their marketing efforts to reach their clients. In many cases where the GTOs are part of a global 
travel chain, franchise or shareholder with other foreign owners, the marketing channels are mostly conducted through the regional or head offices located overseas. In this case, the GTOs are mainly responsible for collecting and updating information for their head offices or partners, who then are largely responsible for marketing and promotion.

\subsection{Booking and payment from community and intermediary perspective}

This section discusses the way in which booking and payment are handled from community and intermediaries' perspectives. Figure 11 below shows that the process of booking and payment basically fall into two main types - direct and indirect. Direct booking and payment is generally straightforward and, therefore, less complicated. However, given the fact that the majority of visitors go to the community through package tours, most booking and payment is done indirectly through the GTOs (channel \#4).

\section{Figure 11: Visitors' booking and payment from community and intermediary perspective}

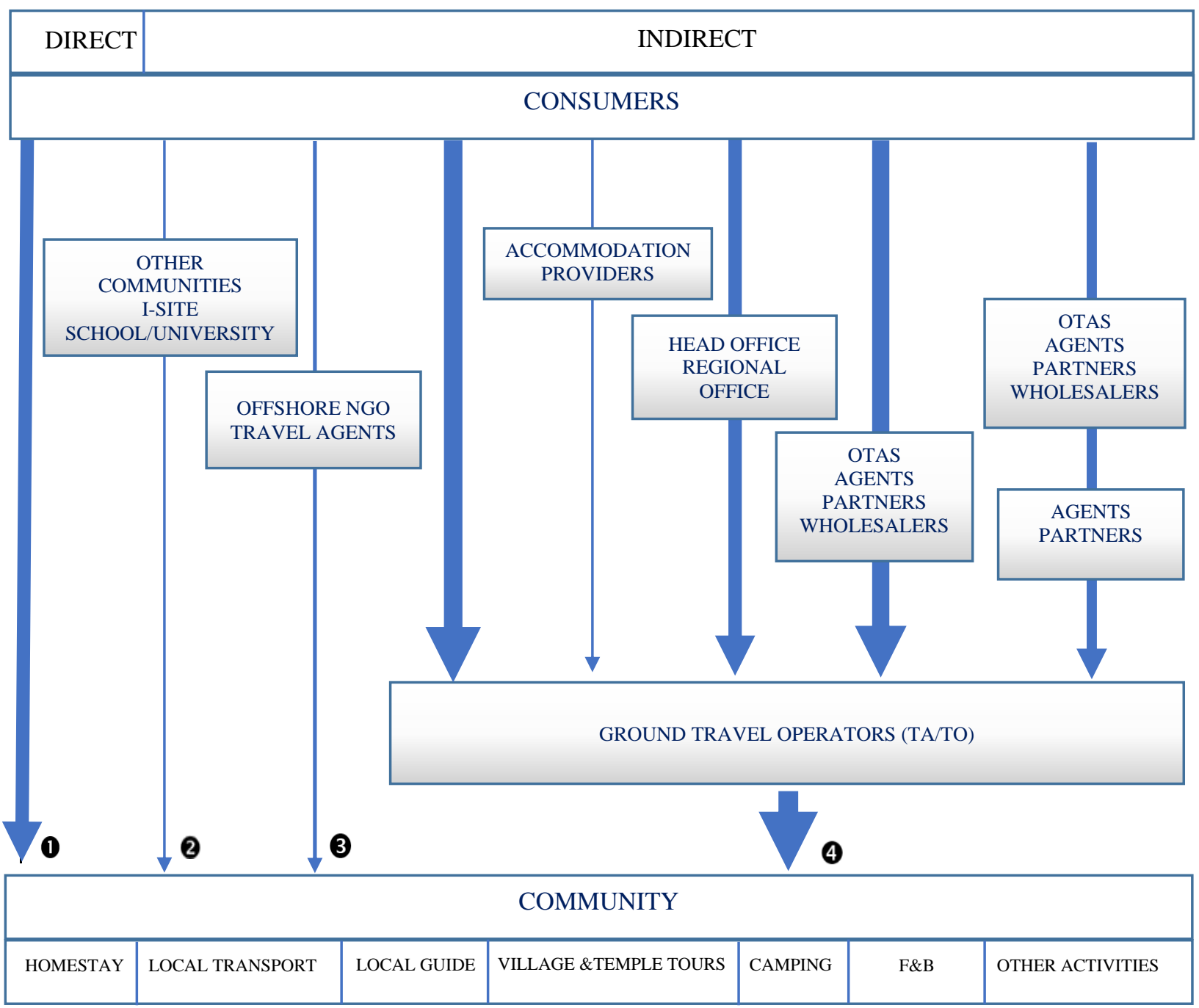




\subsubsection{Direct distribution channels to the community}

According to Figure 11, channel \#1 indicates that direct booking and payment constitute an important part of distribution channels for Banteay Chhmar CBT. The size of the arrow suggests that large numbers of visitors book and pay directly to the community. As a CC notes:

“.... Of the total visitors, approximately $30 \%$ of independent visitors come to community directly...." (CC B)

In many respects, this channel is very common for independent travellers who seek novelty and hand-on community experiences. Independent travellers are a steady-growing market in Cambodia. Many of them travel in small groups and are price conscious - meaning that they are likely to purchase budget products rather than luxurious ones.

The hub of independent travellers who come to the community are looking for backpacker accommodation in either Phnom Penh or Siem Reap. They are likely to explore off the beaten track destinations, sorting and arranging most parts of their trip based on their preferences and available budget. It seems that the community website, word of mouth and printed materials, such as, the guide book are playing a pivotal role in tailoring their attention towards the community. Most direct independent visitors arrange their trip to the community well in advance by booking through email and in a small number of cases with a phone call, while some visitors surprise the community by walking into the community directly.

"... Of the total direct visitors, around 95\% of them email to book the service, while there are only 5\% who walk in. Mostly, walk-in visitors have lonely planet book. They do not book in advance... they find community by asking people along the way." (Representative of NGO A)

\subsubsection{Indirect visitors through local channel members}

Figure 10 (page 56) suggests that there are a number of individual business entities or organizations involved in circulating and disseminating information about the community to travellers. However, based on the responses from the interviewees, channel \#2 indicates that a few travellers book and purchase their trips to the community indirectly through local channel members, such as, tourism information centers, other communities and local 
universities or schools. For example, the visitors who channel through the local universities or schools are not reflected in the tourism database, and hence its influence on the number of visits through the domestic market cannot be estimated.

\subsubsection{Domestic visitors}

Despite of the fact that many respondents stressed the importance of the domestic market, the number of domestic visitors to the community are still very limited when compared to the international market. The nature of the core products is the main pull factor that influences visitors' decision whether or not to visit the community. Banteay Chhmar is based on cultural and heritage resources and such products are not as appealing to the domestic market. Domestic visitors to the community basically include groups of students from different universities or schools within the region and other parts of the county. As shown in Figure 12 below, this distribution channel is less complicated. Although there are intermediaries involved, (universities/schools), the nature of the operation is very basic and usually there is no commission involved. Domestic markets are mostly same-day visits accessing the community by arranging most of the trip components themselves, such as, transportation and food. The main aim of these visitors is for educational purposes. Usually, there is a small group of trip organizers who arrange everything, including booking and payment to the community where services or products are purchased.

Figure 12: Distribution channels for domestic market

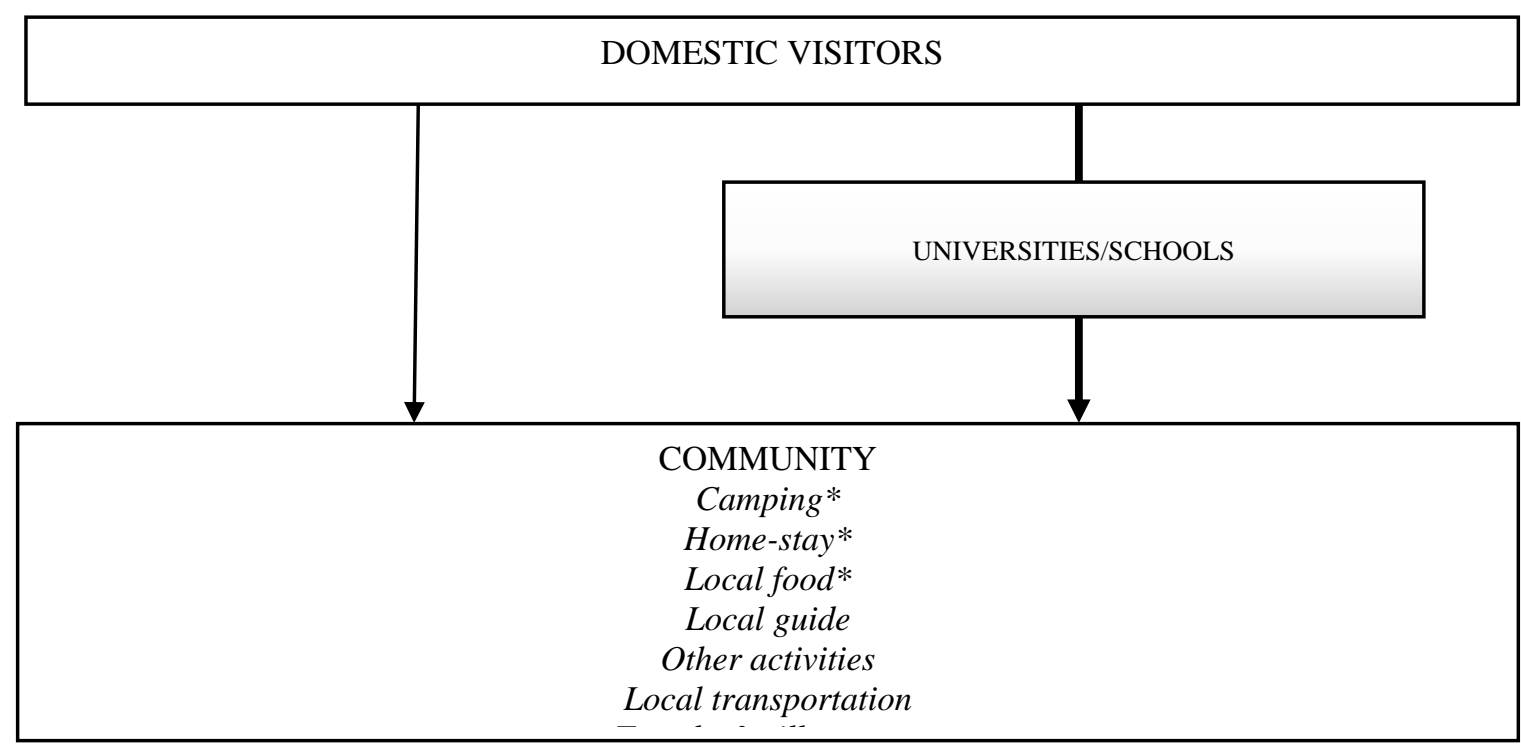

Note: * indicates less frequent use services 
In a few cases one or two Cambodian's are seen joining an organized trip with other foreign visitors. They are usually tour company staff members who get an incentive from their company and hence in this case all aspects of the trip have been organized for them.

"In few cases that you see Cambodian travellers in the group, they are our staff who award the holiday trips as an incentive from the company." (Marketing manager of company $\mathrm{H}$ )

\subsubsection{Special interest groups}

Special interest groups represent a small fragment of the total share of visitations to the community. Typically, these groups include expatriate volunteers or overseas university students who access the community through their organizations or their universities. Their primary purpose is not tourism, but community development, and/or local education. Their length of stay is relatively longer than normal visitors. In many cases, they channel through overseas organizations to local organizations who usually arrange everything during their mission. During their off-mission period, they spend time exploring the community and its surrounding areas as part of their holiday.

\subsubsection{Indirect visitors through offshore agents}

Channel \#3 depicts international visitors channel through overseas agents, often this is through, agents from non-profit organizations who are keen to engage in community activities. There are only a few members of this group, but they constitute a considerable share in the total distribution channels through which the community is operating in. This is because these offshore agents send regular groups of visitors to the community and many of them are keen to learn and contribute something back to the community through their volunteer activities.

According to the informal communication with the $\mathrm{CC}$ members during the fieldwork, a majority of visitors are keen to learn about the community way of life and participate in certain volunteer activities. Very often these groups stay in the community longer than other groups.

"Another private company also creates a volunteer program with some activities such as teaching English to community members and local children, 
repairing and maintaining treks within Banteay Chhmar temple complex. They stay for one week, 10 days or up to 1 month." (CC B)

This organized group is tailor-made based on the objectives of the coordinating agencies; they arrange every aspect of the trip starting from how they reach the trip participants. The channels being used by the groups of offshore agents are quite different from ordinary business entities. This is may be due to the fact that they are NGOs, (though a few offshore agents are profit oriented), who are working to link host and guest relationships by encouraging the education aspect of the tour. The groups are mainly composed of individual overseas university students who are keen to learn from the projects. Basically, there is an advertisement or announcement which provides detailed information about the community, date of the trip and the number of the trip participants. Interested students can register and subsequently join the trip to the community. The characteristics of their trip are quite different from others. They are very enthusiastic guests who are willing to learn everything and give back something to the community.

“... All of them [trip participants] want to travel, but they want to travel in the way that allow them to really see and understand the conditions they are visiting, so they do not want just to be a tourist to go on the tour bus and see the things that guide book want them to see but they really want to understand the culture, they really want to try, meet local people, hear the story... and they want to give back. They want to do some kinds of volunteer work as well." (Regional Manager of NGO B)

\subsubsection{Indirect visitors through ground travel operators}

This section describes the channels used by indirect visitors to Banteay Chhmar CBT through GTOs. Figure 11 (page 60) suggests that channels \#4 is very important for the community in terms of international visitors' indirect booking and payment. This infers that working hand in hand with ground travel operators is a critical factor for bringing in more international visitors to the community. Respondents inform that this channel is the most vital for the community in terms of visitor numbers to the community. The size of the arrow suggests that GTOs bring more visitors to the community than any other channel. This is very consistent to the community database which indicated that around $70 \%$ of total visitors in 2014 came through GTOs. 
Noticeably, there are four sub-channels that visitors commonly use to reach community through ground travel operators. These are - (1) indirect channel through GTOs, (2) through local channel members to GTOs and subsequently to the community, (3) through overseas head office or regional office to GTOs and subsequently to the community, and (4) through multiple overseas channels members to GTOs and subsequently to the community. The following sub-sections discuss each of these channels separately.

\subsubsection{Indirect visitors to the community through GTOs direct channels}

Like community or other business entities, GTOs use multiple channels to reach their customers both directly and indirectly. Based on figure 11 (page 60), the number of visitors to the community who go through GTOs direct channels is quite voluminous. Consistent with the direct marketing effort, many tour companies are able to sell their CBT packages directly to the visitors. For this sub-channel, the website is reported to be a vital means for connecting the demand and supply sides, and subsequently to facilitate booking and payment. It is even important for the website to sell the group series for some travel firms.

"The main market of our company is group series. We mainly sell this through website. We organize 20 packages to Banteay Chhmar every year. All packages have their own schedules. So, when visitors like a package, they can buy as individual or group. When the travel due, they have to travel with other visitors in a group as registered..." (Marketing manager of company $\mathrm{H}$ )

Although some travel firms are part of a much bigger chain, they still acknowledge the significance of the direct channel through their website because it not only supports 'survival' but also provides sustainability for the company, especially in a very competitive business environment.

"We do not only depend on major market. We have to find other ways to survive or sustain. In doing so, we start to sell through website such as travel GURU. It focuses on special group, FIT, customize client, and tailor-made... That is the reason why we have to have our own website..." (Marketing manager of company $\mathrm{H}$ )

In some cases the firms are small, locally operated and not part of a chain, and therefore do not have an overseas office or in other regions of the country. These firms usually focus 
on budget and middle class markets and channel the visitors through informal networks or through recommendations from previous visitors (WOM). Very often, these visitors prefer tailor-made products and have flexibility.

“...some of them suggest us to prepare package, so we have collaborated with our partners like hotel, Banteay Chhmar CBT...some provide us ideas while other need us to help them prepare packages..." (General Manager of company D)

\subsubsection{Indirect visitors to the community through local channel members and GTOs}

As shown in figure 10 (page 56), local channels members seem to play an active role in the information provision function of the CBT distribution channels. Yet, in terms of facilitating booking and payment, this group appears to play a minimal role. Therefore, this channel is not effective for CBT. This is perhaps owing to the fact that there is no sophisticated system that can track every aspect of the distribution channel. Furthermore, it may be because a majority of the local channel members know very little detailed information about Banteay Chhmar, and that many of them have never visited the community.

“...hotels are also our partners who introduce us to their clients. We have three-days-and-two-nights homestay package in Banteay Chhmar. If visitors are interested in the package they can contact us through them (hotels)..." (Product manager of company $\mathrm{J}$ )

\subsubsection{Indirect visitors to the community through GTOs head or regional offices}

It is common that, in the realm of an increasingly competitive environment, most travel firms are becoming part of a chain or a franchise, this is especially true for larger sized firms. They have more offices, spreading out to wider geographical locations, particularly in major tourism destinations throughout the world. In this case, marketing and distribution channels are commonly done through the interwoven connections among all of the offices. Basically, they pass down the visitors from the head or regional offices to the sub-offices where destination of choice is located. The operation needs to be very consistent and similar services and products standard is commonly expected. 
"Our marketing department in Bangkok is responsible for all the marketing activities for our companies around the world...." (Regional manager of company I)

“...visitors book the package through head office that mainly responsible for sale and marketing. Once they (head office) get the confirmation, they refer those to me in order to arrange hotel, transportation and so on..." (Reservation manager of company $G$ )

In some cases, there is a commission applied between the head office and the destination office even though they are part of the chain. This is usually based on the different strategies they implement. As product manager of company $\mathrm{H}$ suggests:

“... Actually, office in Cambodia develops the packages and then sends to other offices in Australia and subsequently they mark up the price and continue to sell. Although we are the same company, commission is till applied because we need to make our own profits in order to sustain..."

\subsubsection{Indirect visitors to the community through GTOs and offshore channel partners (multiple stages)}

Besides being part of a chain, or brother or sister companies, most travel companies also build partnerships with many other offshore travel companies too. These partnerships are very important for them to reach their end-customers and eventually sell their products. Just as the community endeavors to maintain good relationships with existing partners and tries to establish more partners, GTOs are also actively trying to make and retain business partnerships with offshore travel partners because they help enormously in terms of marketing activities and reaching visitors. Product manager of company $\mathrm{J}$ and product manager of company $\mathrm{C}$ similarly note that:

"They (offshore business partners) are very important. More than 90\% of our clients come from them. Without them, our company could not be that successful... They also do marketing for us...they have their own customer's data base and they have their own marketing strategies..." 
Understanding how partnerships develop in the marketplace and the partnership characteristics helps to gain a deeper understanding of distribution channel structures and practices. Owing to the fact that not all members involved in the channels, especially those in the tourism generating regions, are accounted for in this study, there are some parts of these channels that is less known.

The offshore travel firms include - travel partners, travel agents, online travel agents and wholesalers. Basically, they are involved in facilitating the information (marketing), booking and payment process. In terms of benefits, some of them take a commission while others mark-up the price of the packages. This channel, according to figure 11 (page 60) is important for the community because a large number of visitors are channeled through them.

Some GTOs tend to have a flexible partnership with their overseas partners. This may be due to the fact that some partners sell better volumes than others, while, some may offer more margin than others do. In most cases, whether a partnership develops well or not is dependent on sale volume - meaning that their business partnership is still vibrant if such a relationship can help boost their sales. Obviously, then the tendency is to be very selective when creating or retaining partnerships, as they naturally want partners who can help increase sales. Product manager of company J suggests that:

"...I think that it is not the real relationship because there are many companies like us in market place. They have a lot of choices, so we try to stay competitive. Sometime our offshore agents might leave to other companies or some of them may leave other companies to work with us in order to look for something better. Therefore, we need to offer something unique, competitive price and try to fulfill clients' expectation."

However, some GTOs develop rather structural business partnership with their offshore partners. To some extent, they tend to be very loyal to their business partners and basically information provision, bundling and packaging, and booking and payment are required to go through each layer of their partners before reaching their final customers. Product manager of company $\mathrm{C}$ comments: 
“...almost all bookings go through our partners...we have the policy with them...sometime, other travel agencies or hotels want to cooperate directly with us and offer competitive price, we just reject it because we are afraid that our partners would loss the commission or margin... The first thing is honesty... In the cases that other companies contact our partners, they will refer that to us too..."

Though it is undesirable, it is sometimes unavoidable to have multiple channel members who are involved in the distribution system. This is very common for CBT products due to the fact that the distance between demand and supply is substantial. Very often, each member involved in the channel marks up the price or demands a commission from each package, which eventually this makes the products costly and uncompetitive. Moreover, the profit is divided and shared among each channel member and subsequently there is little gained by the intermediaries involved.

“...we have a partner in Italy who contacts us and books through other travel agency in Vietnam. Subsequently, the agent in Vietnam transfers that to us. So, agent in Vietnam is our intermediary. We can see that, if we work with direct partner (like those in Italy), we will earn more profit than indirect partner or intermediaries (like those in Vietnam). That is the reason why most of the large travel agencies do not want indirect partner.” (Sale manager of company B)

\subsection{CBT distribution channels from the visitors' perspective}

\subsubsection{Visitors' profiles and characteristics}

This section deals with CBT distribution channels from the visitors' perspective. This is one of the fundamental aspects of a distribution channel study because incorporating the demand side is helpful in order to understand the whole picture, and as a consequence the recommendations or implications drawn are then more relevant and effective to all channel members. In this sense, the survey data plays an important role in providing explicit information from the demand side that subsequently will help to develop a holistic distribution system. For this study, the information from the visitors are essential to fill the gap and respond to the objectives being investigated. Data was collected from 64 visitors to the community during the study period. They were invited to take part in a selfcompletion questionnaire. 
Before going through critical discussions regarding CBT distribution channels from the visitors' perspective, this section begins with a brief overview of the visitors' profiles and characteristics.

Table 7: Visitors' profiles and characteristics:

\begin{tabular}{|c|c|c|}
\hline Description & Characteristics & Percentages \\
\hline \multirow{3}{*}{ Trip objectives } & Temples/Heritage & 26.60 \\
\hline & Holiday/Leisure & 46.90 \\
\hline & $\begin{array}{l}\text { Experience local culture and rural } \\
\text { lifestyle }\end{array}$ & 26.60 \\
\hline \multirow{2}{*}{ Length of stay } & One night & 89.10 \\
\hline & Two nights & 10.90 \\
\hline \multirow{2}{*}{ Trip arrangement } & Group package & 73.40 \\
\hline & Travel independently & 26.60 \\
\hline \multirow{2}{*}{ CBT information search } & Before trip to Cambodia & 49.20 \\
\hline & During visiting Cambodia & 50.80 \\
\hline \multirow{6}{*}{ Age groups } & $<20$ & 1.60 \\
\hline & $20-29$ & 19 \\
\hline & $30-30$ & 9.50 \\
\hline & $40-49$ & 9.50 \\
\hline & $50-59$ & 27 \\
\hline & $60-69$ & 33.30 \\
\hline \multirow{2}{*}{ Gender } & Female & 52.40 \\
\hline & Male & 47.6 \\
\hline \multirow{3}{*}{ Origin } & Australia & 45.30 \\
\hline & UK & 10.90 \\
\hline & Others & 43.80 \\
\hline
\end{tabular}

Table 7 reveals that almost half of the responds $(46.9 \%)$ said holiday or leisure was the most important factor that triggered their interest to visit the community. Almost a third $(26.6 \%)$ of total visitors were interested in the temples or heritage and a similar amount (26.6\%) wanted to experience local culture and rural lifestyle. The length of stay in the community was relatively short, with a majority of visitors spending just one night in the community and only $10 \%$ of the total visitors staying two nights in the community during their trip. 
Of the total visitors who responded to the questionnaire, those coming through a package tour $(73.40 \%)$ to the community far outnumbered the independent travellers $(26.60 \%)$. Concerning CBT information search, there is almost no difference in terms of when they learn about the community. Half of them search information about the community before their trip to Cambodia while the other half do their information search while they are travelling in the kingdom. The results also point out that a majority of the visitors are older; approximately $60 \%$ of them are in the 50 to 70 age group. However, $19 \%$ of the visitors were in the younger age group, between 20 and 29 , this was a reasonably significant share of the total community visits during the study. There is almost no difference in terms of gender, male and female visitors who travelled to the community are shown at $47.60 \%$ and $52.40 \%$ respectively. The table also shows that a majority of visitors are from Australia (45.30\%), followed by UK visitors (10.90\%), and the remainder from diverse geographical locations.

\subsubsection{CBT information search and its influencing factors}

Information search is one of the fundamental parts of a distribution channel. Commonly, it is the initial stage before any purchasing decision is made. As earlier suggested in this chapter, the community has been trying many ways to promote their products to the market. In the meantime, the community's partners, the GTOs are also playing a major role in this promotion. However, it is critical to investigate which of these channels is more appealing to the market. A visitor survey is a pivotal tool to work out how they hear about the community.

Table 8: CBT information search

\begin{tabular}{lll}
\hline & Description & Percentage \\
\cline { 2 - 3 } & Internet (includes trip advisor) & $\mathbf{5 0}$ \\
\cline { 2 - 3 } & Travel agent & $\mathbf{2 0 . 6 0}$ \\
\cline { 2 - 3 } Search & Word of mouth & 9.80 \\
\cline { 2 - 3 } CBT information & Lonely planet & 7.80 \\
\cline { 2 - 3 } & Guide book & 7.80 \\
\cline { 2 - 3 } & Previous experience & 2.00 \\
\cline { 2 - 3 } & Transport operator & 1.00 \\
\cline { 2 - 3 } & Brochure & 1.00
\end{tabular}




\begin{tabular}{lll}
\hline & Easy and convenience & $\mathbf{5 4 . 7 0}$ \\
\cline { 2 - 3 } Reasons for & Quality of information & 17.40 \\
information search & Trust & 15.10 \\
\cline { 2 - 3 } & Previous relationship/experience & 12.80 \\
\hline
\end{tabular}

Table 8 suggests that the internet is the most important channel visitors used to search for information about the community. Representing about a third of the total, it can be argued that the internet is very important for the community and its marketing efforts. Following the internet, at $20.60 \%$ and $15.70 \%$ respectively, information flow through the GTOs and "trip advisor" are also effective channels which voice the community's products and services to the market.

Visitors give multiple reasons why they choose certain information channels. Just over half of the visitors $(54.70 \%)$ stated that ease and convenience are the most important factors why they use those channels. A sizeable proportion of the respondents also said that the quality of information $(17.40 \%)$, trust $(15.10 \%)$ and previous a relationship or experience $(12.80 \%)$ are also important reasons associated with the choice of information channels.

\subsubsection{Booking, payment and reason}

It could be argued that booking and payment are the most critical aspects of distribution channels. To some extent, they are usually the last stage before consumption is made. It is always important for the community, as well as other business entities, to understand how booking and payment is finally made and the reasons for doing so. Table 9 indicates that most CBT product bookings $(68.30 \%)$ are made through the GTOs. This may be due to the fact that a majority of visitors purchase organized tours from the GTOs. Using the internet and email as direct communication between the community and the visitors, which subsequently leads to the direct booking, is the second most important method of booking $(15.90 \%)$. Obviously it follows that if a majority of the bookings are done through the GTOs, then so are the payments; the survey shows that almost three quarters of the total visitors who consume community products pay directly to the GTOs. However, $23 \%$ direct payment to the community also shows that this is an important payment method. 
Table 9: Booking and payment and reasons for doing so

\begin{tabular}{llll}
\hline & Description & \% of Booking & \% of Payment \\
\cline { 2 - 4 } $\begin{array}{l}\text { Methods of } \\
\text { booking and } \\
\text { payment }\end{array}$ & Travel agent & $\mathbf{6 8 . 3 0}$ & $\mathbf{7 0 . 7 0}$ \\
\cline { 2 - 4 } & Internet & $\mathbf{1 5 . 9 0}$ & 3.30 \\
\cline { 2 - 4 } & Directly with community & 6.30 & $\mathbf{2 3 . 0}$ \\
\cline { 2 - 4 } & By other person & 4.80 & 3.30 \\
\cline { 2 - 4 } & Did not book & 1.60 & - \\
\hline \multirow{3}{*}{ Reasons } & Easy and convenience & $\mathbf{6 8 . 6 0}$ & $\mathbf{7 3 . 3 0}$ \\
\cline { 2 - 4 } & Trust and reputation & $\mathbf{1 8 . 6 0}$ & $\mathbf{1 6}$ \\
\cline { 2 - 4 } & Previous relationship and & 8.10 & 2.70 \\
\cline { 2 - 4 } & experience & & - \\
\cline { 2 - 4 } & Price and payment related & 2.30 & \\
\cline { 2 - 4 } & Time related & 2.30 & \\
\hline
\end{tabular}

The way in which the visitor chooses to pay and book their trip to the community may be determined by a number of reasons. Among the reasons given, 'easy and convenience' is consistently the reason they choose to book $(68.60 \%)$ and to pay $(73.30 \%)$ for the community products. In addition, respondents also revealed that 'trust and reputation' ( $18.60 \%$ and $16 \%$ respectively), is also considered an important reason for booking and payment. 


\subsection{CBT distribution channel structure}

Figure 13: CBT distribution channel structure

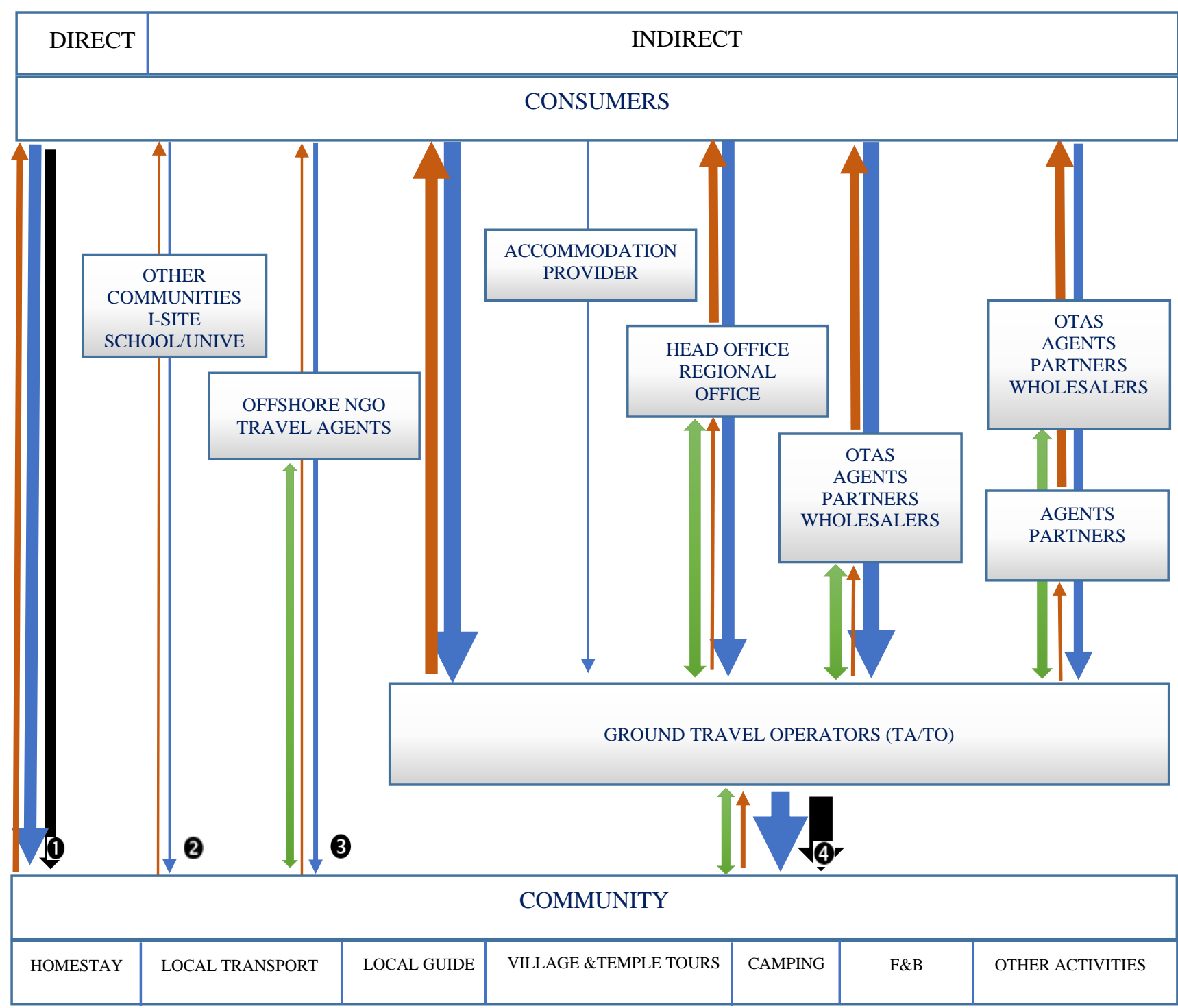

4 Marketing channels

$\downarrow$ Booking and payment from community and intermediaries' perspectives

1 Booking and payment from visitors' perspectives

Bundling and packaging

Figure 13 indicates the whole complexity of the CBT distribution channels. The figure shows the involvement of every aspect of the distribution channels - marketing channels, bundling and packing, and finally booking and payment from the demand and supply sides' perspectives. 
Channel \#1 suggests that both suppliers, (also intermediaries), and visitors acknowledge the significance of the direct distribution channel. Following the direct marketing efforts, quite a number of visitors used this channel as a means to reach the community directly. This indicates that concerted marketing and promotion efforts should be enhanced, especially user-friendly digital marketing. It is without doubt that the use of technology and technology development is growing and will continue to grow at an even faster pace. Thus, such a trend comes into play in direct channeling for CBT. In addition, the increasing influence in which WoM or eWoM have on the direct distribution channel for CBT should also not be overlooked as this is a zero-cost marketing technique and is very important for community. This suggests the quality of core CBT products and services are critical and the community should pay more attention on such things. In addition, although a few deny the importance of printed material, such as, a brochure or map, this traditional marketing channel still plays a key role in information provision, especially for en route visitors.

Channels \#2 and \#3 do not show much consistency between the degree of marketing and booking and purchasing. The community tends to overlook these indirect channels, especially channel \#2. This may be due to the limited resources and capacity which hinder the community from proactively targeting this market. Although there are some channel members involved, they are less complicated and straightforward. There appears to be more local channel members involved in distributing information to the consumers. Yet, the effectiveness of channel \#2 is largely questionable because booking and payment through this channel are rather negligible. Bundling and packaging do not have any role in this channel because it is a channel more appealing to the domestic visitors who are very familiar with the community.

Channel \#3 is very important for the community because most visitors who use this channel are characterized by a number of special features, such as, a stronger level of community participation, longer length of stay, and greater levels of enthusiasm and appreciation. They tend to bring more benefits to the community through their volunteer activities, such as, teaching local children or participating in farming activities. Bundling and packing is very important when dealing with offshore NGOs and travel agents (channel \#3) because they send visitors who are more passionate and willing to learn from and about the community. Very often, they tend to stay longer and prefer tailor-made products. 
Channel \#4 illustrates rather complicated channels concerning connection between the community and GTOs. Figure 13 (page 74) suggests from the marketing channel that the community pays little attention on marketing their products to the GTOs. Although the community acknowledges that business meetings with GTOs are important, the challenge of a limited budget often hinders them from being more proactive in this area. Similarly, most GTOs do not actively engage in marketing and promotion because, in almost all cases, they rely on their regional or overseas head offices or offshore agents and partners to do these activities. However, a few of the smaller GTOs tend to focus their marketing directly to the market.

The survey informs that a majority of visitors (over 70\%) who travel to the community purchased a package organized by the GTOs and, therefore, such a direct distribution channel is very critical for CBT. Based on the current volume of visitors through this indirect channel, the community should have well-developed strategies to work with the GTOs in order to maximize the benefits. Due to the absence of sophisticated methods, (similar to other previous studies), this investigation could not capture in detail how visitors flow from one layer of the distribution channel to another. Despite this, the significance of indirect distribution channels is largely underscored by the community itself and other respondents from the GTOs.

Concerning product bundling and packaging; although there are a series of already developed products the community can offer, as is often the case, most GTOs still usually work with the community in redevelop the packages so they can be based on their clients' interests. In some cases, interested GTOs conduct site visits and then develop a series of tour programs in collaboration with the CCs; they then suggest these programs to their offshore partners and agents for sale. GTOs play a very important role in packaging and bundling the products, especially when they deal with a head or regional office, overseas partners, and other agents. In the case of the three-level channel, packaging and bundling are critical at all stages because the GTOs still need to work with their offshore agents and partners in redesigning their products in response to their market needs.

Above all, in order to understand the complexity of the distribution channels for CBT, this study incorporates both the demand and supply sides perspectives. As integral parts of the distribution channels, the marketing channel, packaging and bundling channel, and booking and payment channel are also investigated, especially from community and 
intermediary viewpoints. The key findings suggest that direct distribution channels are commonly straightforward and less complicated. This maybe largely due to the limited capacity of the community in dealing with an ever growing market demand. The GTOs are critical players in CBT distribution channels and their engagement largely expands its vertical integration. GTOs bring in more sophisticated and state-of-the-art ICT and many of them work with multiple offshore agents and partners in dealing with such a niche market. 


\section{Chapter 5: Factors influencing CBT Distribution Channels}

\subsection{Introduction}

It is largely the community who coordinate most of the day-to-day tourism activities. Therefore, factors influencing the distribution channels for the CBT are mainly associated with their daily business operations, both directly and indirectly. This chapter is divided into six sections. These are - commissionable product, products characteristics and market access, information communication and technology, partnership issues and the nature of the operators, community capacity and the final section discusses CBT market trends. Each section that follows is based on the order of the factors identified in table 10.

Table 10: Factors influencing CBT distribution channels

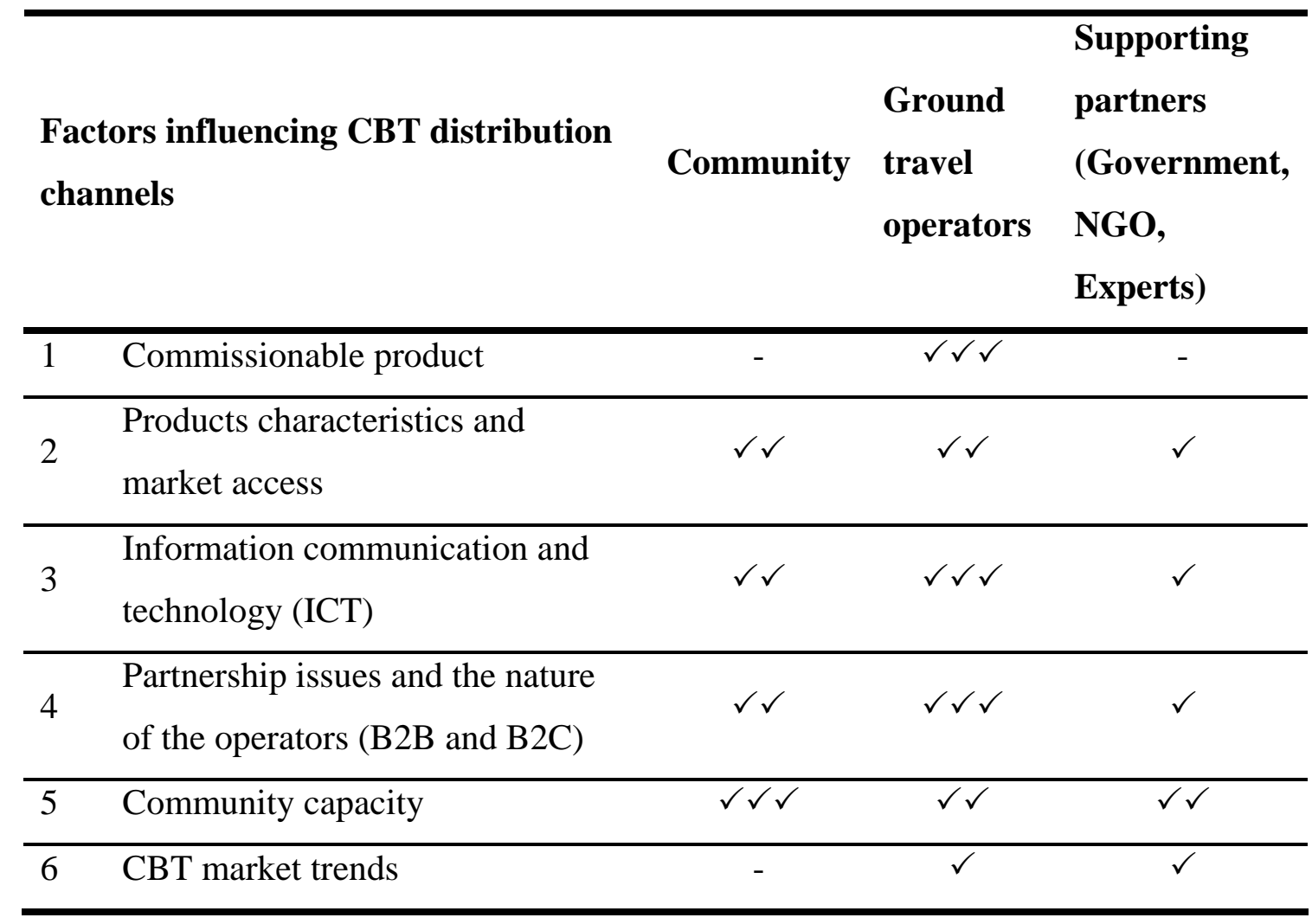

*Note: $\checkmark$ Indicates mild, $\checkmark \checkmark$ indicates medium and $\checkmark \checkmark \checkmark$ indicates strong influence of the factors on the DCCBT, while - indicates that it is not applicable in these groups

Table 10 above, summarises the key findings of the factors which influence the distribution channels for CBT. This table is very helpful because it serves as an interpretation framework and guides the development and discussion in each of the sections. The identified factors were drawn out through the thematic analysis process used to analyse the 
respondents' interviews. The interviewees included members of the community, ground travel operators, and other supporting partners (governments, NGO and experts in the area).

As described above, there are six factors influencing the distribution channels for the CBT. These factors are discussed in the following sections.

\subsection{Commissionable product}

According to Pearce and Tan (2004), commissionable product is one of the key factors influencing distribution structures. It is characterised by the financial benefits of the channel members who are involved in the products distribution. It is also a critical factor in determining the nature and extent of the various distribution channels. The degree of commission may vary from business to business. In practice, being able to offer a better commission or the opportunity for a bigger mark up, increases the financial benefits, and as a consequence is most likely the preferable channel, attracting more potential business partners, ranging from local travel agents to offshore wholesalers. Yet, this can prove to be an issue as the product may then become too costly and hence uncompetitive in the market place.

Offers of commission or marking up prices is not applicable for the Banteay Chhmar CBT because like most other CBT initiatives in the Cambodian context, the prices of any product or service remain the same, even if the sale is by unit or in bulk. They practice a non-commission system regarding products and service distribution. Unlike most other tourism related products, there is a fixed pricing mechanism for CBT and this was developed in the beginning, with strong participation from all of the local service providers (local community members). In principle, as shown in table 11 below, the prices of all products and services remain static and are unchanged even when the purchase is done through regular partners in high volumes. 
Table 11: Price of products and service of Banteay Chhmar CBT

\begin{tabular}{ll}
\hline Service/ Product & Cost of Product/Service (USD) \\
\hline Home-stay (per night) & 7 \\
\hline Food & 3 (breakfast) \\
& 4 (dinner) \\
\hline Tour guide (per group) & 5 \\
\hline Ox card ride/Kuyon & 6
\end{tabular}

Source: Visit Banteay Chhmar: http://www.visitbanteaychhmar.org/prices-and-tours/ retrieved on 02 February 2016

The community does not offer commission or special discounts to either direct visitors or indirect visitors through any intermediary. Therefore, commissionable product could not be considered as a factor influencing the direct distribution channel, especially at the community level. A NGO representative comments that:

"...we (community) do not have commission policy...we will not have commission for them (intermediaries)... intermediaries may need to prepare a new price for their packages or services without taking commission from community. They cannot force community to set certain prices for products; consequently, they have to negotiate with visitors for their profits..." (Representative of NGO A)

However, according to figure 14, the area highlighted in light blue is applicable to commission and/or mark-up. As this area constitutes an important part in the CBT distribution system, this factor obviously plays an important role in the way that it determines the channel length and extent. Commission is not offered by community, instead intermediaries add a mark-up to gain benefits from the sales. This is especially true when the GTOs work with their offshore travel partners and agents to distribute their CBT related packages to the end market. 
Figure 14: Commissionable and/or mark-up areas of the CBT distribution channels

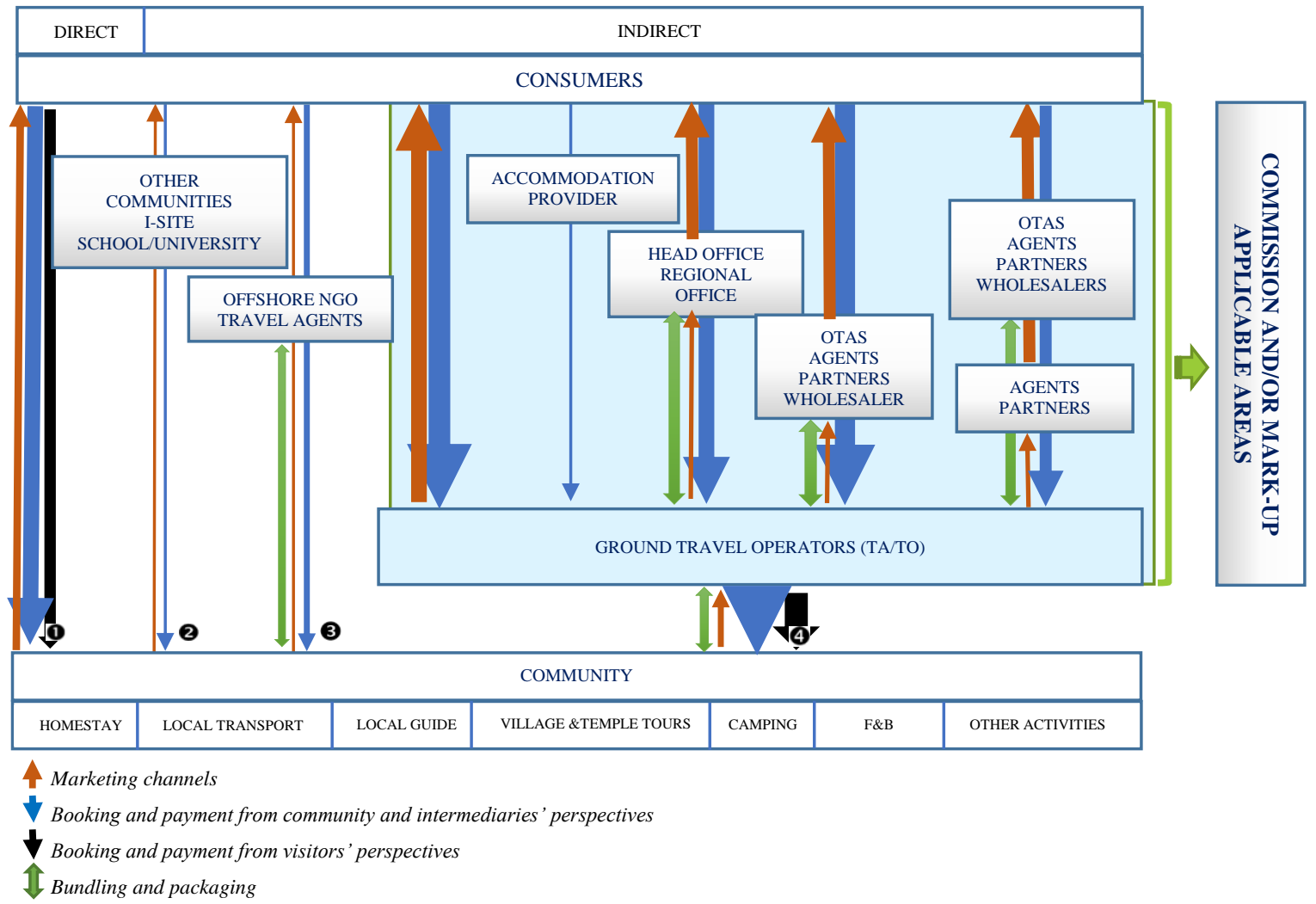

GTOs organize CBT-related packages together with other intermediaries for which they get commissions. GTOs influence distribution channels through this practice and they hold a lot of power due to their resources, skills and industry connections. In most cases, distribution channel is structured in favor of the level of commissions offered, (usually between $10 \%$ and $25 \%$ of total package cost). Basically, the commissions offered vary depending on the relationship between each channel member.

Some of the larger GTOs tend to have a more systematic and formal commission system where a fix percentage is offered based on earlier agreements with other channel members. They tend to be very protective of these agreements and only concentrate on their offshore partners, even if they are contacted by other agents or directly by visitors. In these partnerships, commission applies once they have made the business deal.

“...There are some visitors contact us directly but we do not accept them because we are afraid that our partners would loss a commission..." (Product manager of company C) 
Other GTOs tend to have more sophisticated commission systems, a system that is open to variation of the commission offered. This is mainly because of the popularity and variety of the products they are offering. The percentage of the commission is determined by the volume of sales and who is involved in the upstream market. In this scenario, business partners tend to change partnerships on a regular basis; always searching for other potential partners who offer better commissions. Hence, their distribution structures are rather complicated. It is basically company policy as to whether they have a commission system, mark-up or both. Some companies develop their own commission system based on their agreements with all of their partners. In this case, their package costs are largely the same regardless of the distribution channels. As marketing manager of company A mentions:

“...Based on the company policy, our company we do not mark up the price. Therefore, tourists could buy our products from any agents, or online at the same price." (Marketing manager of company $\mathrm{H}$ )

Unlike their counterparts, small travel operators tend to have unstructured and usually flexible commission systems, which are generally less complicated and based mainly on personal relationships. This suggests that there are only a few channel members involved in their product distribution, and that it is a relatively straightforward channel. The commission rate is usually around $10 \%$ of the package cost.

An alternative to the commission system is mark-up which is a relatively common practice for many businesses involved in products or services distribution,. and is often used by GTOs selling CBT products. When a community implements a non-commission system, GTOs need to mark up the price of the community products as part of their packages. Some travel operators tend to follow the common business flow, whereby a distribution channel is through regional agents and subsequently on to offshore agents. In this situation, price mark-up is a critical issue, as it needs to ensure that each channel member gets a certain percentage of the profits, while the total package costs remains competitive in the market place. Very often, GTOs make less profit when dealing with multiple levels in the distribution channels. Conversely, it is more profitable when they deal directly with the offshore agents in the tourism generating regions. Sales manager of company B notes that:

“...we cannot set high price once we work with regional agents in Vietnam because they need to take margin from the packages they sell to third agents in 
Italy. In case the other agents in Germany book us directly, we can set the price higher. For example, if we work with agents in Vietnam we will make profit only 15\%, but if we work directly with agents in Germany we will get $20 \% \ldots$.. (Sales Manager of Company B)

Overall, commission and/or mark-up affect the CBT distribution system indirectly through indirect distribution channels. Due to the fact that indirect distribution channels constitute a very important part in the whole CBT distribution system, the effects of this factor are considered to have a large influence in the DCCBT. Although a few GTOs are more partner-focused, it is likely that, in most cases, distribution choice tends to be based on the level of margins gained from the commission or mark-up. The more the margins, the more likely the channels are used.

\subsection{Product characteristics and market access}

CBT products and services are characterised by a collective business entity, where locals work together to offer different components of the products and services, all of which are brought together as a total CBT package. These packages are based on the available resources within the community. Often, the communities are located in remote destinations and therefore such products and services are off the beaten track, and consequently lesser known to large groups of visitors. Therefore determining how product awareness can be made to potential visitors and how its distribution to the market can be achieved is a critical issue for these communities. CBT is a niche market and therefore appeals to only special interest groups; those who are passionate about certain things, such as, local culture and heritages, local ways of life, meaningful host-guest interactions, home-stay experiences, and volunteering opportunities. To some extent, CBT products lack breath of appeal, not only for the international market but also for the local people. These characteristics of the products are critical issues determining the challenges of market access and expansion.

“... There are many people asking me why I bring them (visitors) there (community). I just answer that there are many thing to do and see. Some locals simply do not know anything about Banteay Chhmar, let alone international visitors..." (General Manager of company D) 
The consumers of the products are mainly independent travellers and group tours. Independent travellers who directly approach the CBT to purchase products and services are more flexible in terms of activity choice and available time. Thus they are more likely to try different types of products offered within the community. Product appeal is not a critical factor in determining how such visitors search for CBT products because they are normally better informed about the destination, and product appeal is not necessarily the driving factor for their visit. On the other hand, package groups are less flexible and very often they only consume core products in the community, products which are thought to be the most appealing according to the private tour company which organized the packages.

When it comes to the package tour, CBT products are vital components for some GTOs. Such products play an important role in triggering market attention because they are aggressively highlighted in the marketing campaigns. CBT products are included into most of GTOs' regional packages, mainly with Vietnam and Laos PDR. Subsequently, they are appealing to the market. However, some other GTOs tend to include CBT products as just part of their new product innovation strategies. When expanding into new markets they try to diversify their products to attract more clients. In some cases, it is systematically organized whether or not to include such products in their packages. Offshore partners play a critical role in such decision-making. In this regard, the CBT products are just part of the new strategies and therefore the depth of their appeal is limited.

“... We need our business to grow. Therefore, we have to include more innovative products such as CBT in our packages, because most tourists will not come back to use the same products again and again" (Product Manager of company C)

"... Normally, there are many competitions in the market. So we have to find something new and innovative to include in the packages. However, it is based on our partner as well. If they want to expand to CBT market, we will include that accordingly. Actually, CBT is our new market for 2016." (Sales Manager of company B)

Market access is also seen as another factor affecting the extent and how CBT products are distributed. This issue is strongly associated with number of challenges, such as, distance from the market, insufficient supporting tourism infrastructures, and community and 
market information. These challenges make CBT products more vulnerable in terms of market access. Operationally, these challenges are quite common to many other CBT initiatives and it even more critical for those communities that are less-developed and located off the beaten track.

For Banteay Chhmar, the degree of remoteness appears to be a major issue, restricting direct contact with visitors in order to make sales, This is due to the fact that the visitors who come to the general area are likely to concentrate in the urban central and other tourism hubs. Distance from the market makes transportation to the community rather complicated, time-consuming and costly. Some independent travellers may find it potentially challenging to physically reach the community, while others would find it an issue if they were particularly time poor. A NGO representative mentions that:

“... The connecting transportation to Banteay Chhmar community is very complex. When they (visitors) reach provincial town, they have to change to another local taxi stand (Phsar Themy), before catching up the direct taxi. As a stranger to the new location, they find this quite confusing, especially when they do not speak local language... It costs between USD 25 and 30 for pick up taxi from Sisophon (provincial town). It is difficult for foreign visitors..." (Representative of NGO A).

Similarly, limited tourism infrastructures are considered to be another issue affecting demand in the community. Poor road conditions and insufficient connections from both inter and intra regions, potentially further dampen the desire to visit the community and hence purchase their products. Also this infrastructure challenge provides an additional obstacle when trying to develop sales-related contacts with potential visitors and other travel firms. Some GTOs are still concerned about the access to the community as this may downgrade the quality of their packages. However, such an issue is no longer a challenge since a paved road has recently been completed and this news is being promoted to wider partners and potential visitors. It is undeniable that limited infrastructures may diminish a community to perform at its best, but it should not be an issue as long as detailed information is circulated along with the packages to ensure visitor awareness so they can be prepared for the situation. As manager of company A suggests: 
"Previously, it was flooded thus we could not access the community. But, now we have recently build road so there is much less difficulties. Some people (visitors) are not afraid of those challenges to come to community. But, we have to explain them clearly about that, and also to prepare them from those challenges." (General Manager of company A)

Community and market information is also an important component in the market access factor. Market information is beneficial for the community as they can prepare and develop in response to the market needs effectively, as well as take advantage of those markets. Furthermore, how they are heard in the market is also very important because it is the start of the purchasing and selling relationship. Similarly, information about the community and detailed product information are undeniably important for visitors as they need to make decisions and prepare for a trip. Usually business entities or communities are actively trying to circulate their information through a number of marketing channels, to attract potential visitors and also business partners, obviously with an expectation to increase sales and develop sales-related contacts.

As mentioned above, a community is using many different ways to market itself both directly and indirectly. However, the inability to implement marketing activities yearround, which arises from an inadequate budget, can be a disadvantage to the wider market. Such an off-and-on marketing style is very common for CBT initiatives, especially for those communities who do not get sufficient external support from development partners. This is true for the Banteay Chhmar CBT, where the limited funds are allocated to support activities such as capacity building while the marketing effort is not a priority.

Partnership with private sectors both formally and informally is beneficial to the community in many ways. GTOs help the CBT's aggressively in terms of marketing. They include CBT products in a series of packages and they promote to wider markets through regional and offshore partners. Some of them include community information in their brochures, package information and even within their website. Thus, GTOs are very beneficial as they help to promote and sell CBT products widely. However, most private sector interviewees said that the developing a community-company relationship is quite challenging for the community. Almost all of them suggested that they always had to approach the community first, and the community often failed to provide adequate information or update their information. Managers of company $\mathrm{J}$ comments that: 
"CBT is not well-known. When we include it in the itinerary, we have to put the description about community, and how the tourist's money could help community. When they know clear about this, they would happy to join with us...I think we do not get more information from them (community). From my experiences, there are many hotels contact me because they want me to sell their products, yet community does not do this. I have to contact them for information. They do not contact and give me the updated information. For example, what are they doing? And what is going on next in community? If we have more information about them we could tell others or put in our itinerary as well. I think it is the main problem that we do not get the information from them. I think that they should have the marketing manager and update the information with me every month, so I will keep an eye on and promote it more." (Product manager of company J)

\subsection{Information communication and technology (ICT)}

The proliferation of the internet and technology has led to an unprecedented growth of inter-connection and information flow than ever before. Such an increase has influenced the tourism industry in many ways. In regards to tourism distribution channels, this ongoing expansion of the internet and technology has, according to O'Conner et al., (2001), increased the number of channels available in the market, where channels are becoming more inter-connected and the routes to reach wider market have grown in number. Furthermore, it has also established better linkages between demand and supply.

Like all other business entities, CBT can also take advantage from such an emerging growth. ICT facilitates access to fast and convenient information. In addition, it is costeffective and less labor-intensive compared to traditional marketing channels, such as, print-based media. Given the collected information, as shown in the figure 10 (page 56), the extension of ICT is crucial for CBT. In the form of websites, direct e-mail marketing, social media (mainly Facebook and Blogger), e-newsletters and mail, ICT shares a greater part in the direct marketing channels. For independent travellers, the community website is their primary source of information and then correspondence through email has seen an important development in a community's ability to direct market. Moreover, email is also the main communication tool for the community when dealing with the GTOs and other offshore agents. The $\mathrm{CC}$ member who responded to the interviews said the following: 
“...It (website) is crucial for us to share information and promote our products globally. All visitors can get important details from it... Mostly, they (independent traveller) check community website to arrange their trip and they book through email...it would be very challenging for both community and visitors if there are no these online stuff..." (CC A)

Besides its usefulness for communication and promotion, ICT also offers different opportunities to the community to reach the market through diversifying the channel options. In addition, it helps the community to capture more direct visitors by offering more competitive prices while reducing the number of intermediaries involved in the product distribution. Similarly, ICT is also important to visitors as they can get detailed information about the products faster than ever. The availability of the information and multiple distribution routes makes it easier for travellers in terms of travel choice and price of the products.

ICT and its applications are even more obvious for GTOs whose businesses are more competitive. Most travel companies take advantage of ICT by increasing their direct distribution channels while holding price at a very competitive rate. Some realise that selling their products digitally through online travel agencies (OTAs) is very beneficial and cost-effective. However, products must be innovative in order to be appealing to the wider market. As managers of company A and D suggest:

“...First, I build network directly with customers and other famous websites like Trip Advisor and Expedia. There are more competitive online businesses which I now do not think about anything besides improving my products. Now, my team register in Trip Advisor so that it can help to reach more customers..." (General Manager of company D)

"Online bookings through OTA is very prevalent now and they are very important because they have huge network. When we upload information, customers will find us worldwide. Community website is secondly important..." (General Manager of company A) 
Although ICT tends to be significant for travel firms in general, smaller companies are likely to be challenged with the overwhelming competition, especially when travellers are more experienced and technology is ubiquitous. It is even more daunting if the small companies do not keep up to date with digital trends. The proliferation of ICT is also an emerging potential threat, as it becomes more apparent that visitors are looking for more direct routes, with more competitive pricing, yet with the same value.

"These are all about technology. During 5 to 10 years, travel agents will be decreased as I anticipated previously. Technology is very considerable. Many people use technology to search for information very fast. So travel agents should be adaptive to technology... Obviously, they (travel agents) will bankrupt in the future. Not all will bankrupt, but there are only few who can survive. Previously, if there are some groups of people who want to travel they have to contact with travel agents. But now, customers find information easily from internet. I recently met a customer who did not use travel agent's services 5 years ago as he can save $25 \%$ of the expense while he can organize the hotel services easily on the internet. He, then, crosscheck with Trip Advisor and OTA for the price. As hotel wants customers, they set lower price. Finally, he gets a low-cost hotel room directly rather than from travel agents." (General Manager of company A)

ICT plays an important roles in facilitating a more direct distribution channel (figure 10 of page 56), by connecting travel operators with the market and their regional and offshore agents. Some GTOs make use of ICT in many ways, such as, accessing visitor databases, as a communication tool amongst their travel partners, and for booking and confirming availability of products and services. Despite of these advantages, some GTOs tend to still allow their regional and offshore travel partners to distribute their products to the market. This is mainly due to the fact that their partners are more appealing in the market, and the GTO brand still needs to build trustworthiness, hence using a well renowned brand is their better option. In this case, ICT does not reduce the number of intermediaries involved in the product distribution; ICT also offers GTOs more distribution choice when dealing with multiple channel members, making their distribution structures more sophisticated.

“...Previously, we had staff handle with direct booking. We tried for one or two years but it was not effective because we are not famous like other large 
travel firms which have connection in many other countries. So, most tourists

do not trust us. I could say that website or direct channel is not so important for us." (Sales Manager of company B)

\subsection{Partnership issue and nature of the operators}

The partnership issue is regarded as an important factor affecting CBT distribution channels. Respondents from the GTOs and the community perceive this factor as a major impact on how products are distributed and why certain channels are chosen. Basically, it is not a stand-alone factor. There is an interwoven connection among other factors, such as, product characteristics, (see the section above), demand features, product cost, and the characteristics of the suppliers and operators.

The CBT market is niche and therefore the whole market system is less complicated. Given the fact that approximately $70 \%$ of the total visitors approach community products through the GTOs, they are an essential part of the channels being investigated. The GTOscommunity partnership and how the GTOs deal with other intermediaries in the market place, explains to a large extent how such partnerships affect product distribution. Currently, there are approximately 40 travel companies working and sending visitors to Banteay Chhmar. A few of them have developed a more serious relationship with the community by means of a memorandum of understand (MoU), year-end appraisals and feedback meetings. However, many others tend to have an informal relationship with the community. The formal partners are likely to send visitors more regularly to the community while informal partners tend to send a lesser number of visitors, and also in an off-and-on basis.

As the previous section on commissionable product suggests, the community does not take commission from any GTOs and the prices of all products remain the same (table 11 of page 80). Thus, GTOs need to mark-up the price and include this into their whole package before making a direct sale or sending the package to their offshore partners. The level of mark-up is beyond the community's control and they do not interfere in their partners' pricing decisions. In this regard, such a partnership means the community has no influence on how much the products should actually cost. GTOs have complete freedom to set the price to whatever they can sell the product for and still make a profit. A representative of NGO informs that: 
“... They (GTOs) have to include CBT products into newly prepared packages and sell without taking commission from community...We have never discussed how much they should price. Each GTO are the only one who makes decision on prices before continue to sell..." (Representative of NGO A)

Due to their special features (being more responsible and niche), partners who are involved in selling CBT products are characterised by being supportive, not solely profit-oriented, and willing to help. Hence, a community-private sector partnership denotes a distinctive characteristic from other business-to-business (B2B) relationships. A majority of the GTOs are supportive to the community in terms of product marketing, market feedback and market access. Some GTOs include community details in their package information while others include community information in their regular newsletters or on their websites. Marketing manager of company $\mathrm{C}$ explains that:

“... We promote their homestay.....we put detail information about community in the package including how to take bath, how to stay well with community, code of conduct and so on....and our partners or agents also include such information in their packages as well..." (Marketing manager of company C)

A few of the community's partners who are not profit-oriented tend to have more straight forward channels. Mostly, they send their trip participants to the community directly and the quality of the tour is a primary objective. Often these trip participants are likely to stay longer and join in with the volunteering activities in the community while learning to appreciate many aspects of their trip. This suggests that these partners have developed the relationship beyond the business level, possibly to a personal level. Such relationships are important for the community as that means they have strong committed partners who will always be there to give support. A founder of NGO C indicates that:

“... Our partners in US suggest us to change to other places rather than going to Banteay Chhmar next year, but we already responded that, based on what community can offer, we will stick to the same plan and none of the changes will be made..." (A founder of NGO C)

One of the fundamental aspects of the partnership issue is the commitment and intention from the private sector partners. All interviewees from travel companies suggested that 
they approached the community first before the real business relationship took place. They learnt about the community through participation in farm trips, business meetings, or from the community website before conducting an on-site appraisal, and then subsequently developing their packages which they send out to their regional and offshore partners for sale. This is important for the community as they then have a good connection to the market. This is because all of the interested travel companies have strong relationships with many tourism related businesses in wider geographical locations, and especially in tourism generating regions. It is even more critical when the travel company is passionate about CBT and willing to have a stronger connection with the community, particularly in a business-to-community (B2C) basis.

"We are B2B business. But we also operate B2C though it is small part in our market. The main advantage is that we have a wide distribution channel... so we have much wider rang to sell. Furthermore, we have good relationship with them, so it could be easier for us to find out about local products, what different people like and what can we design for them." (Product Manager of company $\mathbf{J}$ )

At the vertical level where a number of CBT-related B2B relationships take place, partnership issue is a critical factor in determining the distribution channel structures and choices. Like many other tourism business entities, the GTOs develop rather complicated business relationships and, therefore, often have multiple routes they can access the products to the market. Yet, some of them tend to follow far less complicated structures and this is especially true for small GTOs.

There are a number of reasons why some GTOs choose to follow certain channels and not others. These reasons are mainly associated with the company's common policy and protectionism. The former is influenced by the internal factors which guide the way the GTOs operate their businesses, while the latter is influenced by the external factors, the way each channel member agrees to treat each partner. In this regard, they have very strong relationships with local and overseas business partners and such relationships determine the way products are distributed. They generally deal with their business partners in the major aspects of the distribution channel; this involves information provision, bundling and packaging of products, and finally booking and payment. They are 
likely to follow a loyalty system in that all of the involved channel members trust one another exclusively to support each other.

"If there are some companies or visitors contact us directly, we do not accept that. We will refer to our partners because we are afraid that our partners may loss the benefit..." (Product manager of company $C$ )

"It based on our policy. Our business focuses only on partners because walk-in tourists are not important for us... The effective way is working with partners because they sell most of our Indochina packages which include Thai, Loa PDR, Vietnam, and Cambodia..." (Sale manager of company B)

Among all interviewed respondents from the GTOs it was suggested that all forms of intermediaries, including regional and offshore offices, overseas partners, agents, and OTAs, are playing a pivotal role in CBT distribution channels. They are a very important part of their business because not only do they have a huge connection in wider market, but they also offer technical support to the GTOs, such as, marketing and market research. Many managers from the GTOs similarly explain that:

“...They are the central point that could be considered as our eyes. They are very essential...It is our business model that we connect directly with our partners. They are very priceless and in the future, you know, they will be our main concentration in Southeast Asia.” (Regional Manager of company I)

“They are very important. Over 90\% of our sale made through offshore agents and partners. Without them our company could not be this successful...they also do the marketing for us. All of foreigner agents have their own customer database, and they have their own marketing strategy like brochure, magazine, newsletter, and e-mail...Therefore, they are very important. (Product manager of company $\mathbf{J}$ )

"They are absolutely important because they sell our products... They send many tourist to us very year. They are very honest..." (Product Manager of company C) 
Despite of the fact that regional and offshore agents are important for GTOs in CBT distribution channels, not all of them add additional value to the packages to make the products more competitive and appealing to the market. In contrast, they bring certain issues to the distribution channels, such as, increasing the price in the form of commission, adding another layer to the channel, and can cause more gaps in communication. However, due to the business relationships that have developed over time, they cannot be excluded from the channels, although they are not the preferred option. In this regard, more direct routes are potentially the preferable choice for the GTOs in their product distribution.

"I think working with direct partners is easier than working with intermediaries. We encounter some difficulties working with some of them (intermediaries). For instance, in reality they already sell packages in high price, but they still ask us to decrease the cost or sometime they said that they sold out the wrong price and they ask us to decrease our price. Thus, we cannot make profit. But, because of the relationship, we have to agree with them. In contrast, we work smoothly with our direct partners and we get higher revenue as well." (Sales manager of company $\mathrm{B})$

\subsection{Community capacity}

Capacity issue is another important factor determining the CBT distribution channel structures and how it works in the market. Table 10 (page 78) suggests that this factor is more appealing for the community and the GTOs. Well-developed communities tend to have more straight forward channels and large numbers of private sector partners involved in their product distribution. This is because those communities tend to have experienced community members who can cope with business effectively, have sufficient financial resources to invest in the community development, and more specifically their products are more appealing due the extensive marketing efforts. Conversely, less developed communities are likely to rely on a limited number of private sector partners and direct visitors to remain subsistent. This may be due to the fact that they do not have enough resources, both human and capital, to invest in community development.

Even though Banteay Chhmar has witnessed an impressive growth of $300 \%$ over the last five years, community capacity is still an issue, preventing more prosperous growth. This may be due to the insufficient financial resources being invested in the CBT development. Most of the operational costs still largely rely on non-governmental organization's support 
(NGO), and although there is evidence that the community will be self-sustainable in the coming years, the current financial needs are very critical. As suggested earlier, human resources are also very important for the community when dealing with their businesses as well as the private sector partners. Although overall community capacity is improving, the community's current status suggests that certain skills are needed to keep pace with the ongoing growth. CCs and NGO representative similarly suggest that:

"We should improve human resource, especially language skills because this accelerate visitors' satisfaction on our products...we do have not enough capacity to attract visitors to our community yet... We have limited skills in the areas of English language, information update on Website, marketing, how to use email and keeping track of the booking...we are not strong enough to communicate with tourists..." (CCs A and B and Representative of NGO A)

Majority of visitors to Banteay Chhmar are channeled through the GTOs. Thus, it is also important to understand how these partners perceive community capacity in dealing with the market. Overall community capacity affects the way in which they deal with visitors and their private partners. Although business partnership between the community and the GTOs has improved over time and is predicted to continue into the future, many GTOs still raise concerns regarding the community products and services.

“...we have to have our guide because community guides do not have broad idea to link to other places...they should continue to create new products and keep us informed... Sometime, some of their products do not reach our requirements...so we need to negotiate with them in order to minimize the gaps... (Sales manager of company B)

Their capacity is still limited... They do not know how to sell the products effectively...it is their challenge... (Founder of NGO C)

They somehow depend on travel agents to sell and promote their products." (Product manager of company $\mathrm{C}$ )

However, some other GTOs tend to believe that community capacity is not a drawback and should not pose a threat to its distribution channels. Unlike luxury service providers, the 
community is limited in what it can provide and all that is needed is for this to be clearly explained to all key channel members as well as to potential visitors. Being a communitybased tourism destination it has the ability to offer a high level of authenticity, which is seen as an advantage; one that the community is proud of. In this regard, some managers from the GTOs similarly address that:

"They (community) can extend their products in the way that authenticity is still guaranteed... I think there is no problem with their capacity to sell the products. I told visitors that our trip is not about travelling to a place where five-star service standard are served. Most of the visitors are already aware of community..." (General Managers of company A and D)

“... I like Banteay Chhmar...We work with each other very well because they can offer very interesting things and activities for our clients. We promote and market this too many partners." (Product manager of company J)

"I think Banteay Chhmar has the capacity to target whatever groups to their place." (Regional manager of NGO B)

\subsection{CBT market trends}

One of the fundamental factors affecting CBT distribution channels is market trend. It is largely concerned with the on-going changes of visitor choice, and the characteristics and ways in which the community and the GTOs operate their businesses. The former is mainly affected by the emerging growth of more responsible consumption behaviour, better education and the demand to travel, while the latter is associated with the proliferation of ICT.

A growing number of educated visitors are able to access community information far easier. This is due to the increased availability of information through wider distribution and facilitation by the influx of ICT. They are likely to get more detailed information about a community's products easier, faster, and access to their choice more conveniently. The cconsumption behaviour of these educated visitors will see a shift to be more responsible and greener, thus, CBT products could be more appealing to such a trend. Furthermore, travel is becoming an accepted norm and experienced travellers are on the increase. 
A majority of travellers tend to search for information and arrange their trips themselves, therefore more direct distribution channels could be a rewarding outcome of this trend.

In addition, based on the reasoning above, the number of local small travel operators would shrink due to the fact that more accommodation providers and other tourism-related businesses, such as, souvenir shops, food and beverages, and tourism information centres will play a larger role in arranging local trips and providing information. As such, vertical integration will be expanded and vibrant linkages between the community and the other key channel members will become evident. CBT distribution channels are improving markedly at the local level. As general manager of company A firmly advises:

“...tourism becomes one of the common demand for people...it is a trend that travellers want to explore the community where special and unique products are offered...there are only few (travel operators) that can survive... Previously, if there are some groups of people who want to travel they have to contact travel agents. But now, customers find information (about community) from internet easily...experienced travellers are on the increase...access to technology is ubiquitous... In the future, travel agents will be decrease as most of visitors would search and find the information from internet and arrange their trips accordingly... hotels and other tourism-related businesses will work as tour operators. For example, if a customer needs a guide, they will find a guide for them..." (General Manager of company A)

This chapter discusses the factors, as illustrated in table 10 (page 78), which have an impact on CBT distribution channels. These factors are rather diverse and mainly draw from the community and intermediary perspective. These are commissionable products, products characteristics and market access, information communication and technology, partnership issues and the nature of the operators, community capacity and the CBT market trends. Similarly, most of these emerging trend factors are external factors and they are beyond the control of the community. Yet, it is critical for a community to incorporate these into its strategic development plan in order to maintain growth and to achieve sustainability. 


\section{Chapter 6: Discussion}

\subsection{Introduction}

The aim of this chapter is to discuss the key findings which have emerged from the data analysis and data interpretation throughout the previous two chapters (chapter 4 and 5), using the research objectives as a guide. In doing so, the key findings will be highlighted in correspondence to the literature review (chapter 2), and the findings are compared to and contrasted with previous research studies. This is followed by a synthesis of the study.

Based on research objectives, the organization of this chapter is divided into two main sections: distribution channel structures for Banteay Chhmar CBT and the factors influencing this structure. Using figure 13 (page 74) as a guide, the former discusses the common channel functions (which include marketing channels, bundling and packaging, and booking and payment), product features and the intermediaries' size. The latter focuses on a number of key factors that influence distribution channels.

\subsection{CBT distribution channel structures}

The examination of the distribution channels for Banteay Chhmar CBT reveals that there are a number of commonalities and differences in distribution channel structures found in different products such as adventure tourism (Schott, 2007); cultural and heritage-based tourism (Pearce, 2005; Pearce \& Tan, 2004); wine tourism (Liu, 2012), and other destination-based investigations (Mkumbo, 2010; Andrade, 2013; and Stuart, 2005). As indicated in figure 13, the community as well as its intermediaries use a distribution mix which include direct and a wide range of indirect channel choices. Table 12 is a framework that guides the discussions of CBT distribution channel structure through the variations of the channels and three inter-related channels sets: distribution functions (marketing channels, bundling and packaging and booking and payment), products attributes and intermediaries' size. These are discussed in order in the following sections. 
Table 12: Elements determining CBT distribution channel structures

\begin{tabular}{|c|c|c|c|c|}
\hline \multirow{6}{*}{ 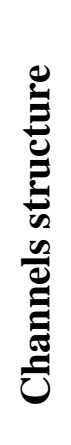 } & & & Direct & Indirect \\
\hline & \multirow{3}{*}{$\begin{array}{l}\text { Distribution } \\
\text { functions }\end{array}$} & $\circ$ Marketing channels & $\ldots$ & $\ldots$ \\
\hline & & $\circ \quad$ Bundling and packaging & $\ldots$ & $\ldots$ \\
\hline & & $\circ$ Booking and payment & $\ldots$ & $\ldots$ \\
\hline & \multicolumn{2}{|c|}{ - $\quad$ Product attributes } & $\ldots$ & $\ldots$ \\
\hline & \multicolumn{2}{|c|}{ - Operators' size (community and GTOs) } & $\ldots$ & $\ldots$ \\
\hline
\end{tabular}

\subsubsection{Distribution functions}

\subsubsection{Marketing channels}

Table 12 shows that distribution functions play a lead role in determining the overall distribution channel structure. Key findings in chapter 5 suggest that marketing channels are important to CBT distribution channel structure in the way that they communicate and link community either directly (ICT and/or WoM) or indirectly through intermediaries.

Pearce and Tan (2004) commented that the role of the internet is consistent and important throughout broad destinations in New Zealand. In addition, Reid and Pearce (2008) found that e-distribution is effective for its capacity to shorten the distribution chain and strengthen the ability for both suppliers and intermediaries to focus more on consumers directly. In the context of adventure tourism, Schott (2007), found that using internet is not only effective in connecting to the wider markets but also economical for operators, especially for a community that has limited resources. More importantly, internet plays a critical role in raising product awareness and providing product education. This study provides additional evidence to support internet as the most important direct distribution and marketing channel. Digital distribution is therefore cost-saving, labour-efficient, and effective in terms of reaching prospective visitors globally. Given the fact that the internet is used for $50 \%$ of the total CBT information search, it confirms that internet or their website is undeniably important for the community.

In line with Schott's findings, internet or a website is also crucial for its raising awareness role. In addition to providing detailed information about the community's products, internet or email is an essential tool to educate visitors about community code of conduct during the information search process. Unlike many other tourism products, this is 
fundamental for the fact that $d o$ and don't is necessary, especially for responsible travellers visiting culturally or environmentally sensitive communities. A representative of NGO A comments:

“...compare to group package, direct visitors who search our website [community' website] tend to know more about our products, details about community, code of conduct and subsequently they are likely to behave appropriately ... this is very important for us...".

For indirect distribution channels, internet or website is also important, especially for GTOs who sell CBT-related packages to the consumers indirectly through their offshore agents or partners. As shown in figure 10 (page 56), ICT in the form of websites, internet, and email is the most important marketing channel GTOs use to establish point of sale through communication with travel partners and other key channel members.

In the context of adventure tourism, word of mouth plays a very important role because it is a trusted source of information. Schott (2007) commented that it is the most effective channel of distribution. Similarly, in a study on surface transportation distribution channels, Pearce and Sahli (2009) also noted that word-of-mouth is one of the most important means to establish sale-related points of a trip organized by regional or local coach operators. Another research study by Stuart et al. (2005) also found that almost all attraction and activity providers accepted that word-of-mouth marketing is essential to attract the international backpacker market. In addition to these findings, Pearce and Tan (2006) acknowledged the power of word of mouth. They further suggested that this marketing technique, as well as facilitating referrals from other providers, is very important in attracting both international and domestic travellers, especially in the accommodation sections. This suggestion recognizes the importance of inter-relationships among local and offshore channel members in recommending visitors to certain products and services. In consistency with the findings from the studies referenced above, this study provides more evidence to support that WoM, after ICT, is the second most important marketing channel for CBT as well as for GTOs to reach broader markets and subsequently can increase sale volume. However, in the case of CBT, the referrals from other channel members, especially locally-based members are seen as ineffective. The possible explanation for this may lie in the fact that many of the locally-based members do not know what Banteay Chhmar can offer or have never personally visited the community. In 
order to enhance this, the most practical and feasible solution is to facilitate more familiarization trips for important and highly-relevant channel members who potentially could bring more detailed information to the wider market.

\subsubsection{Bundling and packaging}

As illustrated in figure 13 (page 74), bundling or packaging does not play a role in the direct CBT distribution channel. This is not altogether surprising, as confirmed by Pearce (2005) such a function does not occur for independent travellers. He went on to suggest that bundling cultural tourism products is challenging because of their diverse status and that often these resources belong to different institutions. This is not the case of Banteay Chhmar CBT. The community is able to bundle all core products together and get them ready for sale. Additionally, as shown in channel \#3 of figure 13, the community works with offshore NGOs and travel agencies to bundle and package their products for visitors. Similarly channel \#4 indicates that the community and GTOs also work together to redesign the packages and bundles for further sales. A possible explanation of this may be because the community has a sense of ownership and right to manage and control the cultural and heritage resources in their vicinity. Although there are a number of other local and national government agencies and NGOs involved in management of the resources, they are rather supportive of the CBT initiative.

For group tours, CBT is not a standalone product. Generally, many of the GTOs that sell CBT-related packages include a number of other products from nearby destinations, other parts of the country or sometimes it is part of a multiple countries package. In this case, CBT products are just part of the total package and are bundled with different product features. Yet, in a few cases, especially for specialized travel agents, CBT is the main focus of the trip.

\subsubsection{Booking and payment}

Booking and payment is one of the most important functions in tourism distribution channels. Therefore, the way in which booking and payment is made are the foundation of the distribution structure. According to Pearce and Tan (2004), in many cases, cultural and heritage-based micro and small operators do not demonstrate sufficient capacity to accommodate group bookings and, therefore, they are heavily dependent upon independent visitors who mostly make direct booking and payment. This situation does not apply for Banteay Chhmar because, despite limited capacity, the community is able to receive both 
direct and indirect bookings. As illustrated in figure 13 group bookings through GTOs constitute a very important part in the overall CBT distribution structure. These bookings are made through a number of inter-related channel members, especially offshore-based intermediaries. Another possible explanation for this may be because the community has an inclusive role in managing all tourism-related resources in the area. This enables bundling and packaging CBT products a lot easier compared to cultural and heritage products revealed by Pearce and Tan (2005).

Regarding direct booking, the findings of this study are consistent with Reid and Pearce (2008) who argue that such an activity can be enhanced by the expansion of ICT. Therefore, internet comes into play for direct booking and payment. Operationally, the community has gained tremendous advantages from using a website and the internet as a means to advertise, inform and communicate directly with potential visitors.

Schott (2007) commented that early booking and payment are highly unlikely for adventure tourists because this may restrict their flexibility in terms of travel schedules or activities. However early booking for direct channels and more importantly for indirect channels is essential in the case of Banteay Chhmar because the community service providers need to prepare well in advance for visitor arrivals. For example, the right amount of food needs to be prepared prior to the visitors' arrival. However, there are a few cases, where very adventurous tourists have shown up and surprised the community.

\subsubsection{Products attributes}

Stuart et al. (2005, p. 249), commented that "different distribution channels are used to reach different market segments, with channel structures reflecting to a large degree the characteristics and needs of both consumers and suppliers." To a certain extent, this suggests that, although there are some commonalities and differences, distribution channel structure for CBT differs from those of adventure tourism (Schott, 2007), wine tourism (Lie, 2012), safari tourism (Mkumbo, 2010), or events (Smith, 2007). Furthermore, this may also be true for cultural and heritage based tourism (Pearce \& Tan, 2004; Pearce, 2005). A possible explanation for this may be due to a number of features associated with product characteristics.

CBT products or services are characterized by the combination of micro and small familybased ventures. Service providers are local people who live in the vicinity with a variety of 
backgrounds and often a low level of skills. Therefore, it is not surprising that CBT products present high fragmentation and there is no single standard. As argued by Goodwin and Santilli (2009), CBT products are very much supply-oriented and, therefore, they are not so appealing to the market and consequently demand for such products is very limited.

Another important product feature is the context and location. This refers to the general characteristics of the products. Typically, CBT ventures are located in remote destinations and in many cases transportation to the community is rather adventurous and costly. An important aspect which makes distribution channel structure for Banteay Chhmar different from other community destinations lies in the fact that domestic demand is limited compared to international demand. The features of the products define the demand volume, characteristics of suppliers and consumers, and subsequently the channel choices.

\subsubsection{Intermediaries' size}

Pearce and Tan (2004) suggest that whether or not the distribution strategy is sophisticated is usually associated with the business size. Similarly, Schott (2007) found that micro and small businesses are likely to use short and straightforward channels in distributing their products and services while large tourism business operators take advantage of using a diverse range of distribution strategies covering large geographical destinations: in market, while travelling and at the destination. These findings are supported by the case of Banteay Chhmar where a number of intermediaries of diverse sizing are involved in selling CBTrelated packages. The findings confirm that small specialized GTOs tend to use direct and straightforward channels while large GTOs, especially those that are part of the global travel chains, are likely to use complicated, multi-layer distribution channels involving many other intermediaries such as offshore travel agents, wholesalers or other OTAs.

\subsection{Factors influencing CBT distribution channel structures}

In order to discuss the factors affecting CBT distribution channels, this section makes use of the key findings in chapter 5 by consulting with commonalities and differences found in relevant previous studies. Figure 15 (page 104)is utilized as a framework to guide this section, with particular focus on (1) commissionable products, (2) Information Communication and Technology, (3) partnership issues, and (4) community capacity. 
Figure 15: CBT distribution channel structure and factors that influence it

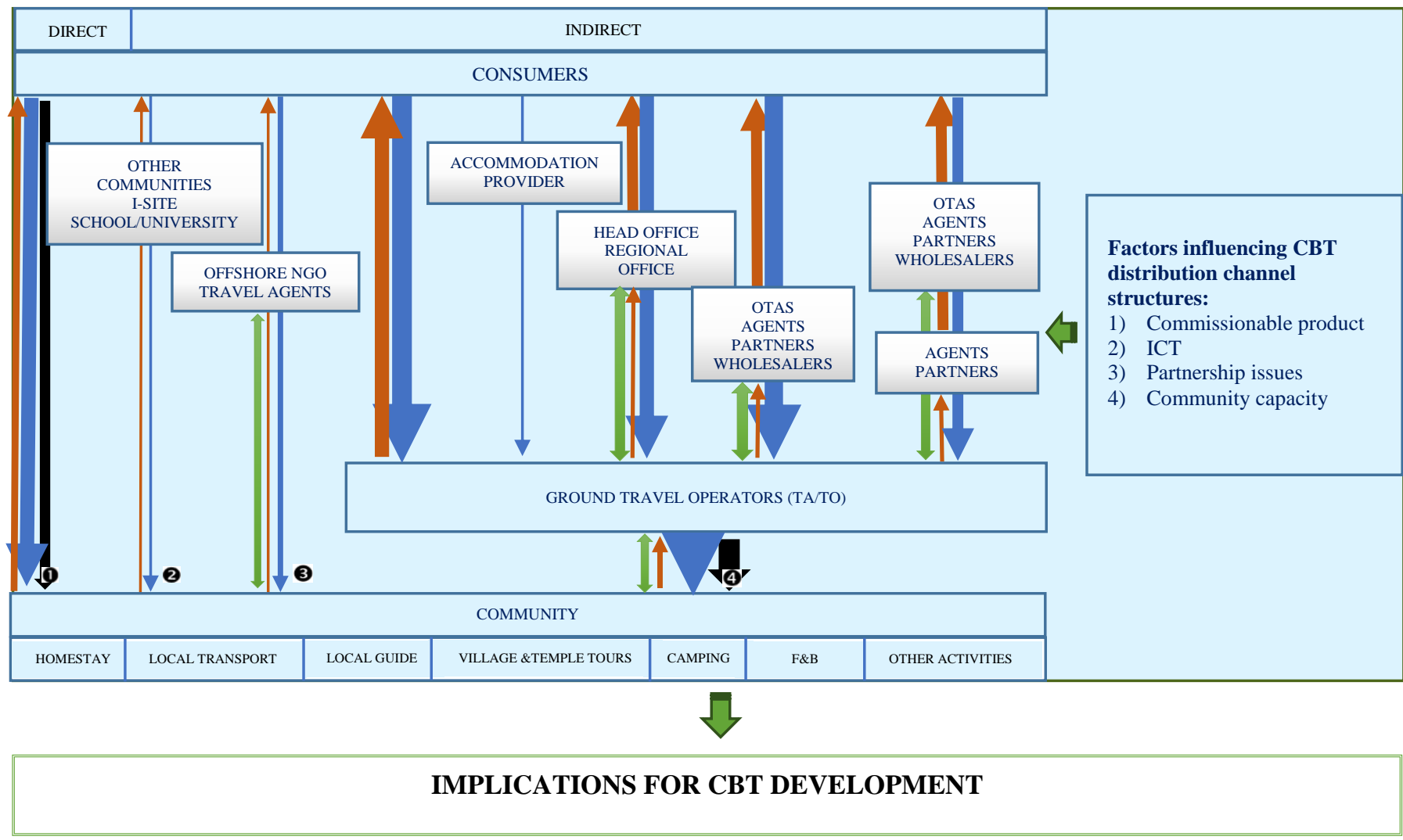

- Marketing channels

Booking and payment from community and intermediaries' perspectives

Booking and payment from visitors' perspectives

1. Bundling and packaging

\subsubsection{Commissionable products}

Commission-related issues are found to have effects on tourism distribution channels structures (Pearce \& Tan, 2004: Pearce, 2005: Reid \& Pearce, 2005: and Liu, 2012). In terms of attracting more independent travellers, Pearce and Tan (2004) commented that heritage and cultural tourism operators are more successful by offering low commissions to accommodation providers and information centers rather than offering special rates to inbound operators or wholesalers. Different from Pearce and Tan (2004), this study found that local channels members, such as, accommodation providers or the information centers involved in CBT marketing channels are much less effective in terms of establishing points of sale for CBT products. This may be because most of these channel members do not know the community in detail or have never visited the community. Another possible explanation is may be CBT is not seen as a lucrative business and involvement in this initiative is not beneficial for local channel members. 
Cultural tourism attractions are less interested in gaining benefits from the intermediaries. Conversely, tourism operators engaged in selling such products are likely to set high commission rates or mark-up (Pearce \& Tan, 2004). Likewise, Pearce (2005) and Liu (2012) found that mark-up or commission is one of the most common ways in which tour organizers and inbound tour operators make their profits. This study provides more evidence to confirm that the community does not gain margins from GTOs or any other intermediaries involved. They make profit simply from selling their core products either directly or indirectly. However, similar to what Pearce and Tan (2004) pointed out, GTOs that work with the community to sell CBT-related packages make revenue from either setting a commission or mark-up. The study finds that the commission or mark-up rate is generally set between $10 \%$ and $25 \%$. This rate is generally based on the relationship between the GTOs and their offshore agents. To some extent, this rate is rather similar to what was revealed by Reid and Pearce (2005) in their study on distribution channels for outbound tourism in New Zealand.

\subsubsection{Information Communication and Technology (ICT)}

Reid and Pearce (2008) explained that the internet has a critical effect on the distribution of outbound travel in New Zealand. It helps to facilitate and increase choice for consumers (Yin, 2012; Murphy \& Tan, 2003). Therefore, in order to remain competitive, intermediaries need to become adept with e-distribution channels. It is a trend that will continue to affect the industry greatly. Reid and Pearce (2008) further suggested that such a trend could shorten distribution layers and, therefore, both the suppliers and intermediaries focus would be more on the consumer directly. However alternatively, the expansion of ICT may also add extra channels to existing structures and this would accelerate more diverse channels. To some degree, these findings are consistent with the present findings. The community indicated that their website and internet are really important in order to help the community reach wider markets through online marketing. As illustrated in figure 10 (page 56), website or internet is the most important means of direct distribution channel. Overall, ICT has accelerated direct connection between the community and the market, making it more effective in terms of product education and community awareness.

Pearce and Tan (2004) noticed that adopting technology may be costly and resourceintensive. Hence this may present additional challenges for micro and small tourism operators. This is essentially true for Banteay Chhmar CBT because community members 
as well as community committees are technological novices. At the present time, they do not have adequate capacity necessary for adopting technology. Any technological-related inquiries such as website development are supported by an expat volunteer. This suggests that the community still lacks basic technological knowledge necessary for their business. Although some committee members can manage email bookings, more attention should be paid to improve e-distribution channels in order to improve CBT selling.

Song (2012) indicated that senior travellers do not always acquire technology and as a consequence they tend to purchase holiday packages through traditional distribution channels. This also applies for Banteay Chhmar where a majority of the visitors are in their $50 \mathrm{~s}$ and $60 \mathrm{~s}$, and a majority of them purchase their community packages through the GTOs making indirect distribution channels noticeable. Although ICT influence Banteay Chhmar CBT distribution structure in many ways, tradition distribution channels still play an important role.

\subsubsection{Partnership issues}

Reid and Pearce (2008) suggested that tighter margins lead to the increase in vertical integration in distribution channels. In the context of outbound tourism in New Zealand, they commented that intermediaries are likely to switch from one to another supplier in search of better margins and prices.

This suggestion is also valid for Banteay Chhmar CBT because a number of GTOs that sell CBT-related packages tend to switch from one to another intermediary in search for better commissions or margins. In this case they do not have fixed partners. However, this research also found that there are some GTOs committed to their offshore partners or agents to the extent that a formal partnership is established.

\subsubsection{Community capacity}

There are a number of studies that suggest capacity issues affect the way in which channels are distributed, (Pearce, 2005; Pearce \& Tan, 2004; Schott, 2007; Lie, 2012; and Andrade, 2013).

Pearce (2005) revealed that tourism attractions which have well-developed distribution and promotion policy are not so challenged with capacity issues when dealing with their businesses. Yet, in the case of cultural and heritage tourism attractions in New Zealand, 
capacity constraints are inhibiting these attractions from working with tour operators. Similarly, in the context of wine tourism, Liu (2012) also found that capacity constraints limited the ability of wineries to host tour group visitors. Other research has found that the issues of capacity constraint also affect the way in which small businesses in Queenstown distribute their products and services (Schott, 2007). Similarly, Andrade (2013), commented that problems of business capacity is also experienced by the smaller ground operators at Fernando de Noronha in Brazil. This limited capacity not only affects the actual business but also impacts on tourist operators in that the limited capacity prevents them from making group bookings, and therefore, they are heavily reliant on independent travellers. To some extent, these findings are partly consistent with those found in the current study. Although Banteay Chhmar CBT demonstrates limited capacity in terms of marketing, management and business operation, they are able to manage either individual or group bookings. The possible explanation for this may be because CBT operates on a cooperative basis by combining different individual service providers. In addition, CBT does not work alone in hosting group tours. Typically, GTOs provide some support to the community. For example, a representative from the GTOs will help with some tasks, such as, logistics and facilitation. This support is helpful for the community in managing visitors and providing services.

Middleton (1997) confirmed that many of the cultural and heritage sites were challenged with managing effectively capacity issues, especially in terms of marketing management. Similarly, Pearce and Tan (2004), indicated that people who are responsible for cultural and heritage sites are experienced and competent in their work, but may demonstrate limited expertise in skills necessary for effective international tourism management. This study provides more evidence to confirm that most relevant CBT supporters are skillful in conservation and temple restoration, yet many of them have limited tourism expertise. As a result, specific areas of support for the CBT operation are still limited.

Overall, this chapter discusses the key findings from the study by referring back to previous relevant studies. Commonality and differences are highlighted and discussed throughout. The first section of this chapter discussed the distribution channel structure for CBT and what determines it. These include: distribution functions, products features and operator size. The second part of this chapter discussed the key factors affecting distribution channel structure for CBT. These key factors are commission-related issues, information communication and technology, partnership issues, and finally capacity issues. 


\section{Chapter 7: Conclusion, implications and recommendations}

\subsection{Introduction}

This final chapter concludes the key aspects of the previous chapters. This study has investigated the distribution channels for the Banteay Chhmar community. The main objectives of this research were to investigate (1) distribution structure for CBT, (2) factors influencing its structure, and then by using the findings from (1) and (2) draw out (3) the implications for CBT development.

In order to understand the whole distribution structure and influencing factors in detail, this case study considers both the demand and supply side perspectives. From the supply side, this study incorporates perspectives from the community and other key channel members, such as, intermediaries (GTOs), government, non-governmental organizations and key informants. Semi-structured in-depth interviews were employed to gather information from a total of twenty-one respondents who are mainly based in the community, Phnom Penh, and Siem Reap town. Interviews were conducted either in the community office, the respondents' office or in a café. From the demand side, a self-completion visitor survey was utilized to collect information from 64 visitors who travelled to the community.

The structure of this concluding chapter is based on the presentation of key findings as discussed in previous chapters through consultation with a literature review of distribution channels and CBT. The sections that follow will include distribution structure for CBT, factors influencing distribution channels, implications and recommendations, contribution of the study and the avenues for future research.

\subsection{Distribution structure for CBT}

The whole structure of CBT distribution channels is presented in figure 13 (page 74) in chapter 4. As identified in this figure, the main structure of distribution channels for CBT is concentrated on the use of direct and indirect distribution channels (through GTOs and other offshore agents), marketing channels, and the roles of packaging, bundling booking and payment.

The CBT's direct distribution channel constitutes an important part in the total overview of the numerous types of distribution channels used by CBT to promote and sell their products and services. ICT is seen to have a great impact on the channel by facilitating 
direct contact between community and the prospective visitors through internet and/or website. The promising growth of ICT stimulates greater importance of the direct channel than ever before. Regarding marketing channels, internet and/or website and word-ofmouth are the most important means of marketing that the community uses to reach broader markets. As shown in figure 12 (page 62), the domestic market also plays a role in CBT distribution channels. It demonstrates a short and straightforward structure.

Indirect distribution through local channel members is seen to have very limited importance for the community. On one hand, this may be due to the limited connection between other business ventures and the community. On the other hand, this may be due to the fact that CBT-related business is not lucrative. However, another indirect distribution channel through offshore NGO or travel agents is rather significant for the community because the demand volume is noticeable.

Given the large distance between demand and supply, indirect distribution channels through GTOs indicates that there are a number of intermediaries involved in this indirect distribution channel. GTOs usually perform a variety of distribution functions, such as, bundling and packaging, and booking and payment. Due to the high demand volume through GTOs, the indirect channel through GTOs dominates the whole CBT distribution structure making it more complicated and lengthy. In some cases, a three-layer channel is seen in the distribution structure.

Overall, the examination of distribution channels for CBT reveals considerable channel diversity. The community is found to utilize a wide range of channels both direct and indirect to reach the market. Direct channel is commonly short and straightforward while indirect distribution channels involve a number of intermediaries.

\subsection{Factors influencing CBT distribution structure}

As indicated in table 10 (page 78), there are a number of factors that influence distribution channels for CBT. Similar to previous research, such as, Pearce and Tan (2004), Pearce (2005), Reid and Pearce (2005), and Liu (2012), this study also found that commissionrelated issues have profound effects on CBT distribution structure, particularly for indirect distribution channels which involve a wide range of intermediaries. Some intermediaries tend to switch from one to another intermediary or GTO in search of better commissions or margins. The way in which they switch may leads to a number of changes in the 
distribution structure. However, in the case of the direct distribution channel, such a factor does not have impact on CBT distribution structure. This is mainly due to the fact that Banteay Chhmar prefers a non-commission system.

Another noticeable factor is the characteristics of the products and market access. CBT products are characterized by being isolated and located off the beaten track. CBT products are not so appealing, and therefore, are less known to broader markets. More importantly, accessing such products is somewhat challenging because of their location, inadequate supporting tourism infrastructure and the market information. These are the common issues affecting distribution channels. It is probably due to these issues that indirect distribution channels through GTOs constitute most part of CBT distribution structure.

The unprecedented growth of ICT marks an important contribution to the overall distribution channels. ICT plays an important role in facilitating information, making this part of the distribution process easier for both suppliers and consumers. For the community, ICT is one of the most effective tools for marketing and communication. Most CBT distribution functions, such as, information provision, bundling and packaging, and booking and payment are accelerated by the proliferation of technology. In the meantime, consumers have more access to product information than ever before. This influences their travel choices and travel behaviours, and subsequently influences the distribution structure as a whole. Therefore, the growth of ICT can potentially make channels more direct and shorter, and enable consumers to have more choice.

Partnership issues and the nature of the operators are considered as factors influencing CBT distribution structure. Given the indirect distribution channels through GTOs dominate CBT distribution channels, the characteristics and the ways in which each GTO work with the community and other intermediaries can have considerable effect on the distribution structure. Some GTOs build serious and formal relationship with the community. In this case, they are more committed and tend to send regular visitors to the community. However, many others tend to have ad hoc relationships with the community and other intermediaries. In this case they tend to switch around from one to another supplier or other intermediaries. These two forms of business relationships have considerable influence on CBT distribution structure. Additionally, a majority of partners who are involved in CBT ventures are characterized by being supportive, not solely profit- 
oriented, and are willing to help. Hence, these characteristics also influence CBT distribution structure.

Capacity issue is another important factor determining the CBT distribution channel structures. Well-developed and mature communities tend to have experienced community members who deal with the business effectively on a day-to-day basis. In addition, they are likely to do marketing directly and hence direct channels will be prevalent. Conversely, less developed communities tend to rely heavily on a number of tourism operators. In this case, the distribution channel structure is also formed based on the partners they have. Overall, Banteay Chhmar's distribution channel structure is somewhat affected by its capacity in dealing with the business operation.

One of the fundamental factors affecting CBT distribution channel structure is market trend. The changing consumers' attitudes, needs, and wants have considerable effect on the structure. The growth of responsible consumption, better education and more travel demand has accelerated diverse channel choices. As Stuart et al. (2005) suggest, the tendency of travelling to the off the beaten track destinations goes up in line with the increasing awareness on environmental issues and the recognition of cultural diversity. In addition, Song (2012) argues that well-educated young dynamic travellers tend to buy their holiday package online. Given these trends, direct CBT distribution channel will increase considerably.

\subsection{Implications and recommendations}

This section is divided into two subsections and discusses the following points - (1) implications and recommendations for the community (2) implications and recommendations for other key channel members (government, GTOs, and other development partners).

\subsubsection{Implications and recommendations for the community}

The findings formed in figure 13 (page 74) indicate that the community used a distribution mix. The figure also shows that while the direct distribution channel used by the community represents a considerable share, the indirect distribution channels through GTOs dominate the whole structure. The possible explanation for this may be due to the limited community capacity in attracting direct visitors. This may be a result of inadequate marketing efforts which stem from the limited financial resources and skills in using ICT. Another possible explanation for this may lie in the issues associated with GTOs business 
interests. The findings reveal that most GTOs currently working with the community approached the community first, and subsequently work with community to establish their new packages in order to sell to the market or send to their offshore travel partners. This suggests that CBT-related packages have promising selling points.

From a direct marketing channel perspective, a number of implications can be drawn from the findings. First, given the share of independent travellers is still low (approximately $26 \%$ ) compared to group visits (approximately 74\%), a concerted effort should be made to maximize opportunities to attract more direct visitors. In doing so, the community should be working strategically to develop effective marketing channels that are appealing for direct visitors. This study found that the community and other supporting partners pay little attention to marketing and promotion, and somewhat overlook the commercial aspects of the CBT although they claim that economic sustainability is crucial. Due to the fact that the community has very limited financial resources, low-cost and highly effective marketing strategies are crucial. In order to address this, the findings of the study come into play. The community does not have a marketing plan, let alone marketing strategies. Most marketing related activities are done intermittently on the basis of available resources. Without such a plan, it is challenging to target particular groups of visitors and as a result the community tries to attract wider markets in an ad hoc manner, potentially wasting valuable resources in attempting to attract markets to which their products are not so appealing.

According to figure 10 (page 56), it is suggested that the community have not yet utilized existing marketing tools effectively. Given the fact that the internet and/or a website is the most important of the various marketing channels, the community should try to ensure that all information is up-to-date and the interface is easy and convenient to follow. From a longer term perspective, the community should have full capacity to update the community website on a continuous basis without relying on others. Furthermore, in order to deal with direct visitors, all $\mathrm{CC}$ members should demonstrate sufficient capacity to cope with email bookings and to respond to visitors' inquiries effectively. In order to make use of ICT, it is ideal for the community to develop online booking, and also to ensure that they have sufficient capacity to manage it, as it is becoming the most common part of travel arrangement. Email marketing should be used to constantly update information about the community to those who have already visited the community. It is likely that such a marketing technique may attract repeat visits or they will pass the information on to their 
friends or relatives. In addition, the community should try to work more with OTAs because they can help to sell the product worldwide.

The findings also suggested that word-of-mouth is the second most important marketing channel for the community. From within the community perspective, it is important that the community should try to improve the overall quality of their products and services, such as, hospitality of the home-stay providers and the quality of food and beverage. Although this zero-cost marketing channel is beneficial, the community should be aware that unsatisfied visitors can voice their bad experience more than one can imagine, especially today with the increasing use of social media to share opinions and experiences, often to a wide audience. Therefore, it is essential to ensure that each visitor enjoys the community experience. Product education and raising awareness are also important to ensure visitors' expectations and satisfaction. In addition, small detailed information about the community should be available to each individual visitor. Hence, the information provision function of the distribution channels should come into play. In the meantime, eword-of-mouth is also critical, especially during the exponential growth of ICT. Therefore, the community should try to encourage bloggers to write more about the community. Additionally, the community should encourage visitors to review and express their experience through Trip advisor and other social medial templates, such as, Facebook and Twitter. Facebook is seen as a major social media platform and, therefore, the official page for the community should be more active and updated constantly. In some cases, Facebook may connect between the community and visitors, and subsequently establish sale-related contacts.

Findings also reveal that there is almost no connection between the community and other local channel members, such as, accommodation providers, souvenir shops, and food and beverage outlets located in other tourism destinations. The possible explanation for this may be because most local channels members do not know the community in detail and have never visited the community. It is tremendously advantageous to have good relationships with these local channel members as they are an important part of the CBT distribution channels, and they could be very effective and trustful recommenders to potential visitors who are already in the nearby area. In order to ensure its effectiveness, the community should organize a number of familiarization trips and invite potential, (and influential) channel members, which should include officials from the tourism information centres, to participate and experience the community products and services. 
Another identified implication drawn from the study is the limited connection among other CBT initiatives in the country. Given this fact, a sound mutual recommendation system is absent and as a result each community does not normally refer visitors to other CBT sites. This issue should not be overlooked because visitors who travel to specific CBT sites may be interested in other similar products in different geographical location. Therefore, it is advisable that each community should link together and present their counterparts to their visitors.

Regarding the domestic market, findings indicate that Banteay Chhmar is appealing mainly for school or university students who are keen to learn about CBT, community development, rural development, history, archaeology, and local culture and heritage. Although this community has a number of promising aspects for field-based learning, a distribution channel for this group represent a very small share of the overall distribution structure (channel \# 2 of figure 13. This may be the result of limited connections between the community and other potential local universities and schools. In order to address this, the community should allocate suitable resources for making these connections. This can be done through schools/ universities visits and presentations to raise awareness about the opportunities the community can offer.

Channel \# 3 of figure 13 shows the relationship between the community and offshore NGOs and travel agents. Although this channel represents a small share, the findings suggest that this channel is very beneficial for the community because most visitors through this channel tend to stay longer and spend more in the community. In addition, they are likely to participate in many volunteer activities in the community, such as, conducting health awareness, teaching local children, restoring treks in the temples compound, and helping to rebuild the local school. Due to the perceived benefits of this type of visitor, the community should try to provide an environment conducive to fit this group and also look to attract more NGOs and/or travel agents to help sell such products.

As illustrated in figure 13 (page 74), channel \#4 represents the biggest share of all in the whole distribution channel structure for Banteay Chhmar. This indirect distribution channel relies heavily on GTOs and their offshore travel partners. Although relying on these channel members may lead to an over-dependency on GTOs in selling CBT products, from an immediate to medium-term perspective, CBT should make use of having a wide range of intermediaries, as working with all of them is advantageous for the communities 
because they help the communities to sell their products and also do a number of marketing and promotional activities. In order to take most advantage from the intermediaries, it is advisable that the community pay more attention to retaining the existing GTOs while searching for more potential intermediaries who are involved in selling such products. Regular business meetings to update information and to attend to other inquiries and business matters necessary to facilitate sales should be taken into serious account. The community should take the lead in building community-GTOs partnerships. For the long-term perspective, the community should focus more on increasing their direct distribution channels through taking advantage of the on-going growth of ICT, while improving the capacity to manage sound direct distribution strategies. Moreover, given that indirect distribution channels through GTOs are important to the community, it may be timely for the community to consider a strategic move in offering tiered/staged commissions as incentive to GTOs who help to sell their products. This initiative may be uncommon for the community, but it may add value for their ventures.

Overall, at the present time the community does not have a marketing plan, marketing strategies or distribution strategies. Thus, a purpose of this study is to highlight to key channel members, especially the community, about the significance of having sound distribution strategies. As indicated above, these strategies not only help to establish greater points of sale but also help the community to have greater control over the development processes, especially minimizing adverse consequences.

\subsubsection{Implications and recommendations for other key channel members}

Government can help to stimulate CBT distribution channels by providing general support to the industry, such as, marketing and promotion and a legal framework that enables a favourable business environment. In addition in the governments' broad destination marketing campaign, they should try to focus more on CBT product marketing and promotion. In the meantime, the government, especially Ministry of Tourism (MoT) should provide and facilitate more business-oriented capacity building activities to the CBT initiatives, so that they are more effective in dealing with the markets and other intermediaries involved in the whole distribution system.

Given the fact that GTOs play a crucial role in indirect distribution channels for Banteay Chhmar, they have considerable influence on the structure. A number of GTOs work with 
the community and sell CBT-related packages. Therefore, in order to improve the channels they are involved with, they should support the community in terms of product development, certain business capacity building and how to communicate effectively with visitors. It is a win-win solution because GTOs can also improve their sales by helping the community to grow.

NGOs and other concerned development partners are also an important part of the CBT development process. Although the conservation goals are essential for the initiative, the value of business-related support should not be underestimated. It is believed that financial self-sufficiency is also one of the most important aspects of CBT development. Therefore, NGOs and other development partners should pay more critical attention in supporting CBT so that it has sufficient capacity to deal with markets and other channels member effectively.

\subsection{Contributions of the study}

Distribution channels for CBT have received little attention so far. This study brings two divergent concepts together - distribution channels and CBT with the aim to contribute theoretically and operationally. From a theoretical perspective, this study is expected to add to the wider literature on distribution channels and CBT. A number of studies have been conducted to investigate many aspects of distribution channels, but none to date have been undertaken on CBT in this particular area, especially in the context of developing countries such as Cambodia. Although many studies have investigated CBT, this study has significantly contributed to CBT research from a distribution channels perspective, an area that has been largely overlook so far.

From an operational perspective, this study has tremendous advantages for CBT initiatives. The findings indicate that Banteay Chhmar does not have either a proper marketing plan or distribution strategies. It is expected that this study will bring greater attention to the necessity of sound distribution strategies among all major channel members, especially the community, because it helps to increase sale volume which is essential for an economically sustainable CBT venture. In the meantime, it helps the community to maximize any possible negative consequences.

Key findings from this study are expected to contribute to any CBT ventures in Cambodia or in other geographical regions which share similar characteristics to Banteay Chhmar. 
These include: (1) dependency on external funding through local and international NGOs in project implementation, (2) located in off the beaten track destinations, (3) limited capacity and resources both human and financial, (4) limited connection with the private sectors and (5) supply-driven concentration rather than a demand focus. Because almost all CBT initiatives share these major commonalities, the key findings from the investigation on distribution channels for Banteay Chhmar also have many implications for other CBT schemes. To some extent, therefore, those CBT initiatives could utilize the findings of this study to gain a better understanding of their distribution structure and recognize that having sound distribution strategies are an invaluable component in the CBT development journey.

\subsection{Avenues for future research}

This study has focused to fill gaps identified by previous researcher and also to contribute to the literature on tourism distribution channels and CBT. It investigates distribution channels for Banteay Chhmar CBT with particular focus on: (1) distribution structure, (2) factors influencing CBT distribution structure, and (3) implications that can be drawn from the study. This case study is based on the perspective from both the demand and the supply sides. However, due to the small number of respondents from the demand side (64 responses), this study is constrained by limited understanding of the visitors and their overall behaviours in the whole distribution system. Therefore, it is suggested that future study should incorporate sufficient numbers of visitors in order to gain a better understanding of the complexity of the whole distribution system.

The distribution channels may vary based on sectors, locations, products and contexts. Given the core products of Banteay Chhmar are dominated by culture and heritage, the distribution channels and overall structure of this community may be different from those of nature-based tourism. In this regard, a recommendation for future study is to investigate distribution channels for community-based ecotourism (CBET). This would be an interesting comparison, as nature-based or ecotourism products are more appealing to young dynamic visitors who tend to part-take in more physically and mentally challenging activities. According to Song (2012), these young visitors tend to purchase their holiday packages directly through online channels; conversely cultural and heritage-based tourism tends to attract more senior visitors who are likely to purchase their holiday packages through traditional distribution channels, such as, tour operators and travel agencies. These different characteristics may lead to the different distribution structure and therefore, a 
study on distribution channels for CBET is necessary to have better understanding of these specific products as well as to contribute to the findings found in this study on distribution channels for CBT.

Channel performance and evaluation is beyond the coverage of the current study. However, it is necessary to understand how each channel performed for the community and also to evaluate that performance. Therefore, future study should focus in-depth on CBT channel performance and evaluation. This is significant for the community because it is expected that such a study could contribute to cost saving and effective use of resources. This is especially critical for CBT initiatives that do not have adequate resources.

Overall, this chapter concludes major research findings which include the structure of distribution channels for Banteay Chhmar CBT, factors influencing distribution structure, and finally implications from the study for CBT development. The implications and recommendations from this study are important for the community because they provide more insightful suggestions that practitioners, especially CC members, should not overlook. The chapter also covers theoretical and operational contributions of the study. The chapter ends with a section discussing the avenues for future research. This is important because further research is still needed in order to build a more comprehensive body of literature, as well as sound practice recommendations in this specific area of study. 


\section{References}

Al-Oun, S., \& Al-Homoud, M. (2008). The potential for developing community-based tourism among the Bedouins in the Badia of Jordan. Journal of Heritage Tourism, 3(1), $36-54$.

Banteay Chhmar (2014) Annual report, Banteay Chhmar CBT

Baromey, N., Rith, S., \& Yokohari, M. (2011). Enhancing sustainability through the building of capabilities: analysis of community-based ecotourism development in Cambodian protected areas, In A. Hamzah (Ed.), Conference Proceedings (pp. 1-19). Sihanoukville, Cambodia: 3rd World Ecotourism Conference.

Beeton, S. (2006). Community development through tourism. Victoria, Australia: Landlinks.

Berthon, P., Ewing, M., Napoli, J., Pit, L., \& Wyne, C. (2001). The Impact of the Internet on the distribution value chain: The case of the South Africa tourism industry. International Marketing Review, 18(4): 420-432.

Blackstock, K. (2005). A critical look at community based tourism. Community Development Journal, 40(1), 39-49.

Boonratana, R. (2010). Community-based Tourism in Thailand: The need and Justification for an Operational Definition. Kasetsart Journal, Social Sciences, 31: 280-289.

Buccus, I., Hemson, D., Hicks, J., \& Piper, L. (2008). Community Development and Engagement with Local Governance in South Africa. Community Development Journal, 43(3), 297-311.

Buhalis, D. (2001). Touirsm distribution channels: practices and processes. In D. Buhalis and E. Laws (Eds), Tourism Distribution Channels: Practices, Issues and Transformations. London: Continuum.

Buhalis, D. (2000). Relationships in distribution channels of tourism: Conflicts between hoteliers and tour operators in the Mediterranean region. International Journal of Hospitality and Tourism Administration, 1(1), pp. 113-139.

CBI. (2007), the EU market for community-based tourism.

CCBEN and SNV, (2009). Community Based Tourism Supply Chain Analysis Report. Phnom Penh: CCBEN.

Christopher, M. (1992). The strategy of distribution management. Oxford, England: Butterworth-Heinemann.

Claudia Dolezal \& Peter M. Burns (2015). ABCD to CBT: asset-based community development's potential for community-based tourism. Development in Practice, 25:1, 133-142. 
Cooper, C., \& Lewis, J. (2001). Transformations and trends in the tourism industry: implications for distribution channels. In D. Buhalis and E. Laws (Eds), Tourism Distribution Channels: Practices, Issues and Transformations. London: Continuum.

Coughlan, A., Anderson, E., Stern, L.W. and El-Ansary, A. (2008). Marketing Channels (7th edn). Pearson education.

Creswell, J. W. (2007). Qualitative inquiry \& research design: Choosing among five approaches. Thousand Oaks: Sage Publications, Inc.

Creswell, J. (2014). Research design: Qualitative, quantitative, and mixed methods approaches (4th ed.). Thousand Oaks: SAGE Publications.

Duffy, R. (2002). A Trip too far: Ecotourism, politics, and exploitation. Sterling, VA: Earthscan.

Ellis, S. (2011). Community based tourism in Cambodia: exploring the role of community for successful implementation in least developed countries. Retrieved from http://ro.ecu.edu.au/theses/451

Ellis, S., \& Sheridan, L. (2014). The legacy of war for community-based tourism development: Learnings from Cambodia. Community Development Journal, 49(1), 129142.

Feng, X. (2008). Who Benefits?: Tourism Development in Fenghuang County, China. Human Organization, 67(2), 207.

Finn, M., Elliott-White, M., \& Walton, M. (2000). Tourism and leisure research methods: data collection, analysis, and interpretation. London: Pearson Education.

Freeman, D. (2000). The Tjapukai Case Study: Best Practice in Interpretation. Tourism Queensland, Brisbane.

Fyall, A., Garrod, B., \& Leask, A. (2003). Managing Visitor Attractions: New directions Oxford: Elselvier Butterworth-Heinemann.

Gilmore, A., \& Simmons, G. (2007). Integrating Sustainable Tourism and Marketing Management: Can National Parks provide the framework for strategic change? Strategic Change, 16(5), 191.

Goodwin, H., \& Santilli, R. (2009). Community-based tourism: A success? Working paper. The International Centre for Responsible Tourism, Leeds Metropolitan University: Leeds.

Goodwin, H. (2008). Pro-poor Tourism: A response. Third World Quarterly, 29(5), 869871.

Gossling, S. (2003). Market Integration and Ecosystem Degradation: Is sustainable tourism development in rural communities a contradiction in terms? Environment, Development and Sustainability, 5(3-4), 383. 
Guest, G., MacQueen, K., \& Namey, E. (2012). Applied thematic analysis. Los Angeles: Sage Publications.

Hall, C.M. (2010a). Tourism and the implementation of the convention on biological diversity. Journal of Heritage Tourism, 5, 267-284.

Hamzah, A., \& Khalifah, Z. (2009). Handbook for Community Based Tourism: How to Develop and Sustain CBT. Asia Pacific Economic Cooperation Tourism Working Group, Singapore.

Jennings, G. (2010). Tourism research (2nd ed.). Milton, Queensland: John Wiley \& Sons.

Kibicho, W. (2008). Community-based tourism: A factor-cluster segmentation approach. Journal of Sustainable Tourism, 16(2), 211-231.

Kogtogeorgopoulos, N. (2005). Community Based Ecotourism in Phuket and Ao Phangnga. Thailand: Partial

Lapeyre, R. (2010). Community-based tourism as a sustainable solution to maximise impacts locally? The Tsiseb Conservancy case, Namibia. Development Southern Africa, 27(5), 757772.

Liu, Y. (2012). Distribution Channels for Wine Tourism in New Zealand (Unpublished master's thesis). Victoria University of Wellington, Wellington, New Zealand.

López-Guzmán, T., Borges, O., \& Hernandez-Merino, M. (2013). Analysis of communitybased tourism in Cape Verde. A study on the island of São Vicente. Anatolia, 24(2), 129-143.

López-Guzmán, T., Borges, O., \& Castillo-Canalejo, A. (2011). COMMUNITY-BASED TOURISM IN CAPE VERDE - A CASE STUDY. Tourism and Hospitality Management, 17(1), 35-44.).

Manyara, G., \& Jones, E. (2007). Community-based Tourism Enterprise Development in Kenya: An exploration of their potential as avenues of poverty reduction. Journal of Sustainable Tourism, 15(6), 628-644.

María José Zapata , C. Michael Hall , Patricia Lindo \& Mieke Vanderschaeghe (2011). Can community-based tourism contribute to development and poverty alleviation? Lessons from Nicaragua. Current Issues in Tourism, 14:8, 725-749.

Mason, P. (2003). Tourism Impacts, Planning and Management. Oxford: Elsevier Butterworth-Heinemann.

Matarrita-Cascante, D. (2010). Beyond Growth: Reaching Tourism-led Development. Annals of Tourism Research, 37 (4): 1141-1163.

Matthews, B., \& Ross, L. (2010). Research methods: A practical guide for the social sciences (1st ed.). New York, NY: Pearson Longman.

Middleton, V. (1994). Marketing in travel and tourism, (2nd ed.). London: ButterworthHeinemann. 
Middleton, V., Fyall, A., \& Morgan, M., (2009) Marketing in Travel and Tourism, $4^{\text {th }}$. Abingdon: Routledge.

Mitchell, C., \& J. Ashley. (2009). Value Chain Analysis and Poverty. ODI Opinion 49. London: Overseas Development Institute.

Mitchell, J., \& Muckosy, P. (2008). A Misguided Quest: Community-Based Tourism in Latin America. ODI Opinion 102. London: Overseas Development Institute.

Mitchell, M. \& Hall, D. (2005). Rural tourism as sustainable business: key themes and issues. In D. R. Hall, Kirkpatrick, I., \& Mitchell, M. (Eds), Rural Tourism and Sustainable Business. England: Channel View.

Mkumbo, P. J. (2010). Tourism distribution channels in the northern tourist circuit of Tanzania (Unpublished master's thesis). Victoria University of Wellington, Wellington, New Zealand.

Moscardo, G., \& Pearce, P. (2003). Presenting Destinations: Marketing Host Communities. In S. Singh, D. J. Timothy, \& Dowling, R.K. (Eds). Tourism in Destination Communities. Wallingford, England: Cabi.

Mowforth, M., \& Munt, I. (2009). Tourism and sustainability: Development and new tourism in the Third World (3rd ed.). New York, NY: Routledge.

Muhanna, E. (2007). Tourism Development Strategies and poverty elimination. Problems and Perspectives in Management, 5(1), 37.

Murphy, P. (1985). Tourism: A community approach. London: Methuen.

Murphy, J. \& Tan, I. (2003). Journey to nowhere? E-mail customer service by travel agent in Singapore. Tourism Management, 24, 543-550.

Ndlovu, J., \& Nyakunu, E. (2011). Community Based Tourism in Twyfelfontei Conservancy: Exploring Local Community's Involvement. International Journal of Hospitality and Tourism Systems, 4(2), 38-45.

Neuman, W. (2011). Social research methods: Qualitative and quantitative approaches (7th ed.). Boston: Allyn \& Bacon.

Nor Haniza Mohamad, \& Amran Hamzah. (2013). Tourism cooperative for scaling up community-based tourism. Worldwide Hospitality and Tourism Themes, 5(4), 315-328.

Nyaupane, Gyan P., Morais, Duarte B., \& Dowler, Lorraine. (2006). The role of community involvement and number/type of visitors on tourism impacts: A controlled comparison of Annapurna, Nepal and Northwest Yunnan, China. Tourism Management, 27(6), 1373-1385.

Patton, M. Q. (2002). Qualitative research and evaluation methods. Thousand Oaks: Sage Publications, Inc.

Pearce, D.G. (2005). Distribution channels for cultural tourism in Catalonia, Spain. Current Issues in Tourism, 8(5), 424-445. 
Pearce, D. G. (2007). Paths to the market: developing an effective tourism distribution strategy. Wellington, New Zealand: Victoria University of Wellington.

Pearce, D. G. (2010a). Tourism distribution: a review and strategic research agenda. In Pearce, D., \& Butler, R. W., (Eds.). (2010). Tourism Research: A 20-20 Vision. Goodfellow Publishing. Oxford pp.94.

Pearce, D. (2012). Frameworks for tourism research. Wallingford, Oxfordshire; Cambridge, MA: CABI.

Pearce, D. G., \& Schott, C. (2005). Tourism distribution channels: The visitors' perspective. Journal of Travel Research, 44(1), 50-63.

Pearce, D. G. \& Tan, R. (2004). Distribution channels for heritage and cultural tourism in New Zealand. Asia Pacific Journal of Tourism Research, 9(3), 225-237.

Pearce, D.G \& Schott, C. (2005). Tourism distribution channels: the visitors' perspective. Journal of Travel Research, 44(1), 50-63.

Pearce, D.G., Tan, R. \& Schott, C. (2004). Tourism distribution channels in Wellington, New Zealand. International Journal of Tourism Research, 6, 397-410.

Pearce, D.G., Tan, R. \& Schott, C. (2007). Distribution channels in international markets: a comparative analysis of the distribution of New Zealand tourism in Australia, Great Britain and the USA. Current Issues in Tourism 10 (1), 33-60.

Phillips, R., \& Pittman, R. H. (2009). A framework for community and economic development. In R. Phillips \& R. H. Pittman (Eds.), An introduction to community development (pp. 3-19). New York, NY: Routledge.

Pongponrat, K., \& Pongquan, S. (2007). Community participation in a local tourism planning process: A case study of Nathon community on Samui Island, Thailand. AsiaPacific Journal of Rural Development, 17(2), 27-46.

Punch, K. (2014). Introduction to social research: Quantitative \& qualitative approaches (3rd ed.). Los Angeles, California: SAGE.

Richards, G., \& Hall, D. (2000). The community: A sustainable concept in tourism development? In G. Richards \& D. Hall (Eds.), Tourism and sustainable community development (pp. 1-13). New York, NY: Routledge.

Rocharungsat, P. (2008). Community-based tourism in Asia. In G. Moscardo (Ed.), Building community capacity for tourism development (pp. 60-74). Cambridge, MA: CABI International.

Rogerson, C. M. (2007). Tourism Routes as Vehicles for Local Economic Development in South Africa: The example of the Magaliesberg Meander. Urban Forum, 18(2).

Salazar, N. B. (2012). Community-based cultural tourism: Issues, threats and opportunities. Journal of Sustainable Tourism, 20(1), 9-22. 
Scheyvens, R. (2007). Exploring the tourism-poverty nexus. Current Issues in Tourism, $10(2 \& 3), 231-224$.

Scheyvens, R., \& Momsen, J. H. (2008). Tourism and Poverty Reduction: Issues for Small Island States. Tourism Geographies, 10(1), 22.

Schott, C. (2007). Selling adventure tourism: A distribution channels perspective. International Journal of Tourism Research, 9(4), 257-274.

Shunnaq, M., Schwab, W. A., \& Reid, M. F. (2008). Community Development Using a Sustainable Tourism Strategy: A case study of the Jordan River Valley tourist way. The International Journal of Tourism Research, 10(1), 1.

Simpson, M. (2008). Community Benefit Tourism Initiatives-A conceptual oxymoron? Tourism Management, 29(1), 1-18.

Smith, K. (2007). Distribution channels for events: Supply and demand-side perspective. Journal of Vacation Marketing, 13(4), 321-338.

Song, H. (2012). Tourism supply chain management. (1st ed). Abingdon, Oxon ; New York: Routledge.

Stuart, P. (2004). Tourism distribution channels for peripheral areas: a case study of Southland, New Zealand (Unpublished master's thesis). Victoria University of Wellington, Wellington, New Zealand.

Stuart, P., Pearce, D. G., \& Weaver, A. (2005). Tourism distribution channels in peripheral regions: the case of Southland, New Zealand. Tourism Geographies, 7(3), 235-256.

Suansri, P. (2003). Community based tourism handbook. Bangkok: Responsible Ecological Social Tours Project (REST).

Smith, K. A. (2007). Distribution channels for events: Supply and demand-side perspectives. Journal of Vacation Marketing, 13(4), 321-338.

Smith, K., \& Garnham, R. (2007). Distribution Channels for Convention Tourism. Journal of Convention \& Event Tourism, 8(1), 1-30.

Stake, R. E. (2005). Qualitative case studies. In N. K. Denzin \& Y. S. Lincoln (Eds.), The Sage handbook of qualitative research (pp. 443-466). Thousand Oaks, CA: Sage Thousand Oaks, CA.

Tan, R. (2002). Channels of Distribution Characterising Singapore Holiday to New Zealand: structure and implications (Unpublished master's thesis). Victoria University of Wellington, Wellington, New Zealand.

Tashakkori, A., \& Teddlie, C. (2010). Sage handbook of mixed methods in social \& behavioral research (2nd ed.). Los Angeles: SAGE Publications.

Tepelus, C. M. (2008). Social Responsibility and Innovation on Trafficking and Child Sex Tourism: Morphing of practice into sustainable tourism policies? Tourism and Hospitality Research, 8(2), 98-115. 
The Mountain Institute, (2000) Community-Based Tourism for Conservation and Development: A Resource Kit, The Mountain Institute

Timothy, D. J. (1999). Participatory planning: A view of tourism in Indonesia. Annals of Tourism Research, 26(2), 371-391.

Vajirakachorn, T., \& Nepal, Sanjay. (2011). Determinants of Success for Communitybased Tourism: The Case of Floating Markets in Thailand, ProQuest Dissertations and Theses.

Vignati, F. and Laumans, Q. (2010). Value chain analysis as a kick off for tourism destination development in Maputo City. Conference Proceedings (pp. 1-13). International Conference on Sustainable Tourism in Developing Countries, Dar Es Salam.

Wanhill, S. (1993). Intermediaries. In C. Cooper, F. Fletcher, D. Gilbert, \& Wanhill, S. (Eds.), Tourism - Principles and Practice, (pp. 189-203). London: Pitman.

Warren, C., \& Karner, T. (2005). Discovering Qualitative Methods: Field Research, Interviews and Analysis. Los Angeles, CA: Roxbury Publishing.

Wearing, S., \& Neil, J. (1999). Ecotourism: Impacts, potentials, and possibilities. Oxford, UK: Butterworth-Heinemann.

World Tourism Organisation (1975) Distribution Channels World Tourism Organisation: Madrid.

Yamamoto, D. \& Gill, A. (2002). Issues of globalisation and reflexivity in the Japanese tourism production system: the case of Whistler, British Columbia. The Professional Geographer, 54(1), 83-93.

Yin, R. (2014). Case study research: Design and methods (Fifth ed.). Los Angeles: SAGE Publications.

Yin, P. (2013). Information technology application in tourism distribution channels in China. LISS 2012 - Proceedings of 2nd International Conference on Logistics, Informatics and Service Science, 1271-1276. 


\section{Appendices}

\section{Appendix 1}

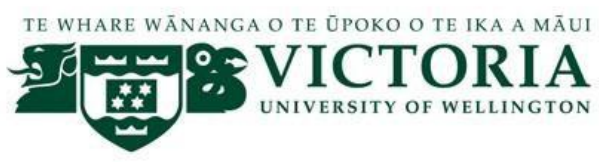

\section{Information sheet for interview}

\section{Participant Information Sheet for a Study on Paths to the market: Distribution Channels for Community-Based Tourism. A Case Study of Banteay Chhmar CBT, Cambodia}

\section{Researcher: NHEM Sochea \\ School of Management \\ Victoria University of Wellington}

I am a Masters student in Tourism Management at Victoria University of Wellington (VUW). As part of this degree I am undertaking a research project leading to a thesis. The project I am undertaking is to find out how distribution channels help to improve community based tourism. This research has been approved by the Victoria University of Wellington Human Ethics Committee with approval number 0000021936.

I am going to interview the experts in tourism industry, Owners/Managers of TA/TO whose products include CBT, NGO and concerned government officials who directly support communities and community committees of Banteay Chhmar CBT. As you are one of these people, I would like to invite you for the interview. The place and time for the interview is at your own convenience. I want to find out the information regarding some key areas of distribution channels which include the channels you use to distribute your CBT products, the structures and why you use these channels. Roughly, the interview will take around 45 minutes.

Your answers will be noted and recorded digitally. However, it would be fine if you wish your answers not to be recorded. During the interview, if you feel uncomfortable to answer or do not want to answer, you can skip to other questions. If you would like to withdraw from the interview, the interview will be terminated. You could also withdraw from the research any time before $30^{\text {th }}$ September 2015.

Responses will form the basis of my research project and will be reported confidentially. It will not be possible for you to be identified personally. When interview is quoted, your consent is needed. All material collected will be kept confidential. No other person besides me and my supervisor Dr. Christian Schott will see the information. The thesis will be submitted for marking to the School of Management and deposited in the University Library. It is intended that one or more articles will be submitted for publication in scholarly journals. Information and notes from the field will be destroyed two years after the end of the project (March 2018).

If you have any further questions or would like to receive further information about the 
project, please contact me at

(email:

or my

supervisor Dr. Christian Schott, at the School of Management (Victoria University of Wellington) $a t$

(email:

Sochea NHEM 


\section{Appendix 2}

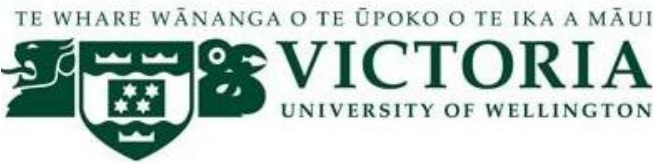

Information sheet for visitor survey (self-completion)

\section{Participant Information Sheet for a Study on Paths to the Market: Distribution Channels for Community-Based Tourism. A Case Study of Banteay Chhmar CBT, Cambodia}

\section{Researcher: NHEM Sochea \\ School of Management \\ Victoria University of Wellington}

I am a Masters student in Tourism Management at Victoria University of Wellington (VUW). As part of this degree I am undertaking a research project leading to a thesis. The project I am undertaking is to find out how distribution channels help to improve community based tourism. This research has been approved by the Victoria University of Wellington Human Ethics Committee with approval number 021936.

As important part of my research project, I am going to conduct a survey with tourists visiting community and those who already visited during the past year. I want to find out the information regarding some key areas of distribution channels which include the channels you use, information search, booking and payment processes. Roughly, the survey will take around 15 minutes.

During the questionnaire completion, if you feel uncomfortable to answer or do not want to answer, you may skip to other questions. If you would like to withdraw, the survey will be terminated.

By completing the questionnaire you provide your consent to participate in this research.

Responses will form the basis of my research project and will be put into a written report on an anonymous basis. It will not be possible for you to be identified personally. Only aggregated form of responses will be presented in this report. All material collected will be kept confidential. No other person besides me and my supervisor Dr. Christian Schott will see the information. The thesis will be submitted for marking to the School of Management and deposited in the University Library. It is intended that one or more articles will be submitted for publication in scholarly journals.

If you have any further questions or would like to receive further information about the project, please contact me at (email: —) or my supervisor Dr. Christian Schott, at the School of Management (Victoria University of Wellington) at (email: 


\section{Appendix 3}

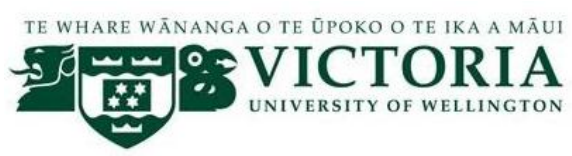

\section{Consent form}

\section{Project title: Paths to the market: Distribution Channels for Community-Based Tourism. A case study of Banteay Chhmar, Cambodia}

- I have been provided with a participant information sheet with adequate information related to the nature and objectives of this project. I have read and understood the requirements and have been given an opportunity to ask any questions I may have about this research and my participation.

- I understand my participation in this research project is entirely voluntary.

- I understand that I may withdraw from participation in this project at any stage before $30^{\text {th }}$ September 2015. In which case, all information obtained will be immediately returned and/or destroyed.

- I understand all audio digital recordings and transcripts will be kept securely for up to 2 years and destroyed no later than March 2018. Any further use will require my written consent.

- I understand that any information I ponder will be treated as confidential and that is verbatim quote will be used in published work.

- I will only be referred to by role and that my organization will be kept confidential. For example: A marketing manager of company X.

- I understand that I will not share any commercially sensitive information.

- I agree to the interview being audio recorded and/or in notes taken.

- I understand the information I provide will be used in a Master's thesis. Hence, a copy will be deposited in the Victoria University of Wellington Library. Findings may be presented at conferences or published in journals at a later date, and a summary will be made available to participants on request.

- I agree to participate in this research.

I understand that the transcript of the interview will be return for my review.

I would like a summary of key findings. Email address:

Signature of participant:

Nam of participant:

Date: 


\section{Appendix 4}

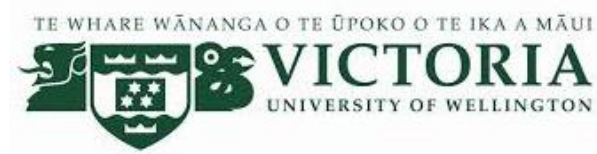

Paths to the market: Distribution Channels for Community-Based Tourism. A case
study of Banteay Chhmar, Cambodia

Name of the organization: (NGO)

Name of the Interviewee:

Position:

\section{NGO PROFILE AND SUPPORT}

1. Could you please describe about the project you are supporting CBT?

2. In terms of market, what have you done to support the community?

3. How does community reach the market? Preferable potential market?

4. Does community have different strategies to reach different market segmentation?

5. What are the opportunities and challenges of community to market their own products?

6. Do you support marketing activities to the community? If so, what are they?

7. What marketing activities does community implement? Please describe each of them.

8. Do you support marketing plans with distribution strategies and practices to the community? If so, what is/are your plan(s)? Do you and community implement them? If no, why not?

\section{DISTRIBUTION CHANNEL STRUCTURE}

9. Please describe community based tourism distribution channels.

\section{DIRECT DISTRIBUTION CHANNELS}

10. How does CBT reach tourists directly?

11. Is website important for CBT? Why?/ Why not?

12. What distribution opportunities does the internet offer community?

\section{INDIRECT DISTRIBUTION CHANNELS}

13. How are intermediaries important to CBT? Please describe.

14. Of the intermediaries, who bring more benefits to the community? Why? How should community do to maximize benefit from its members?

15. Are there any partnership issues you would like to raise?

16. From your view point, what are the pros and cons of using each channel (direct and indirect)? 


\section{FACTOR AFFECTING DISTRIBUTION FUNCTIONS INFORMATION PROVISION/MARKET ACCESS}

17. How do tourists hear of CBT products? How do they access to the products (CBT)? Any issues with market access?

18. Are there any differences in the community's strategies for reaching different segments?

If so, what are the differences? Why are there differences?

19. What factors influence community to use different strategies for different segments of tourists?

\section{BOOKING}

20. Please describe current booking system that community is using? Is current booking system effective?/ users friendly? Are there any challenges? If so, what should be done to improve the situation?

\section{PURCHASE}

21. From your view point, what can be done to improve selling CBT products?

\section{PACKAGING}

22. Please describe community product packaging? How they can improve their product packaging?

\section{BEHAVIOUR}

23. What are the advantages and disadvantages of each (main) channel that community is using?

24. Do you foresee any change on CBT market trends in the near future? If so, what are factors affecting the change(s)? And what does this mean to CBT distribution channels? Please explain your thought?

25 . How do you explain community capacity in relation to the distribution channel?

26. Are there any other issues that you would like to raise?

Thank you for your kind corporation 


\section{Appendix 5}

Paths to the market: Distribution Channels for Community-Based Tourism. A case study of Banteay Chhmar, Cambodia

Name of the community: (Banteay Chhmar CBT)

Name of the Interviewee:

Position:

\section{COMMUNITY PROFILE}

27. Could you please describe about the community (date of establishment, activities, structure, mission and objectives)? [This question mainly for community head]

28. What are your main CBT products?

29. How important is CBT for your community?

30. What are your major markets?

31 . How do you reach your market? Preferable potential market?

32. Do you have different strategies to reach different market segmentation?

33. What marketing activities are you implementing? Please describe each of them.

34. Do you have marketing plans with distribution strategies and practices?

If so, could you please tell me something about your plans? Do you implement them?

If no, why not?

\section{DISTRIBUTION CHANNEL STRUCTURE}

35. Please describe CBT distribution channels?

\section{DIRECT DISTRIBUTION CHANNELS}

36. How do you reach market directly, how do they book? - by email or phone, or do they walk in?

37. For the website, how often do you update the information?

38. What distribution opportunities does the internet offer your community?

\section{INDIRECT DISTRIBUTION CHANNELS}

39. Do you use intermediaries for selling CBT products? If so, how many and which intermediaries do you work with? (Tour operators, wholesalers, visitor information centres, regional tourism organisations...) How important are they (intermediaries) as distribution channel members?

40. Of the intermediaries, who bring more benefits to the community? Why? How should community do to maximize benefit from its members? 
41. Does the community have formal or informal partnerships with these intermediaries? Are there any partnership issues?

\section{FACTOR AFFECTING DISTRIBUTION FUNCTIONS}

\section{INFORMATION PROVISION}

42. How do your potential customers hear of your products? Are there any differences in the strategies for reaching different segments, Domestic and International tourists, and independent and group tourists?

If so, what are the differences? Please describe for each segment.

Why are there differences?

What factors influence the community to utilise different strategies for different segments of tourists?

\section{BOOKING}

43. Please describe you current booking system? Is current booking system effective?/ users friendly? Are there any challenges? If so, what should be done to improve the situation?

\section{PURCHASE}

44. From your view point, how do you improve selling CBT?

45. Which intermediary helps you the most in terms of purchasing your CBT products?

\section{PACKAGING}

46. Do you package your CBT products with tourism partners? If so, what are the main segments these packages appeal to?

\section{BEHAVIOUR}

47. What are the advantages and disadvantages of each (main) channel that community is using?

48. Do you foresee any change on CBT market trends in the near future? If so, what are factors affecting the change(s)? And what does this mean to CBT distribution channels? Please explain your thought?

49. How do you explain community capacity in relation to the distribution channel?

50. Are there any other issues that you would like to raise?

Thank you for your kind corporation 


\section{Appendix 6}

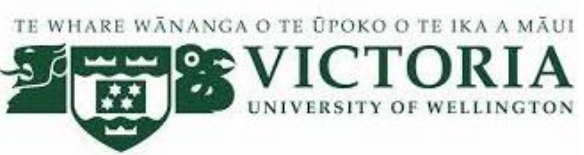

Paths to the market: Distribution Channels for Community-Based Tourism. A case study of Banteay Chhmar, Cambodia

\section{GOVERNMENT}

1. Please describe your roles in community based tourism development?

2. Do you also promote the CBT? To what markets? Why? How often?

3. How can you describe distribution channels for CBT?

4. How can community reach the market?

5. What distribution opportunities does the internet offer community?

6. Are intermediaries important to CBT? If so, why?

7. How do tourists hear of CBT products? How do they access to the products (CBT)? Any issues with market access?

8. Please describe current booking system that community is using? Is current booking system effective?/ users friendly? Are there any challenges? If so, what should be done to improve the situation?

9. From your view point, how to improve selling CBT products?

10. Please describe community product packaging? How can they improve their product packaging?

11. What are the advantages and disadvantages of each (main) channel that community is using?

12. Do you foresee any change on CBT market trends in the near future? If so, what are factors affecting the change(s)? And what does this mean to CBT distribution channels? Please explain your thought?

13. How do you explain community capacity in relation to the distribution channels?

14. Are there any other issues that you would like to raise?

Thank you for your kind corporation 


\section{Appendix 7}

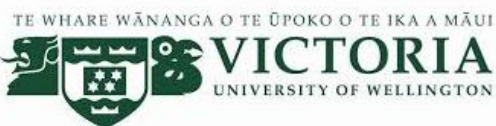

\section{Paths to the market: Distribution Channels for Community-Based Tourism. A case study of Banteay Chhmar, Cambodia}

\section{SELF-COMPLETION QUESTIONNAIRE}

\section{SECTION 1: INFORMATION ABOUT YOUR TRIP TO THE COMMUNITY}

1. What is your main purpose for visiting Banteay Chhmar community?

$\square$ Temples/Heritage

$\square$ Holiday/leisure

$\square$ Experience local culture and rural life style specify)

2. How long do you stay in the community for this trip?
$\square$ Same-day
$\square$ One night
$\square$ Two nights
$\square$ Three nights and more

3. Is it your first time visiting community based tourism initiatives?

$\square$ Yes $\quad \square$ No

If 'No', how many times have you been to CBTs? times.

In which country?

4. Are you visiting this community as part of a package tour or travelling independently?

$\square$ Group package $\quad \square$ Travel independently

5. How many companions are you travelling with on this trip? people

\section{SECTION 2: INFORMATION SEARCH}

6. How do you search for information about the trip to the community?
$\square$ Brochures
$\square$ Guidebooks
$\square$ Internet
Radio/TV
$\square$ Word of mouth
$\square$ Travel agent
Transport operators
$\square$ Trip advisor
$\square$ Lonely Planet
$\square$ Newspapers/ Magazines
$\square$ Previous experiences
$\square$ Visitor information centre
$\square$ Other (specify)

7. Why do you decide to search information in this way?

$\square$ Easy and convenient

$\square$ Previous relationship/experience

$\square$ Quality of information

Trust

$\square$ Other (specify)

8. When do you look for information about the community?
Before trip to Cambodia
$\square$ During visiting Cambodia

Please give reason(s): 
9. Are there any aspects of your visit to the community that you are unable to find sufficient information about in advance?
$\square$ Yes
$\square \mathrm{No}$
If "Yes" what are they?

\section{SECTION 3: TRANSPORTATION TO THE COMMUNITY}

10. What type of transportation do you use to get to the community?
$\square$ Organized bus/van
$\square$ Rental vehicle
$\square$ Private car
Taxi
$\square$ Rental motorbike
Other (specify)

11. What is the most important source of information that you use to make your transport arrangement?
$\square$ Ask community directly
$\square$ Internet
Radio/ TV
$\square$ Newspapers/Magazines
$\square$ Visitor information centre
Travel agent
Guide book
Word of mouth
Other

(specify)

12. Why do you decide to search information through this way?
$\square$ Easy and convenience
$\square$ Trust
Quality of information
$\square$ Previous relationship/experience

$\square$ Other (specify)

13. Do you book and pay for this transport directly with the transport provider?

$\square$ Yes

$\square$ No

If 'Yes', how do you do this?

$\begin{array}{lll} & \text { Book } & \text { Pay } \\ \text { By phone } & \square & \square \\ \text { By internet } & \square & \square \\ \text { In person } & \square & \square \\ \text { In some other way (specify) } & \square & \square\end{array}$

If 'No', whom do you book and purchase it from?

Do you do this?

Travel agent

Book Pay

Visitor information centre

Tour wholesaler

Inbound tour operator

Other (specify)

14. Why do you decide to book and pay your transport in this way?

$\square$ Ease and simplicity $\quad \square$ Price and payment related $\square$ Time related

Availability related $\quad \square$ Knowledge/reputation $\quad \square$ Personal contact 


\section{SECTION 4: BOOKING AND PAYMENT}

15. How do you book your trip to the community? Please tick "ONE".

Book directly to the community $\square$ Internet

$\square$ By other person $\square$ Did not book

Travel agent

Visitor information centre

Other (specify)

16. Why do you decide to book in this way?

$\square$ Easy and convenience

$\square$ Price and payment related

Trust/reputation

Time related

$\square$ Previous relationship/experience

$\square$ Other (specify)

$\square$ Availability related

17. How do you pay for your trip to the community? Please tick "ONE"
$\square$ Pay directly to the community
$\square$ Internet $\square$ Visitor information centre
Travel agent
$\square$ Other (specify)

18. Why do you decide to pay in this way?

$\square$ Easy and convenience

$\square$ Price and payment related

$\square$ Trust/reputation

$\square$ Previous relationship/experience

$\square$ Time related

Availability related

Other (specify)

19. If you did not book and pay for your trip to the community in advance, what factors influence you to decide so?
$\square$ Flexibility
Don't have any plan
No need to
Lack of knowledge
Time related issue
Couldn't book

Other (specify)

\section{SECTION 5: DEMOGRAPHICS}

20 . What is your home country?

21 . What is your occupation?

22 . What age group do you belong to?
$\square$ Under 20
20-29
$\square$ 40-49
50-59

$\square$ 30-39

$\square$ 60-69

$\square 70+$

23. What is your gender?

$\square$ Male

$\square$ Female

Thank you for participation in this survey! 